University of Redlands

\title{
Discover Irrigation and Visualize Vegetation Health for The Wildlands Conservancy
}

A Major Individual Project submitted in partial satisfaction of the requirements for the degree of Master of Science in Geographic Information Systems

by

Michelle R. Williams

Douglas Flewelling, Ph.D., Committee Chair

Ruijin Ma, Ph.D.

April 2020 
Discover Irrigation and Visualize Vegetation Health for The Wildlands Conservancy

Copyright (C) 2020

by

Michelle R. Williams 
The report of Michelle R. Williams is approved by
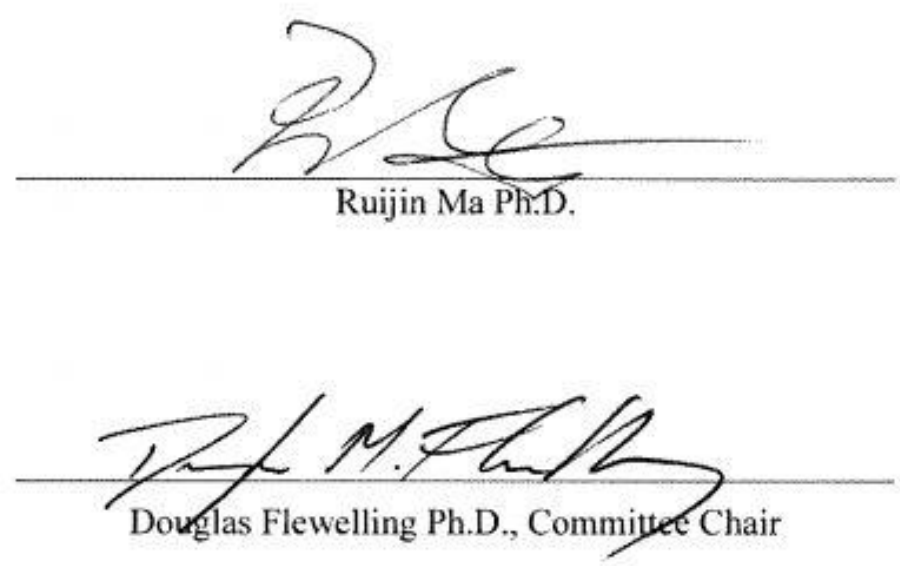

March 2020 



\section{Acknowledgments}

What an amazing opportunity!

Thank you, Lord, for opening the door an MS GIS degree. The financial support of the Morrison Family Trust made this possible. Thank you for entrusting me with your legacy.

My family gave the most significant sacrifice, Bruce, my husband, thank you for all your positive accolades during my most difficult courses and for getting me out of the house during my peak stress levels. To my mom, thank you for taking me shopping or to a movie when Bruce knew I needed to take a break. Sebastian and Chris, my sons, thank you for taking on the extra chores during the year.

Thank you to my advisor Douglas Flewelling, Ph.D., for guiding me through this project and accommodating me with my special requests to add to my MIP even though it was February 2018. Thanks to Andrea, the MS GIS coordinator, for organizing our courses, workshops, and luncheons for our class. You always made our cohort feel special. Thanks to Nate and the Spatial Studies department for the use of its Trimble R1 unit. To my personal GIS Jedi David Crawford from Esri, who helped me fix an issue that I was struggling with in three minutes. To Bola and Reed, who helped me through my programming classes and made this journey enjoyable, I cannot wait to visit everyone at Esri's UC throughout the years to see how we've grown. 



\begin{abstract}
Water is essential to the success of agriculture. Knowing where the water comes from and where it travels determines what can be done with it.

The Wildlands Conservancy owns nine preserves in Southern California. One of the these is the Oak Glen Preserve. Finding the irrigation pipelines was important to The Wildlands Conservancy because not a single staff member knew where the entire system flowed or where the fixtures were located. The data collection design began by designing a Collector application and using tools like Survey123 Connect and a Python script to create the geodatabase schema. Once the Collector application was designed, a Trimble R1 unit was paired with a mobile device for higher accuracy data collection. After completing the data collection, the data was retrieved and used in ArcMap to design a geometric network. As the project progressed, a remote sensing aspect was added to show the health of the orchards. The NAIP imagery used for remote sensing is flown in May every two years.
\end{abstract}





\section{Table of Contents}

Chapter 1 - Introduction ....................................................................................... 19

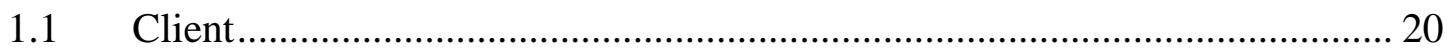

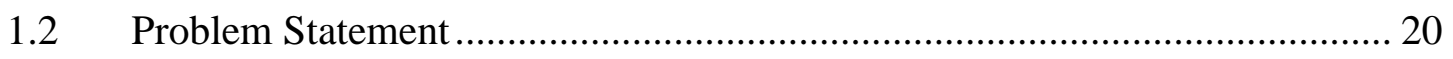

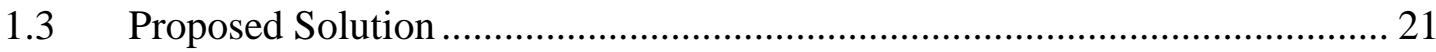

1.3.1 Goals and Objectives ............................................................................ 21

1.3.2 Scope

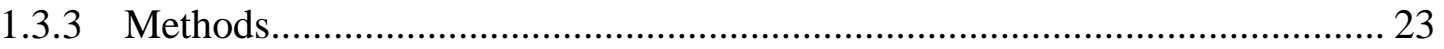

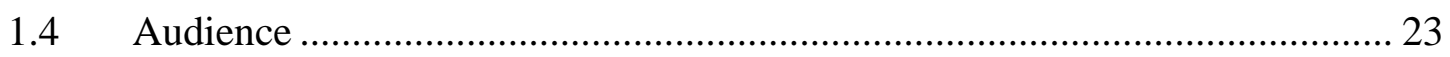

1.5 Overview of the Rest of this Report ............................................................. 23

Chapter 2 - Literature Review................................................................................................ 24

$2.1 \quad$ Mobile Data Collection........................................................................... 24

2.2 Understanding Vegetation Reflect-ability .................................................... 25

2.2.1 Normalized Difference Vegetation Index (NDVI) ....................................... 26

2.3 National Agriculture Imagery Program (NAIP) ………................................ 27

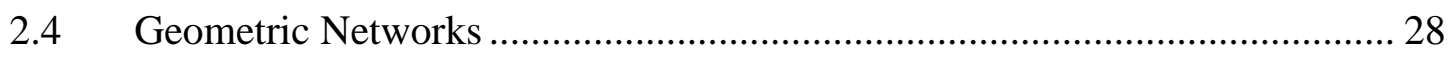

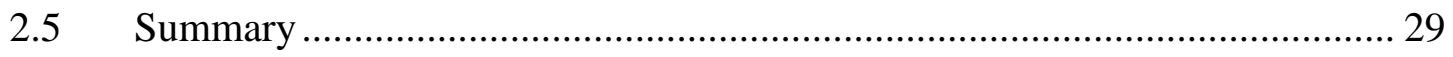

Chapter 3 - Systems Analysis and Design........................................................................ 31

3.1 Problem Statement .................................................................................... 31

3.2 Requirements Analysis .............................................................................. 31

3.2.1 Functional Requirements .................................................................... 32

3.2.2 Non-Functional Requirements .................................................................... 34

3.3 Collector System Design......................................................................... 35 
3.3.1 Mobile Collection Application ……………………......................................... 36

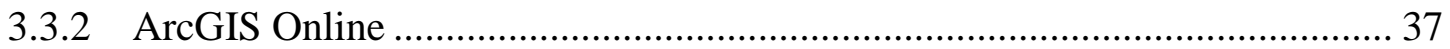

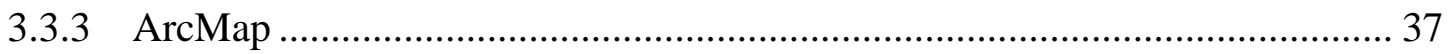

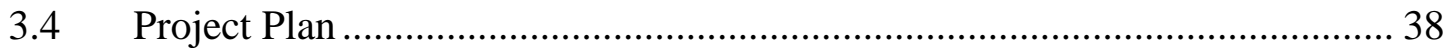

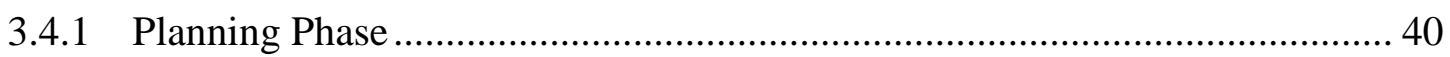

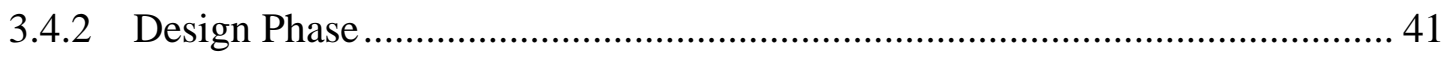

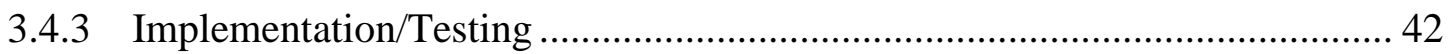

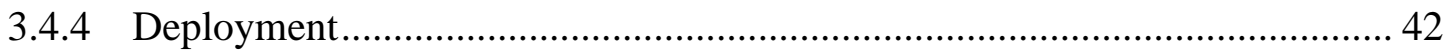

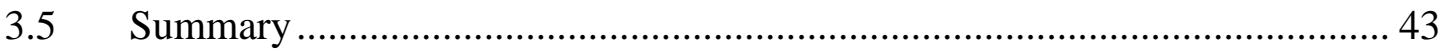

Chapter 4 - Database Design.................................................................................................... 45

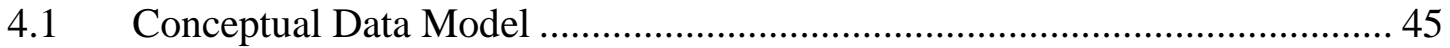

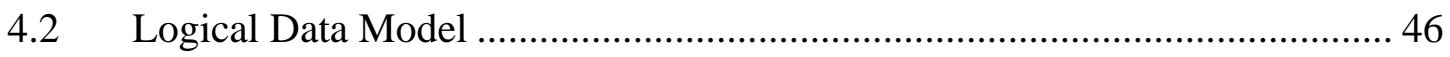

4.2.1 Fixtures Feature Class ............................................................................. 47

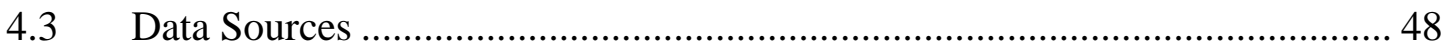

4.4 Data Collection Methods ............................................................................ 49

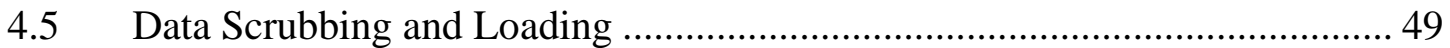

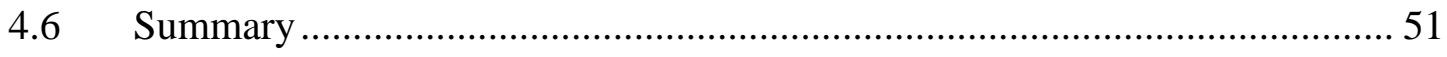

Chapter 5 - Implementation................................................................................................... 53

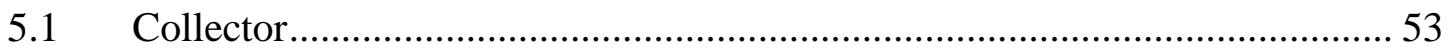

5.1.1 Collector's Graphic User Interface ............................................................ 53

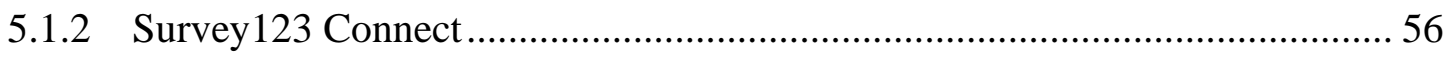

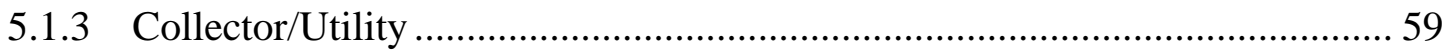

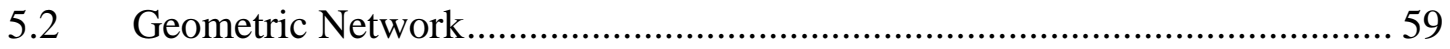




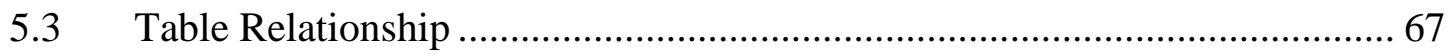

5.4 Normalized Difference Vegetation Index (NDVI) ………………………........ 68

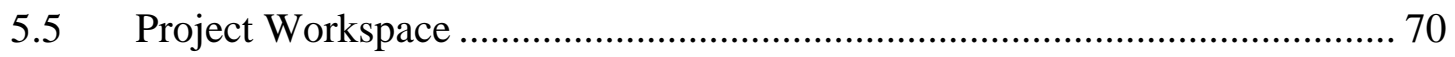

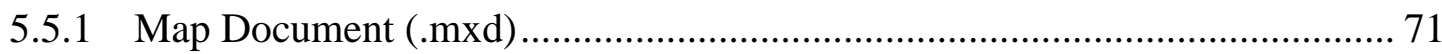

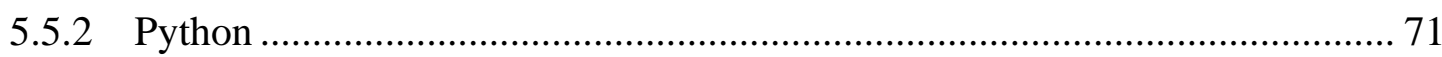

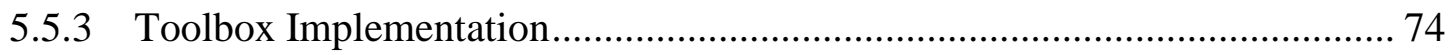

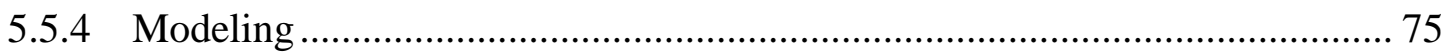

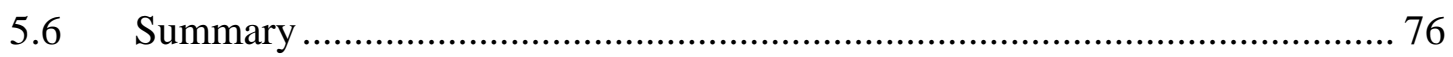

Chapter 6 - Results and Analysis........................................................................................... 77

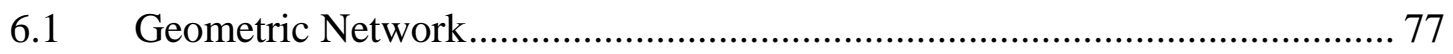

6.2 The Health of the Orchards ........................................................................ 79

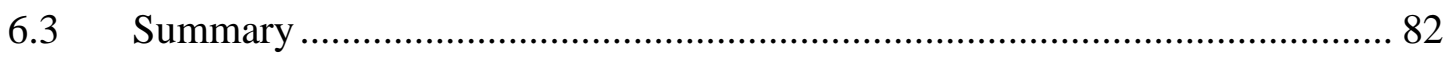

Chapter 7 - Conclusions and Future Work .......................................................................... 83

7.1 Project Summary ………………………………................................. 83

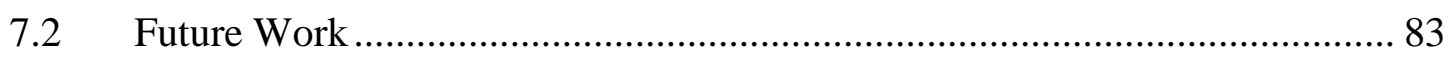

Works Cited 85

Appendix A. Survey123 Connect Type Fields....................................................................... 89

Appendix B. Calculate the Difference Between 2 NDVI Features ............................. 93

Appendix C. Python Script to Calculate NDVI ............................................................... 94

Appendix D. Collector Errors from using a Second Mobile Device ............................ 97

Appendix E. Weather Station Precipitation Readings..Error! Bookmark not defined. 



\section{Table of Figures}

Figure 1-1: The Wildlands Conservancy Oak Glen Preserve ................................. 19

Figure 2-1: Remote Sensing at Work, adapted from (Jenson, 2007).......................27

Figure 3-1: Graphic Representation of Application Components ........................... 36

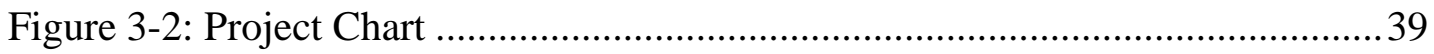

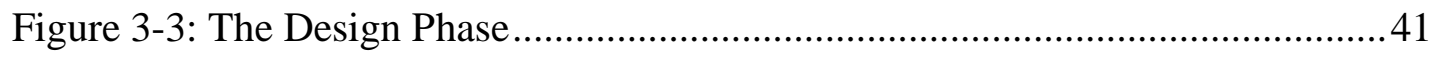

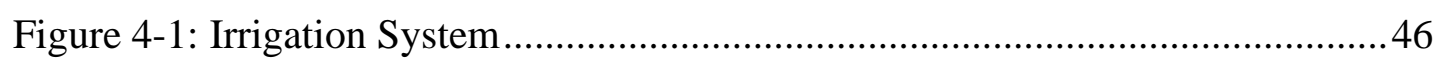

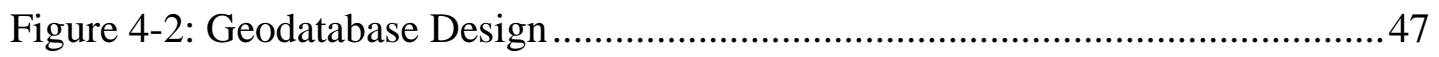

Figure 4-3: Datapoints Manually Adjusted.......................................................50

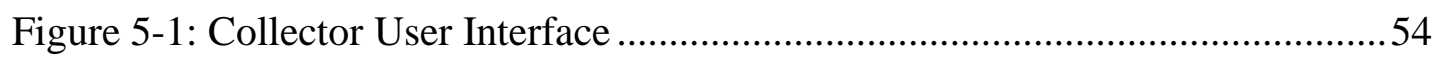

Figure 5-2: Two screen Collector Application .................................................55

Figure 5-3: Collector Application Screens .....................................................56

Figure 5-4: Choices Worksheet and the Collector Drop-down Menu .......................58

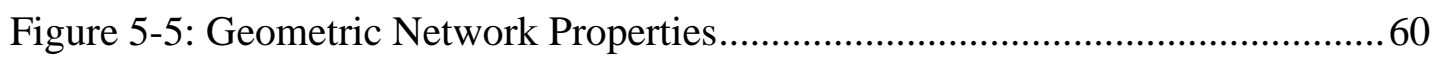

Figure 5-6: Adding Subtypes to Features in a Feature Class ................................6 61

Figure 5-7: Geometric Network Connectivity Rules .........................................63

Figure 5-8: Handwritten (a) vs. ArcMap's Geometric Network (b) .........................64

Figure 5-9: ArcMap Interface Showing the Geometric Network ...........................65

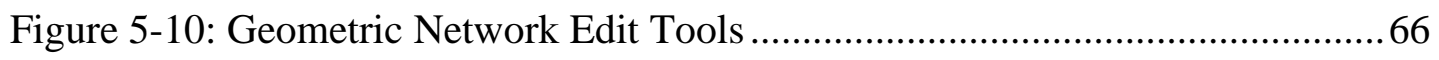

Figure 5-11: Output of Geometric Network, Bottom of Preserve ..........................67

Figure 5-12: Relationship between Farmland and Farmers .................................67

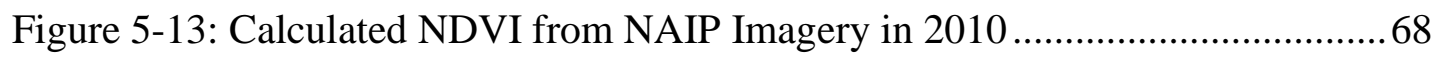

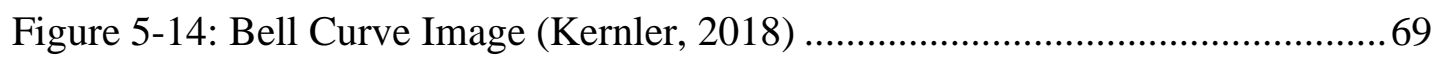




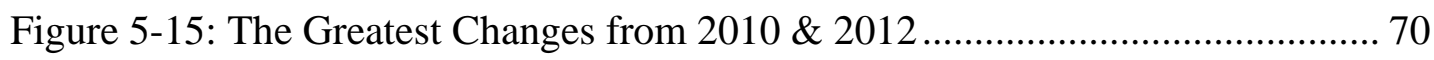

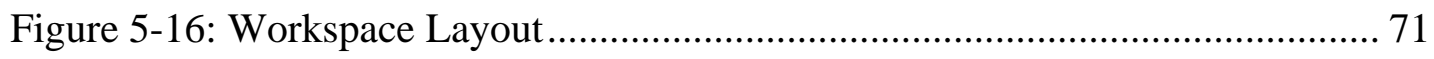

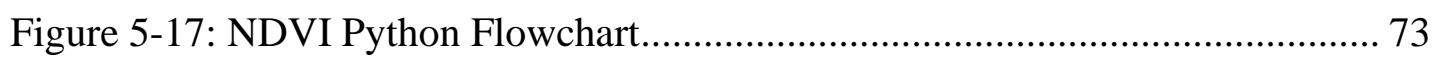

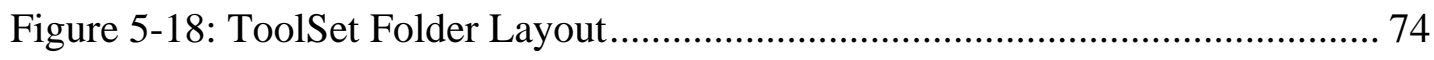

Figure 5-19: NDVI Model to Clip and Calculate the NDVI Layer......................... 75

Figure 5-20: The NDVI Tool Input Interface for the End User ........................... 76

Figure 6-1: ArcMap Interface Showing the Geometric Network ........................... 77

Figure 6-2: Flow Direction \& Traces Downstream............................................ 78

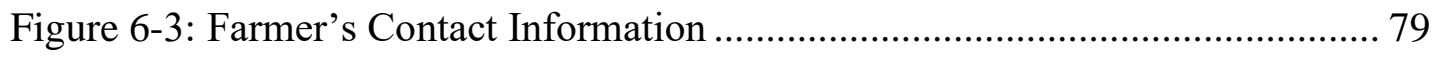

Figure 6-4: ArcMap Interface Showing the Health of the Orchard ......................... 80

Figure 6-5: Showing the Differences Between Three Grouped Years..................... 80

Figure 6-6: 2010-2017 Precipitation Bar Graph.................................................. 81 


\section{List of Tables}

Table 2-1: GPS Positioning Accuracy ( Holland, Pook, \& Capstick, 2016) ................... 25

Table 2-2: Averages of Selected Vegetation Indices, Reprinted (Schram, 2018) ........... 26

Table 3-1: Functional Requirements for the Collector Application ............................... 32

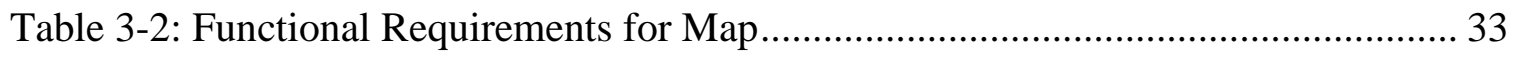

Table 3-3: Nonfunctional Requirements for Collector ............................................ 34

Table 3-4: Nonfunctional Requirements for Map.................................................. 35

Table 3-5: Difference Between Three Mobile Survey Applications (Chivite, 2018)...... 36

Table 5-1: Survey Worksheet Schema of Survey 123 Connect..................................... 58

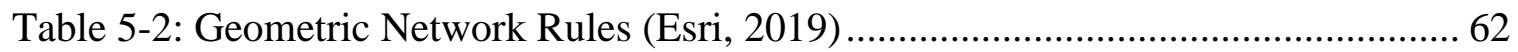





\section{List of Acronyms and Definitions}

$\begin{array}{ll}\text { FSA } & \text { Farm Service Agency } \\ \text { GNSS } & \text { Global Navigation Satellite System } \\ \text { LiDAR } & \text { Light Detection and Ranging } \\ \text { NAIP } & \text { National Agriculture Imagery Program } \\ \text { NDVI } & \text { Normalized Difference Vegetation Index } \\ \text { NIR } & \text { Near-infrared } \\ \text { NOAA } & \text { National Oceanic and Atmospheric Administration } \\ \text { REST } & \text { Representational State Transfer } \\ \text { RGB } & \text { Red, Blue, Green } \\ \text { RMSE } & \text { Root Mean Square Error } \\ \text { TWC } & \text { The Wildlands Conservancy }\end{array}$





\section{Chapter 1 - Introduction}

The Wildlands Conservancy owns nine preserves in Southern California. One of the these is the Oak Glen Preserve which is 2,087 acres of wildland, orchards, berry fields, and walking paths. The original owner of the Oak Glen Preserve was Los Rios Rancho, the largest apple ranch in Southern California. The Wildlands Conservancy bought the property in 1996 after the ranch fell into foreclosure and was planned to become a neighborhood subdivision (Trammell, 2018). Figure 1-1 shows The Wildlands Conservancy Oak Glen Preserve (The Wildlands Conservancy, 2018), the study area for this project.

The Wildlands Conservancy's mission is

To preserve the beauty and biodiversity of the earth and to provide programs so that children may know the wonder and joy of nature. (The

Wildlands Conservancy, 2019)

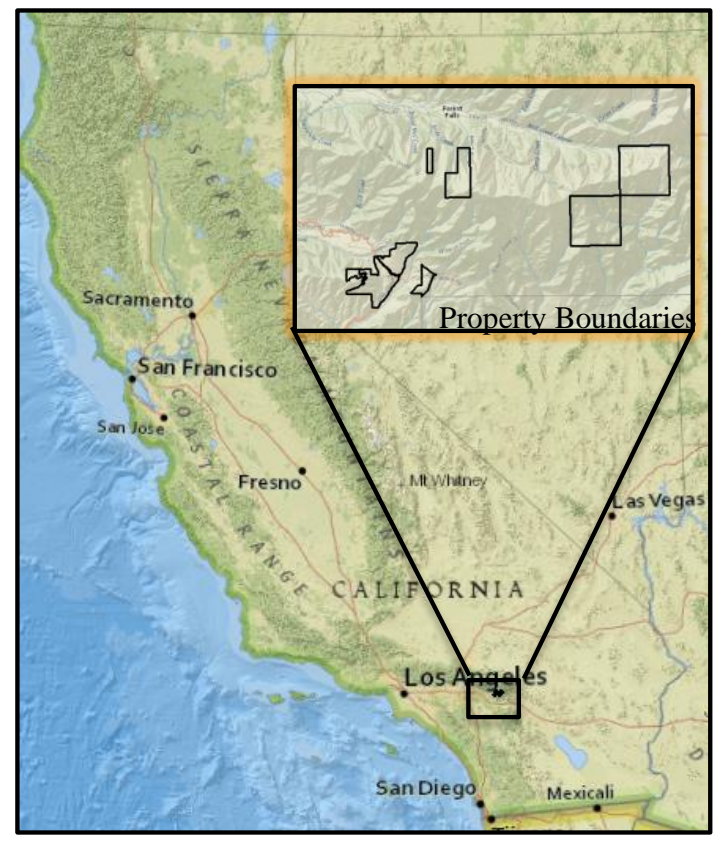

Figure 1-1: The Wildlands Conservancy Oak Glen Preserve 


\subsection{Client}

The client for this project was The Wildlands Conservancy (TWC), and Jakob Larson was the primary point of contact; he oversees all TWC GIS projects. Doug Chudy is the San Bernardino Mountains Regional Director and provided staff to help collect data, and he created the hand drawing for the geometric network.

\subsection{Problem Statement}

As TWC attracts more guests to its many preserves, land management for each preserve's resources has become a more substantial undertaking. Michelle and the client discussed the challenges that TWC had with its irrigation system and farmland, so a plan could be designed to conquer a few key areas.

The first concern was the location of the TWC's complete irrigation system.

Currently, the rangers have paper maps with lines and symbols representing the irrigation system. The paper maps lacked a tracking system to show when a fixture or pipe had last been replaced or maintained and what those fixtures and pipes were, i.e., PVC, stainless steel pipes, or a ball valve fixture, which would be useful for keeping replacement parts in stock. Combining hand drawings, notes, attributes, and maintenance schedules in a centralized location would give the management team a tool to maximize the resources they have. TWC rents its farmland to Riley's Frontier Events and the ability to contact farmers about irrigation issues or maintenance would keep everyone informed. Farmers tend to know what is best for their land, but this creates questions for managers who want to know if the farmland is producing at optimal levels.

Integrating the Oak Glen Preserves' irrigation system into GIS, including data fields that track changes, and linking to the farmer's contact information will enhance the 
irrigation resource. The next task is to use remote sensing to decipher the health of the orchards, giving a visual representation of the farmland. Adding GIS to the workflow transforms the integrity of the Oak Glen Preserve and giving management a tool for better land management. The irrigation system is one of the many GIS projects conducted by the Oak Glen Preserve.

\subsection{Proposed Solution}

The proposed solution for TWC was two-fold; first was to document the irrigation system, and the second was to record the health of the orchards. A mobile application was built to collect data in the field. Many mobile devices were used, so the application needed to reside in the cloud to give full access to mobile devices. Two geodatabases were created; one was the geometric network, which was a stand-alone application, and the second was a geodatabase with the irrigation fixtures, including the fixture photos taken during data collection.

\subsubsection{Goals and Objectives}

Giving the client a GIS would enhance decision making; the GIS would house all the data in one system. A GIS would give TWC the ability to create scenarios to mitigate downtime of ruptured pipes and would show which farmer is working a plot. Having access to the farmer's contact information makes notifications easier to deliver. The client can log maintenance by entering dates of service to individual fixtures in the attribute table.

The objective of this project was to collect over 60 data points over a two-day period. After obtaining and downloading the data into ArcMap, a geometric network was created to show the water flow direction. Once the geometric network was complete, an 
NDVI calculation was used to analyze the health of the orchards and then another calculation was run to find the difference between every two years to show either positive or negative changes. This calculation gave TWC its first scientific look at the health of its orchards.

\subsubsection{Scope}

The project deliverables were a geodatabase with the irrigation fixtures, water lines, plots of land, a table with farmer's contact information, while also including an NDVI analysis over time. A second map included the geometric network. The irrigation points were new and were collected and mapped as a part of this project. The Wildlands Conservancy provided shapefiles including the property boundary lines, the buildings, asphalt, ponds, streams, and the handwritten reference maps showing how the waterline connected the fixtures.

The schema for the geodatabase was created, the Collector application to gather the data points in the field was designed and created. Michelle and the staff went into the field and collected data points for each junction at TWC Oak Glen campus. Then the data points were downloaded into ArcMap, and the water lines were connected to the fixtures using the handwritten drawing for guidance. Next was to change the coordinate system from NAD83 UTM Zone 11N to NAD86 State Plane California V; this was a decision made by the current GIS manager as the coordinate system the preserve will use going forward. Once the coordinate system was set, the NAIP imagery was downloaded from EarthExplorer, and a tool was designed to clip the imagery to TWC boundary, then calculate the NDVI raster using a Python script. Once the NDVI raster was finalized, the next step was to calculate the differences between the two NDVI raster sets. 
The additional map with the geometric network began by creating rules for the waterlines to follow, then tracing the waterlines from the first map. Tracing the waterlines from the source taught the software to follow the flow rules.

\subsubsection{Methods}

The Collector application was created using Survey123 Connect and a Python script to generate the geodatabase schema. Then a custom toolbox was built using ArcMap's ModelBuilder to organize models and scripting tools. Python 2.7 script converted an NAIP image into an NDVI raster file.

\subsection{Audience}

This report is intended for The Wildlands Conservancy management team as well as those who have an interest in irrigation, agriculture, gardens, and land management. The assumption is that this audience has some knowledge of ArcMap, geometric networks, and collector.

\subsection{Overview of the Rest of this Report}

The following chapters specify the design aspect, implementation, challenges, and future work. Chapter 2 examines the literature used to back up this project. Chapter 3 explains the system design and the project plan. Chapter 4 is the database design, which is the key to this project. Then discussing the conceptual model and logical models and how they were designed to show relationships between data. Chapter 5 talks about the implementation of each area of the project and how the files were set up. Chapter 6 gives the analysis and results of this project. Chapter 7 includes potential future work that could be completed by upcoming MS GIS students. 


\section{Chapter 2 - Literature Review}

This chapter reviews the literature associated with data collection, NDVI, and NAIP imagery. It examines literature about Global Navigation Satellite System (GNSS) software and how it can be used to make a smart mobile device's GPS more accurate. This chapter also looks at the reflectivity of plant leaves and fruit with respect to an NDVI feature class. Also touching on the history of the National Agricultural Imagery Program (NAIP). Next is a description of geometric networks and a project completed by the City of Minnesota Department of Public Works.

\subsection{Mobile Data Collection}

Smart mobile devices can collect data points via GPS within several meter accuracy.

Mobile devices can collect data points in the field with better efficiency when paired with a secondary GPS receiver using GNSS. Holland (2016) stated

The accuracy of the GNSS position recorded by [smart devices], is generally at a level of 5-10 meters, which is good enough for the general consumer, but not for a surveyor. To obtain a positional accuracy suitable for large-scale mapping applications, a survey-grade GPS device is required. (p. 727)

For this project, the Trimble R1 unit was used to bring the accuracy of an Android phone down to centimeters; tighter accuracy was requested by the client to enhance my learning. Table 2-1 is the result of a test conducted by Holland's team showing the accuracy of the Trimble R1 GPS receiver. 
Table 2-1: GPS Positioning Accuracy ( Holland, Pook, \& Capstick, 2016)

\begin{tabular}{|c|c|c|c|}
\hline GNSS Kit & Configuration & $\begin{array}{c}\text { RMSE } \\
(\mathrm{m})\end{array}$ & $\begin{array}{c}\text { RMSE } \\
\text { (in) }\end{array}$ \\
\hline Trimble R1 & $\begin{array}{c}\text { Pole-Mounted } \\
\text { ViewPoint RTX }\end{array}$ & \pm 0.35 & \pm 13.8 \\
\hline
\end{tabular}

The GIS manager requested that Michelle collect data points for the irrigation system at the Oak Glen Preserve. Learning about GPS accuracy enhanced her ability to make the right product decision. The product was a Trimble R1 unit borrowed for the Spatial Studies department.

\subsection{Understanding Vegetation Reflect-ability}

Understanding the fundamentals of photosynthesis helps us understand how remote sensing works to discover the health and wellness of vegetation. Photosynthesis begins when the sun's ray hit the chloroplasts of the leaf. Chloroplasts are small bodies found just under the top layer of the leaf and contain the green substance called chlorophyll. The interaction between photosynthesis and electromagnetic energy impacts how vegetation shows up spectrally when imaged using remote sensing technology. Healthy vegetation reflects the largest amount of near infrared light and green color, while yellowing vegetation reflects near infrared light and green color more evenly.

In the fall, when plants go through senescence or encounter stress, the chlorophyll production diminishes, and carotene pigments become dominant, causing the leaves to yellow (Jensen, 2007, pp. 363-364). Jensen stated, "the mesophyll layer of the green leaf controls the amount of near-infrared energy that is reflected." The reflectivity is caused by the internal scattering of energy between the cell wall and the air within the leaf. 


\subsubsection{Normalized Difference Vegetation Index (NDVI)}

Normalized Difference Vegetation Index (NDVI) quantifies vegetation by measuring the difference between near-infrared and red-light reflectivity (What is NDVI, 2018).

Healthy vegetation reflects more significant amounts of near-infrared and smaller amounts of red light. The NDVI formula is NDVI $=(\mathrm{NIR}-\mathrm{Red}) /(\mathrm{NIR}+\mathrm{Red})$, which means if near infrared is reflection at $50 \%$ and red is reflecting at $8 \%$ then the formula is $(.50-.08) /(.50+.08)$ where NDVI is .72 .

Table 2-3 compares the NDVI distinction between leaves and fruit (Henry \& Fellow, 2016). This report was used as guidelines for The Wildlands Conservancy (TWC) project to match up with the Oak Glen Preserve orchards but found that the imagery was flown in May and was not an optimal timeframe for orchard fruit in Oak Glen.

Table 2-2: Averages of Selected Vegetation Indices, Reprinted (Schram, 2018)

\begin{tabular}{|l|l|}
\hline Type & NDVI \\
\hline Live Leaves & 0.812419 \\
\hline Yellow Leaves & 0.549925 \\
\hline Dead Leaves & 0.299663 \\
\hline Golden Delicious & 0.538026 \\
\hline Granny Smith & 0.70493 \\
\hline Honeycrisp & 0.390704 \\
\hline Red Delicious & 0.539661 \\
\hline
\end{tabular}


In 2013, the Sonoma County Water Agency used NDVI to map the changes in crop fields from 2006 to 2011 . The findings were used to update agricultural fields in the area (Schram, 2018). Michelle used a similar process to calculate the differences in NDVI images over the years to find the health of The Wildland Conservancy's orchards.

\subsection{National Agriculture Imagery Program (NAIP)}

NAIP imagery will be used in this project to find out the health of the orchards over time. The health of the orchards can be deduced by taking two NAIP images and calculating the NDVI then subtracting the earliest year's NDVI from the latest year.

The USDA Farm Service Agencies (FSA) administers the National Agriculture Imagery Program (NAIP). NAIP imagery is collected during the agricultural season and are obtained using Cessna 441 aircraft to acquire digital images nationally every two years (USDA-FSA-APFO Aerial Photography Field Office, 2016). NAIP imagery cameras are multispectral with four-color bands (Red, Green, Blue, and Near-infrared (NIR)) and providing 1-meter resolution. Analysts can use NAIP imagery to help farmers manage agricultural plots by calculating the red and NIR bands. Each individual image

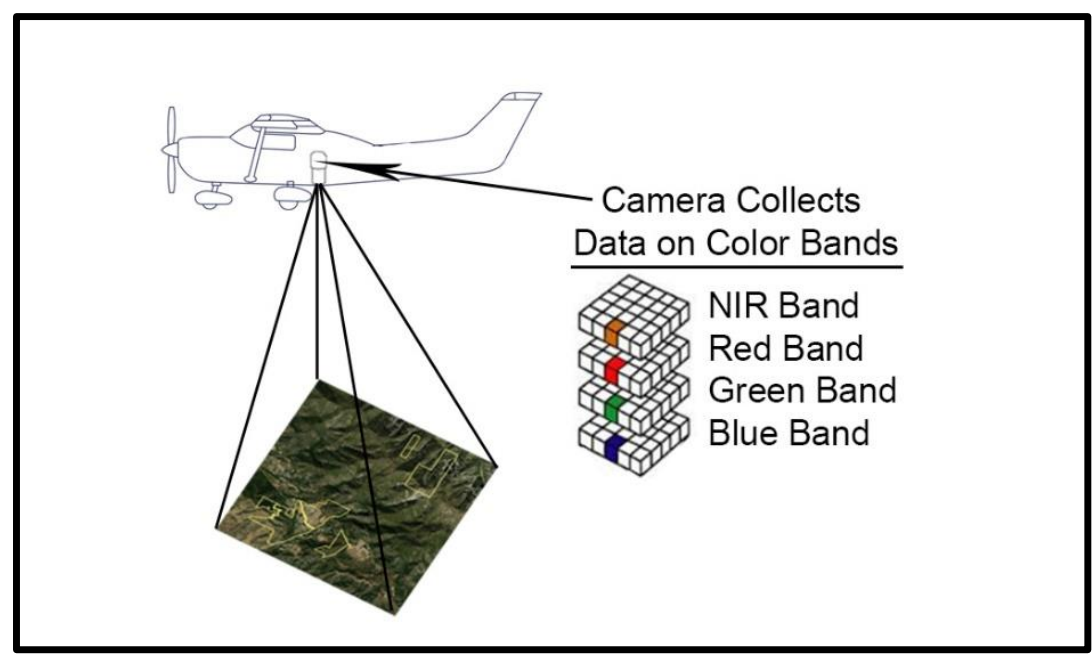

Figure 2-1: Remote Sensing at Work, adapted from (Jenson, 2007) 
covers 3.75 x 3.75-minute quarter quadrangle plus a 300-meter buffer on all four sides (USDA, 2018). Figure 2-1 represents how the camera collects images and records each pixel on its own color band.

The USDA's Farm Service Agencies (FSA) can be traced back to 1933 during the Great Depression. The FSA was created to reduce farm failures and mounting unemployment. The original focus of this division was to relocate entire farm communities to more profitable locations, which did not work as expected due to cost and controversy. Other roles the FSA took on included home and farm loans, debt management, the creation of co-ops, government medical programs, price management, and production caps. The current organization also purchases and delivers commodities for humanitarian programs. (USDA, 2018)

\subsection{Geometric Networks}

A geometric network is a way to model infrastructures like water, sewer, and gas lines which transport fluid, but can also be used for telephone and electric lines. Once the network is modeled, many analysis tools can be activated to calculate the shortest path between two points, find disconnections, determine flow direction, and trace up and downstream from a specified location. The analysis tool helps the end-user make educated guesses before sending a crew out to the area in question (Esri, 2018). Rochester Minnesota used geometric networks to model the flow of its sewer systems using ArcMap 8.2; the Meadow Hills subdivision was the study area for this project. The process used by the City of Minnesota Department of Public Works included using the existing engineering plans for the flow direction, length of pipes, and manhole elevations. Then the team went out to collect missing feature location data using Trimble 
units. After the data was collected, a geodatabase was designed to house all the geographic data. Once the feature classes were in place, a geometric network could be designed, and ancillary roles were enforced. For this project, manholes were designated as the junctions, pipes were the edges, and the water treatment plant was selected as the sink which told the software that the flow was heading to the water treatment plant (Abraham \& Schuster, 2002).

\subsection{Summary}

The literature revealed that smart devices could be used in a non-professional data collection environment with centimeter accuracy by pairing the device with a Trimble R1 unit utilizing the GNSS software. Next discovering that plant reflectivity is important and what NDVI ranges to look for in healthy specimens. Continuing through the literature, we find that NAIP imagery includes the color bands needed to perform the NDVI calculations and has the optimal 1-meter resolution to pinpoint trees in an orchard. The final section is about geometric networks and how it could be used for utilities with the flow direction. 



\section{Chapter 3 - Systems Analysis and Design}

Project management begins with the customer's ideas and goals for the project. First, an explanation of the problem statement for this project. Then a list of the functional and nonfunctional elements collected during meetings and via emails with the client. Finally, a discussion of the system layout and the project schedule.

\subsection{Problem Statement}

The Wildlands Conservancy owns large properties all over California with a small managing GIS staff at the Oak Glen campus. The Oak Glen Preserve requires a set of GIS tools to manage farmers, locate its water resources, and to take a scientific look at the health of its orchards. The client's current geodatabase included the Oak Glen Preserve's property boundary and several feature classes showing trails, buildings, and paved surfaces.

The client needed to know where the irrigation lines reside, as well as where the water meters, hydrants, and other features are located. Locating the irrigation line and its features can be accomplished with GIS and GPS tools.

\subsection{Requirements Analysis}

Requirements were determined by conducting several meetings with the client to solidify the client's needs. The GIS manager decided on the Collector application requirements before starting the data collection. This project had two types of requirements: functional and non-functional. These requirements were obtained over a period of time through a process of meetings and through various communication channels. 


\subsubsection{Functional Requirements}

Functional requirements are user interactions that complete an operation, usually via a click. These are user-controlled actions that tell the program what to do.

Tables 3-1 include the functional requirements for the Collector application of this project.

Table 3-1: Functional Requirements for the Collector Application

\begin{tabular}{|l|l|}
\hline \multicolumn{1}{|c|}{ Functional Requirements } & \multicolumn{1}{c|}{ Description } \\
\hline Two Screen Max & Staff would only like to swipe once \\
\hline Drop-down Menus & Limit errors by adding drop-down menus \\
\hline Note Field & $\begin{array}{l}\text { Include a note field for unexpected issues } \\
\text { found in the field }\end{array}$ \\
\hline Photo & For visual association \\
\hline
\end{tabular}

In order to build a Collector application, the following functional requirements must be met. The two-screen maximum rule required minimal and concise data fields. With $60+$ points collected, staff members wanted a quick survey process. The drop-down menus kept the data clean while also enabling staff to complete the task quickly. The note field gave the team the freedom to add data not included in the Collector drop-down menu or data that needed more explanation. Each collected point could consist of a photo of the fixture, which was beneficial when spigots were hidden behind trees or under weeds or water. Tables 3-2 include the functional requirements for the map for this project. 
Table 3-2: Functional Requirements for Map

\begin{tabular}{|l|l|}
\hline \multicolumn{1}{|c|}{ Functional Requirments } & \multicolumn{1}{c|}{ Description } \\
\hline $\begin{array}{l}\text { Fixture Map: Transferable feature } \\
\text { classes that can move to TWC original } \\
\text { geodatabase }\end{array}$ & $\begin{array}{l}\text { Boundaries, fixture data points, pipelines, } \\
\text { NDVI anomalies }\end{array}$ \\
\hline Fixture Map: & $\begin{array}{l}\text { Property boundary, the fixture data points } \\
\text { (plus two date fields for maintenance), } \\
\text { farmer information, and the differences in } \\
\text { NDVI }\end{array}$ \\
\hline Fixture Map: NDVI Analysis Tool & $\begin{array}{l}\text { The user can use a tool to calculate new } \\
\text { imagery datasets into an NDVI layer }\end{array}$ \\
\hline $\begin{array}{l}\text { Geometric Network: a standalone } \\
\text { geodatabase }\end{array}$ & $\begin{array}{l}\text { Show flow direction, and what is } \\
\text { upstream and downstream from the } \\
\text { disconnect }\end{array}$ \\
\hline Geometric Network: Trace flow & $\begin{array}{l}\text { The user can run standard geoprocessing } \\
\text { tools to determine flow direction }\end{array}$ \\
\hline
\end{tabular}

The Fixture Map must include data that represents the property boundary, the fixture data points, and the differences in NDVI raster sets. The attribute table for the fixtures must also include a "last maintained" date field and an "installed" date field to track maintenance. The analysis tool contains a clip tool to clip the NAIP image to TWC property boundaries, then uses a Python script to calculate the NDVI. Once completed, a calculation of the difference between the two years is conducted.

The geometric network map must show the directional flow of the water and have the ability to differentiate the affected pipes when a fixture is disconnected. Each of these tasks will be accessible through ArcMap's Utility Network Analyst toolbar, this is a standard tool inside ArcMap and requires minimal training for TWC staff. The Utility Network Analyst toolbar gives the staff the ability to route water flow and find issues when breakages occur. 


\subsubsection{Non-Functional Requirements}

Non-functional requirements are criteria for the software that can be measured and tested. Tables 3-3 and 3-4 show the non-functional requirements for the Collector application and the map.

Table 3-3: Nonfunctional Requirements for Collector

\begin{tabular}{|l|l|}
\hline \multicolumn{1}{|c|}{ Nonfunctional Requirements } & \multicolumn{1}{c|}{ Description } \\
\hline Accurate & The application will be valid within 5 feet \\
\hline Graphics User Interface & $\begin{array}{l}\text { Will be self-explanatory and include } \\
\text { accurate information in the drop-down } \\
\text { menu }\end{array}$ \\
\hline
\end{tabular}

The client requested that the data collection be as accurate as possible. The accuracy was accomplished by pairing a Trimble R1 unit to an Android phone, and this process can also be accomplished with an Apple device. Phone GPS receivers are usually precise within 4.9 meters or 16.4 feet, which was not within the five feet requirement set by the customer (National Coordination Office for Space-Based Positioning, Navigation, and Timing, 2018). Thus, pairing a mobile device and a Trimble R1 unit brought the accuracy range below one-meter or around three-feet. The next requirement was for the user interface to be self-explanatory and have correct information in the drop-down menu. This was accomplished by spending time with the GIS manager to discuss specific data needs. 
Table 3-4: Nonfunctional Requirements for Map

\begin{tabular}{|l|l|}
\hline \multicolumn{1}{|c|}{ Nonfunctional Requirements } & \multicolumn{1}{c|}{ Description } \\
\hline $\begin{array}{l}\text { Combine multiple data sets in a single } \\
\text { mapping solution }\end{array}$ & $\begin{array}{l}\text { paper maps, notes, collected data in a } \\
\text { single mapping solution }\end{array}$ \\
\hline Reduce time finding irrigation lines & $\begin{array}{l}\text { The application should reduce extraneous } \\
\text { communication with farmers. }\end{array}$ \\
\hline Interactive & $\begin{array}{l}\text { Management must be able to make } \\
\text { changes and extract data. }\end{array}$ \\
\hline
\end{tabular}

One of the primary motivations for this project was to document the irrigation system in order to make locating it would be less time-consuming. The non-functional requirement of combining multiple datasets into one solution, and by bringing all the datasets into one location made the process of locating a pipe or fixture more efficient.

The client wanted to edit features and create new features with the standard edit tool. Using the standard editing tools ensured that the management team would need minimal training for this step.

\subsection{Collector System Design}

The system design includes online storage of the collected data points and an ArcMap file geodatabase for the analysis (Figure 3-1). The file geodatabase contains one feature dataset with individual feature classes. The schema for the fixture feature class was a collaboration between Michelle and the Wildlands Conservancy (TWC) staff.

The process goes as such, ArcGIS Online holds the original schema for the data collection. The Collector application interacts with the schema pushing and pulling data. Once all the data was collected, the schema and its data are downloaded into ArcMap to be edited and then used in maps. 


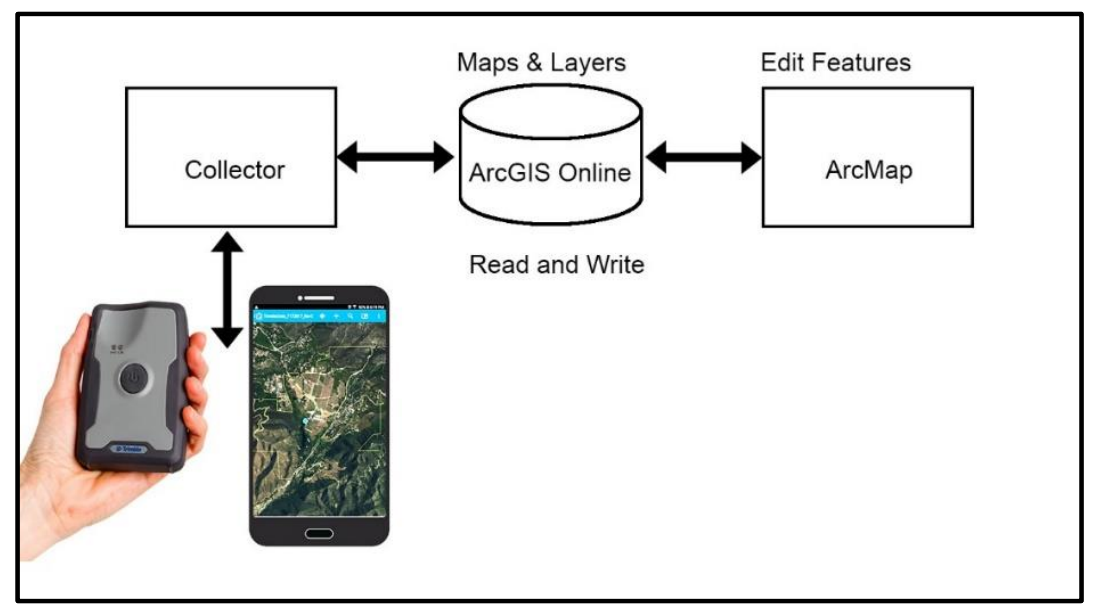

Figure 3-1: Graphic Representation of Application Components

\subsubsection{Mobile Collection Application}

With many options to choose from to collect data on a mobile device, a decision had to be made as to which software would work for this project. Esri's suite of products includes three applications for taking surveys with mobile devices: Collector, Survey123, and GeoForms. Table 3-5 shows each platform and its optimal use features. This project required Collector because of the Global Navigation Satellite System (GNSS) receiver capability.

Table 3-5: Difference Between Three Mobile Survey Applications (Chivite, 2018).

\begin{tabular}{|c|c|c|c|}
\hline & Survey123 for ArcGIS & Collector for ArcGIS & GeoForm \\
\hline Data collection style & Form Centric & Map Centric & Form Centric \\
\hline $\begin{array}{l}\text { Supports capturing new } \\
\text { data }\end{array}$ & Yes (points) & $\begin{array}{l}\text { Yes (points, lines, and } \\
\text { polys) }\end{array}$ & Yes (points) \\
\hline $\begin{array}{l}\text { Supports editing existing } \\
\text { data }\end{array}$ & Yes & Yes & No \\
\hline Smart forms & Yes (xForms) & No & No \\
\hline Works offline & Yes & Yes & $\begin{array}{l}\text { Yes (keep the browser } \\
\text { open) }\end{array}$ \\
\hline $\begin{array}{l}\text { Supports external GNSS } \\
\text { receivers }\end{array}$ & No (planned version 3.0) & Yes & No \\
\hline $\begin{array}{l}\text { Supports integration with } \\
\text { Spike }\end{array}$ & Yes & No & No \\
\hline $\begin{array}{l}\text { Supports anonymous } \\
\text { access }\end{array}$ & Yes & No & Yes \\
\hline Platforms & $\begin{array}{l}\text { iOS, Android, Windows } \\
(7,8,10) \text {, Mac, Linux, Web }\end{array}$ & iOS, Android, Windows 10 & Web \\
\hline
\end{tabular}


The geodatabase schema was built using Survey123 Connect for ArcGIS. After the schema was created the Trimble/GNSS specific data fields and domains were created using a Python script. When the geodatabase schema was completed, it was uploaded to TWC organizational group inside ArcGIS Online. Once the geodatabase was online, mobile devices could download the Collector application and the GNSS application from the app store. The Collector application is the platform used to collect data with a mobile device. The GNSS application gave the phone the ability to connect to the Trimble R1 unit. The Trimble R1 unit was an inexpensive way to get sufficient accuracy.

\subsubsection{ArcGIS Online}

ArcGIS Online was a holding site for data while the data collection was underway. ArcGIS Online was chosen because many mobile devices using the Collector app could add data to one geodatabase inside ArcGIS Online at the same time.

\subsubsection{ArcMap}

After completion of data collection, the file was downloaded into ArcMap using the Representational State Transfer (REST) point so that the photo attachments would stay connected to the data. Two distinct maps were created using the collected data, the Fixture Map, and the geometric network.

The Fixture Map included the collected data points with each image, TWC property boundary lines, farmland plots, NAIP Imagery, NDVI calculations, and the analysis tool to define the health of the vegetation over time.

The geometric network was created using the collected data points and the boundary layer from TWC. Then the geometric network was designed with connectivity rules to ensure accuracy, and the water lines were traced from the source to activate the rules. 


\subsection{Project Plan}

The project plan was developed in March 2017 and revised in May 2017 due to a change in management. The original idea was to map Hummingbird Hill and deliver a Story Map of flowers and memorial plaques so that donors could sponsor an area within Hummingbird Hill. The new GIS manager decided to map the irrigation system for the Oak Glen preserve instead. The Gantt chart (Figure 3-2) shows the timeline for TWC's project and has been adjusted to reflect the actual schedule, originally estimated to take five months. Coursework was taking place until early August, followed by the holidays which are indicated by the breaks in the schedule. January 2018, approval was received to include remote sensing as part of this project. 


\section{Thesis}

Get Started

Meeting at TWC with Tory Elmore

Identify Deliverables

Receive Property Boundary from Clie

Meeting at TWC with Jakob Larson (N

Update deliverables

Prepare to Collect Data

Create Schema for Collector

Pair Trimble Unit with Android Phone

GPS Field Data Collection

\section{Desk Work}

Download Collected Data

Digitize Water Lines

Change Coordinate System to State P...

Create Geometric Network

Add Deliverable

Get Advisor's Approva

Remote Sensing

Design Conceptual Data Model

Design Physical Data Model

Review \& Prepare Client Dat

Write MIP

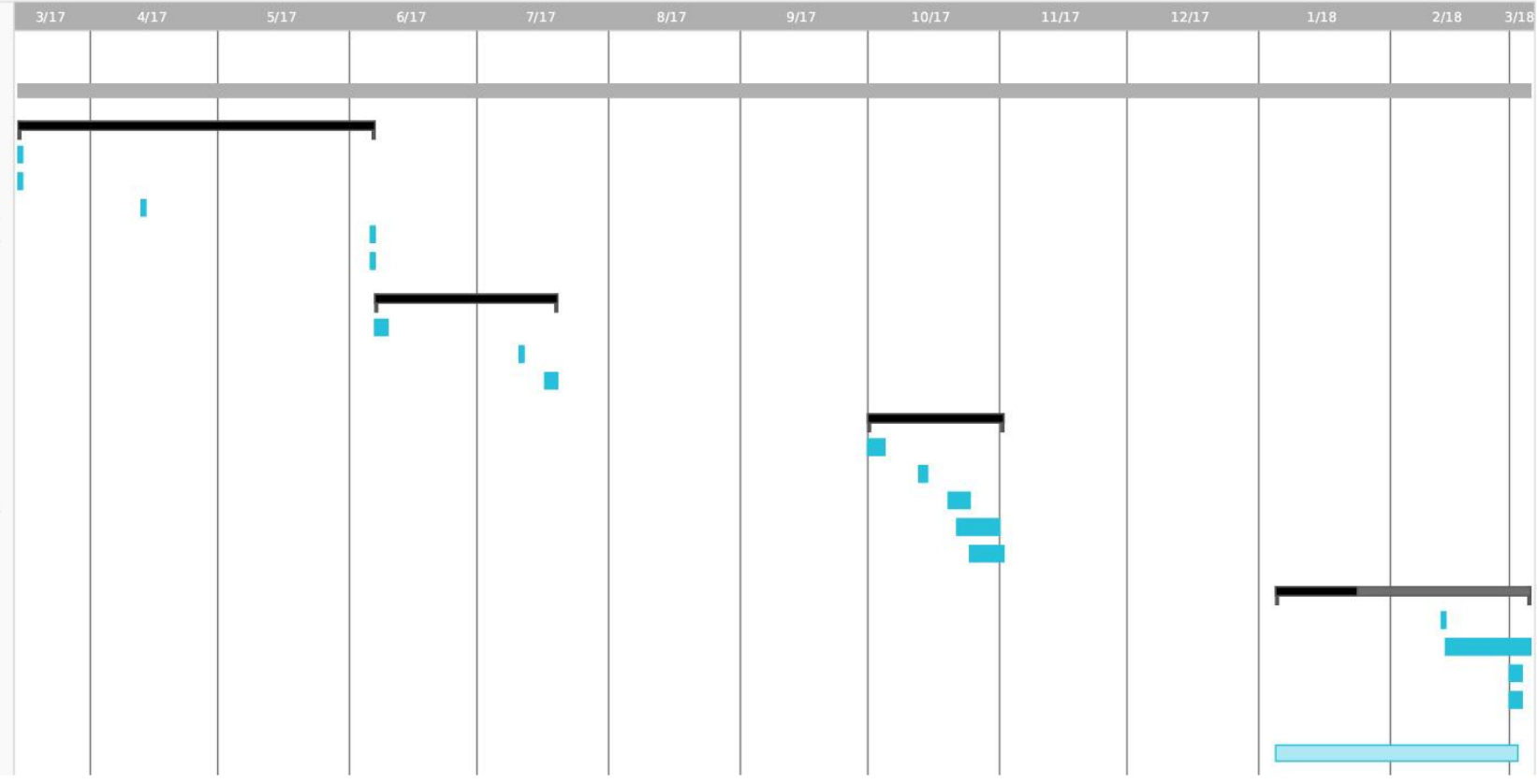

Figure 3-2: Project Chart 


\subsubsection{Planning Phase}

While in the planning phase, meetings were conducted to help Michelle understand the requirements of TWC and its staff. The goal of these meetings was to come to a consensus about the requirements. The outcome of this phase was the agreement on functional and nonfunctional requirements and the project plan. 


\subsubsection{Design Phase}

The system design came directly from the client's requirements in section 3.2. Starting with creating the geodatabase for the Collector application, collect data, build the geometric network and the Fixture Map, and lastly created the analysis tools (Figure 3-4).

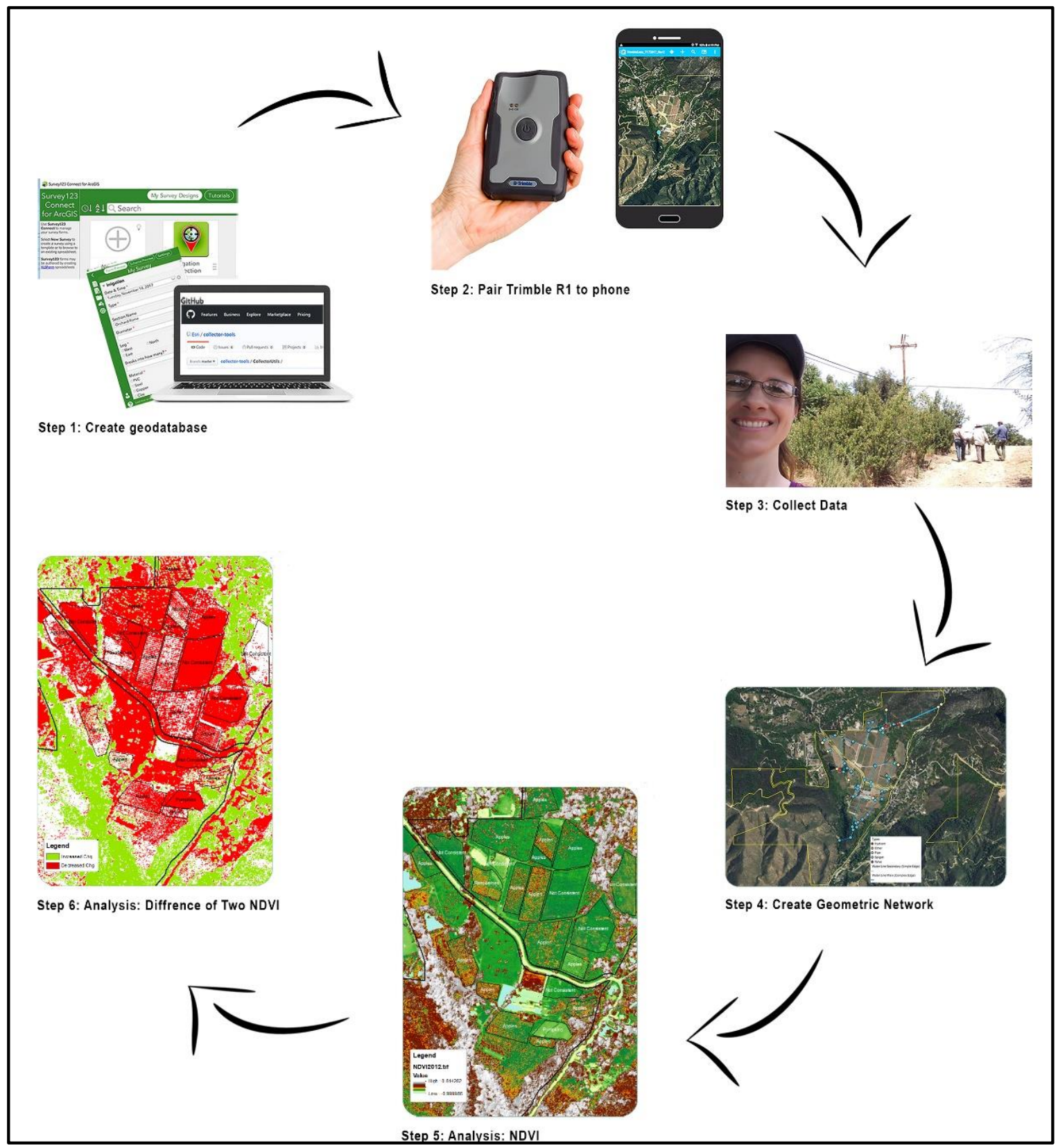

Figure 3-3: The Design Phase 
Michelle taught herself the geometric network aspect of ArcMap a process that was very time-consuming. In January 2018 she took an Esri instructor-led online class for geometric networking which was very beneficial in concluding this project because she learned the proper workflow of planning and designing rules for the geometric network.

\subsubsection{Implementation/Testing}

The Collector application was implemented first, and due to the Rangers' demanding schedules, a review of the hardware, software, and communications were conducted in the field on the first data collection day. The Trimble R1 unit and the Android phone worked with great accuracy the majority of the time; however, three points had to be manually adjusted due to the tree canopy. GPS is available when four or more satellites have a line of sight to the Trimble R1 unit. The tree canopies inhibit line of sight; thus, the manual data manipulation for those three points. Two hours into the data collection the phone overheated because of the constant data transfer between the phone, the satellites, and ArcGIS Online, forcing the team to take a long break. We also found that the Collector application was missing a few coded values, so we added them to the note section during the collection. After concluding the data collection, the missing coded values were added into ArcMap.

\subsubsection{Deployment}

During the deployment stage, Michelle delivered a map package to the GIS manager through the TWC group at ArcGIS Online, and also provided instructions on how to use the analysis tool for NAIP imagery every two years (Appendix B). 


\subsection{Summary}

A successful endeavor requires a detailed plan. The first obstacle was to discover the problem, which was the need to map the irrigation lines and find out the health of the orchards. The requirements were to use the Collector app paired wit a Trimble R1 unit for greater accuracy. The functional and nonfunctional requirements are components that need to be present in the final products, which were a geometric network and a Fixture Map. The system design represents how the Collector app on the mobile device talks to ArcGIS Online, so the final data can be downloaded into ArcMap. Then an explanation of ArcGIS, ArcMap were given in respect to this project. During the project planning phase, Michelle estimated it would take five months to create the Collector application, collect data points, manipulate data, and create a geometric network, which were guidelines to keep the task on track. Michelle indulged in scope creep and added NDVI and the creation of an analysis tool which added more time to this project. 



\section{Chapter 4 - Database Design}

The core of The Wildlands Conservancy (TWC) project is the database of collection points for the irrigation system. This chapter covers how to design a database which includes the conceptual data model showing the relationship between the data elements. Then a discussion about converting a conceptual data model, into a logical data model which was used to design the geodatabase. Then where the data came from and how it's collected followed by the process of data cleaning.

\subsection{Conceptual Data Model}

The conceptual model in Figure 4-1 shows the relationship between the elements of the irrigation system and the farmers for the Oak Glen Preserve. The image depicts the farmer maintains the farmland and logs his maintenance work to update the GIS. The farmer can also turn on and off the fixtures on the orchards. The fixtures control the water flow through the pipes. The water flows to the spigots and will either flow to the plants or pass to the next spigot. 


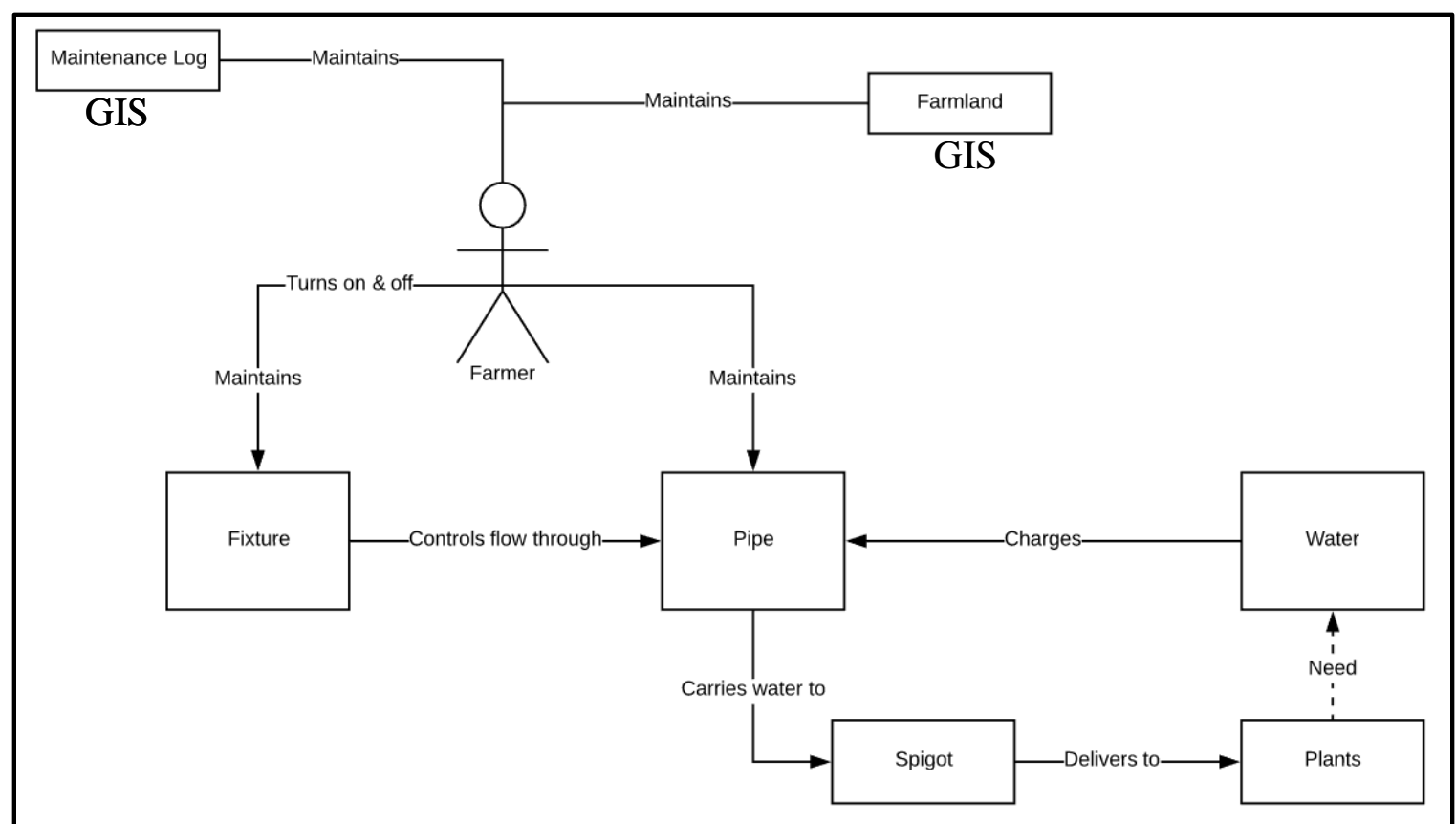

Figure 4-1: Irrigation System

\subsection{Logical Data Model}

Organizing the conceptual model illustrates the layout of a functional geodatabase design.

This model shows feature classes and their attributes as well as the domains that

accompany the attributes, and the relationships to each. The Logical Data Model was

designed using Lucidchart, so a database could be developed in ArcMap 10.5. Figure 4-2

shows the connections between the components.

The decision to create the geodatabase in ArcMap proved to be a successful choice as ArcGIS Pro cannot edit or trace geometric networks. Another option would be to use Enterprise GIS for Utilities to manage the workflow of a complex operation, but that would be excessive for this small project. 


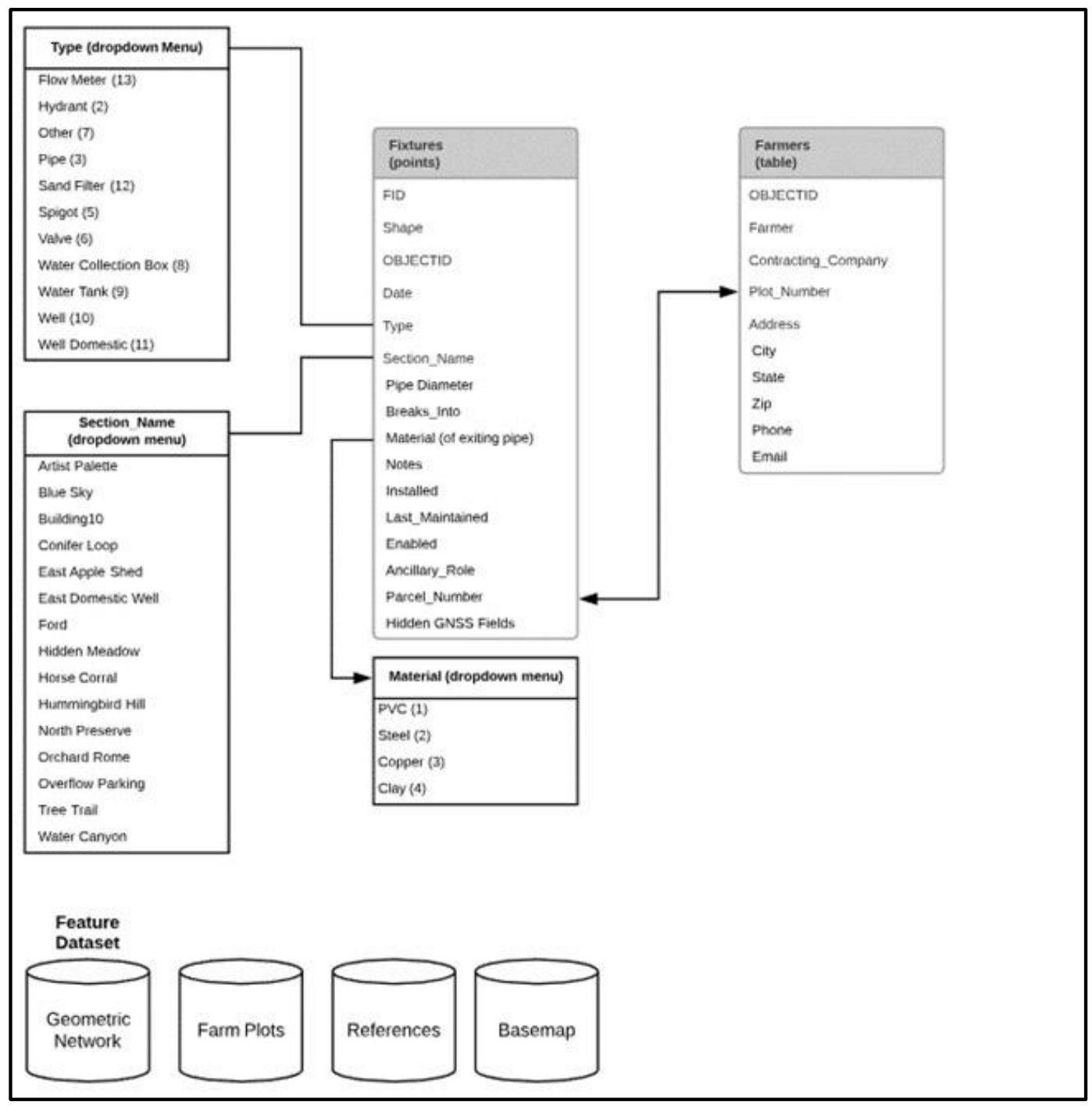

Figure 4-2: Geodatabase Design

\subsubsection{Fixtures Feature Class}

The fixtures feature class is the key dataset for this project. Each point in this dataset contains pertinent information about each fixture on the preserve. The feature class has 15 subtypes, three of the subtypes have domains, and two of the domains have coded values. 
- Domains are used to add new data with consistency. Each time a user adds a new fixture, a predefined drop-down menu provides fields that must be chosen to complete the process. There are two types of domains: range values where data must reside between two values to be accepted and coded values where each item has a number associated with it. Rules dictate compliance; for example, a spigot must connect to a secondary water line. Table 4-3 shows how the rules were set up for the fixture domains.

- Coded values (dropdown menu of attributes) are needed to engage the geometric network. Table 4-3 has a list of coded values (fixtures) used for this project's geometric network.

Table 4-3: Domain Rules, adapted from Esri Utility Network workshop (2018)

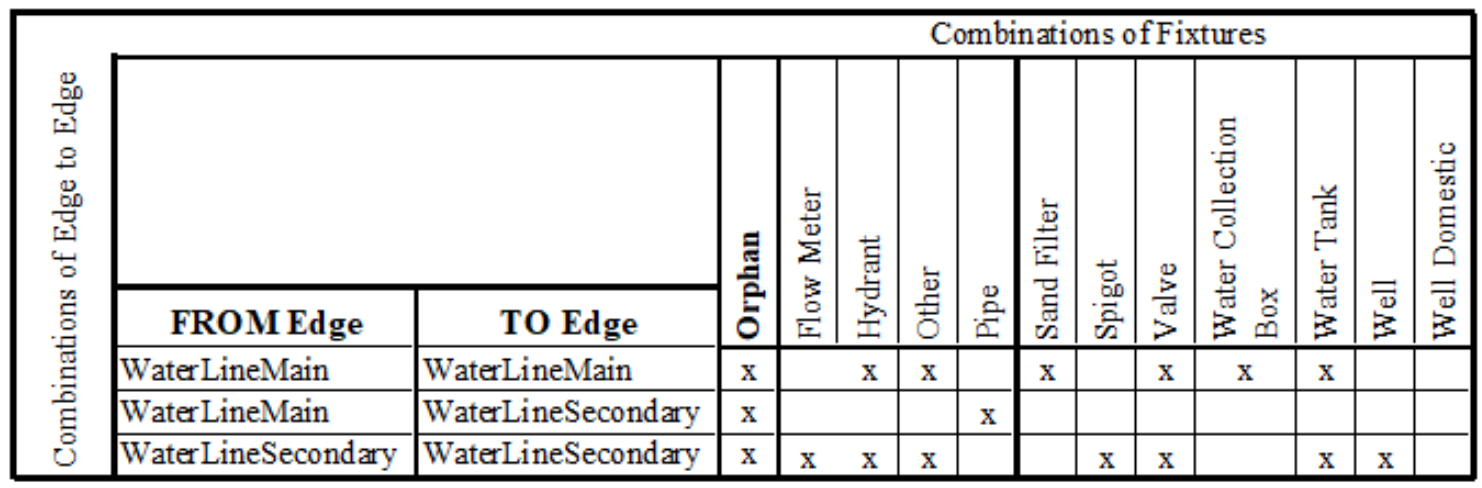

\subsection{Data Sources}

The GIS manager provided the property boundary shapefile. Michelle and TWC staff collected the data points for each junction of the irrigation system. Handwritten drawings were produced by Doug Chudy to represent the pipe connections and the plots of 
farmland. The NAIP imagery was obtained from EarthExplorer, and the precipitation data was retrieved from NOAA.

\subsection{Data Collection Methods}

The Trimble dataset was collected using a Collector application and a Trimble R1 unit paired with an Android device to increase the accuracy of the mobile phone's GPS reception. The process took two days and a total of five staff members and volunteers. The GPS unit was positioned three feet above the ground attached to Michelle's belt. Three feet above the ground is important because the GNSS software needed to buffer the Trimble R1 unit at three feet above the ground for accurate elevation.

\subsection{Data Scrubbing and Loading}

The collected data points were reviewed and required cleaning before being implemented into the geodatabase. Four issues were discovered after completing the data collecting.

- Issue 1: Three data points were in the wrong location due to the tree canopies and hills.

- Issue 2: Section names were not entered as domains, so they were spelled-out manually in the note field.

- Issue 3: Trimble specific fields for the second device were NULL.

- Issue 4: The autofill date did not work as expected, so dates and times were incorrect. 
The second and third data points of the day (Issue 1) were under the tree canopy, and the lack of line of sight caused the receiver not to connect to the satellites. Those two points (Figure 4-3) should have been between the first and fourth point of the day, so those points were manually moved to more correct locations. The last misrepresented datapoint was near the North West corner of the preserve's property line (Figure 4-3). This point was at the bottom of several steep hills which caused a blind spot for the satellites. Michelle walked thirty feet toward the field to correct the line of sight, and then the point was manually adjusted thirty feet pre-production.
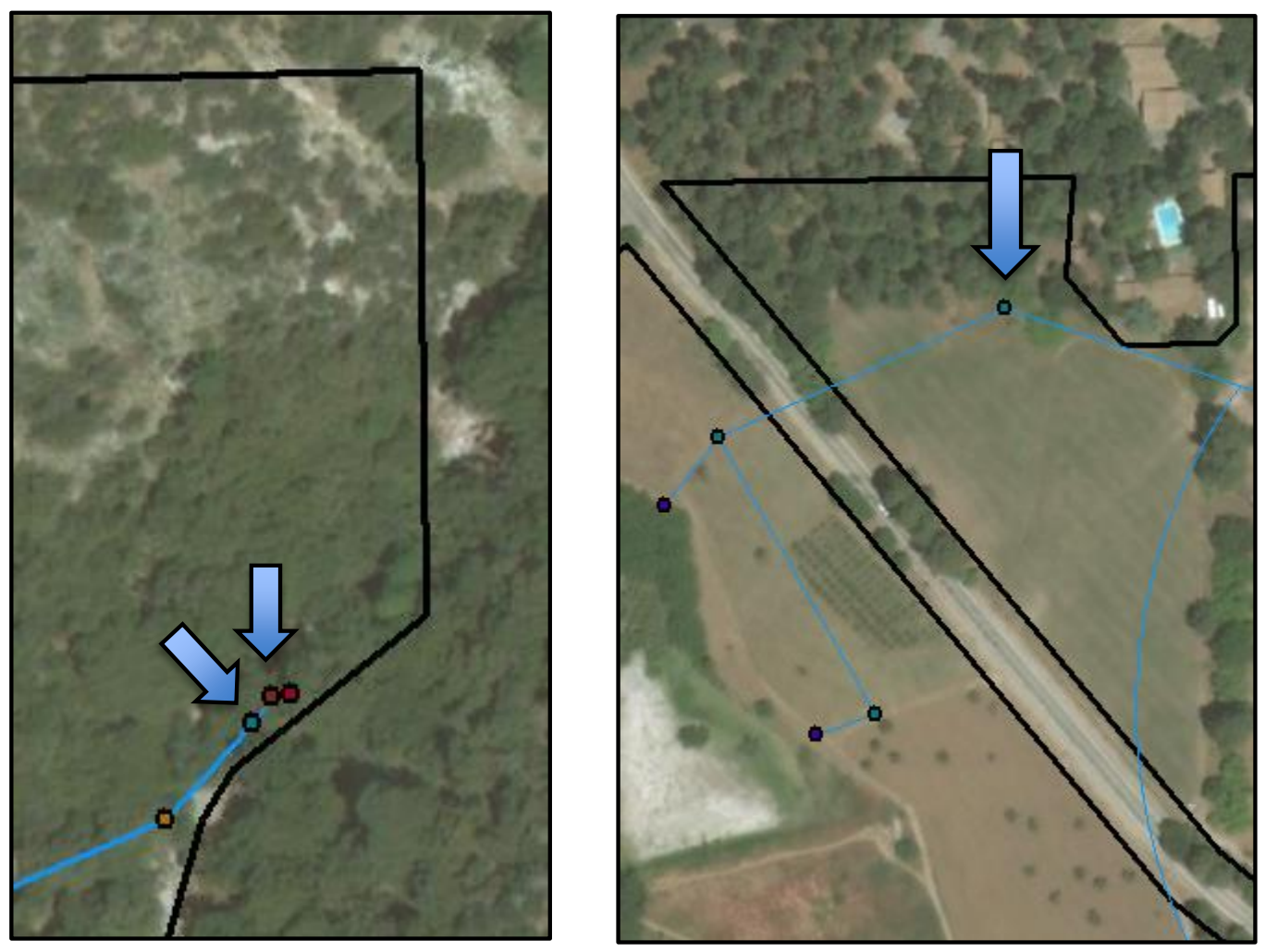

\section{Figure 4-3: Datapoints Manually Adjusted}

Section names were missing from the drop-down menu on the Collector application (Issue 2). The GIS manager knew this was an issue during the setup process, so we added a note field to the Collector application. During inception, only one section 
name was added; however, after completing the data collection, we added seventeen more section names.

On the first day of data collection, a decision was made to pair the second phone so that we could collect more data during the day. After completing the data collection, we discovered an error. The data obtained from the second paired device did not include any Trimble R1 data (issue 3). After contacting the Trimble technical support, we found that the Trimble R1 unit would only sync to one mobile device. This error caused the staff to void all accurate Trimble data for this project. Appendix D includes a table showing the Null Trimble values.

Autofill is a powerful tool if you know how to use it. A date field was included as an autofill field for the Collector survey. After collecting data and downloading into ArcMap, we noticed that all the autofill dates were wrong (Issue 4). After going back into the Collector application and playing with the field, the team learned that the field must be clicked on to active the autofill.

\subsection{Summary}

Chapter four explored the database design process and how to take the concept idea and turn it into a geodatabase with spatial relevance. First, a conceptual model is drawn for the client to ensure that everyone agrees about the design. The logical model shows the relationships between each feature that forms the geodatabase. Next was to define coded values, domains, and domain rules that guide the end-users down a specific path. Then how to acquire data and the data collection methods. The last section of this chapter discussed the cleaning process of the collected data and issues that were overcome. 



\section{Chapter 5 - Implementation}

With the ever-growing properties that The Wildlands Conservancy accumulates, optimizing its GIS land management starts with the Oak Glen Preserve. GIS would give the organization a clearer picture of its resources. By creating a GIS, management could have pertinent information at their fingertips. First, a description of the design process for the Collector application, utilizing Esri’s Survey123 Connect and a Collector/Utility Python script to automate the creation of the geodatabase. Then a lesson on how geometric networks are designed. After geometric networks, we'll view the table relationship between the farmland and the farmer's contact information. When we finish viewing the relationship between tables, we'll complete a tutorial on how vegetation health over a period can be calculated using the NAIP 2 NDVI tool. The workspace, which includes the layout of the folders and how the file location determines how items react to each other, is located next.

\subsection{Collector}

Collector is an Esri application used to collect data in the field either online or offline using a GPS enabled device. Collector has several implementation processes which are shown in these sections: graphical user interface, Survey123, and the Collector/Utility Python script.

\subsubsection{Collector's Graphic User Interface}

The graphical user interface shown in Figure 5-1, is what the user interacts with via the screen. The drop-down menus in the original Collector application were not perfect; there were unknown fixtures and section names that were not included. Thus, we added the 
note section to cover the lacking areas of interest in the original design. A condition from the staff was that the application was self-explanatory. While collecting data, we found that some titles, in the survey, could have been more descriptive. Due to the lack of description in the titles, the team had to rely on the drop-down menu helped decipher what the titles meant. For example, the term "leg" indicated what direction the water flowed could be deciphered by the North, South, East, and West dropdown menu. So, at the time, the product did not fulfill either of the non-functional requirements.

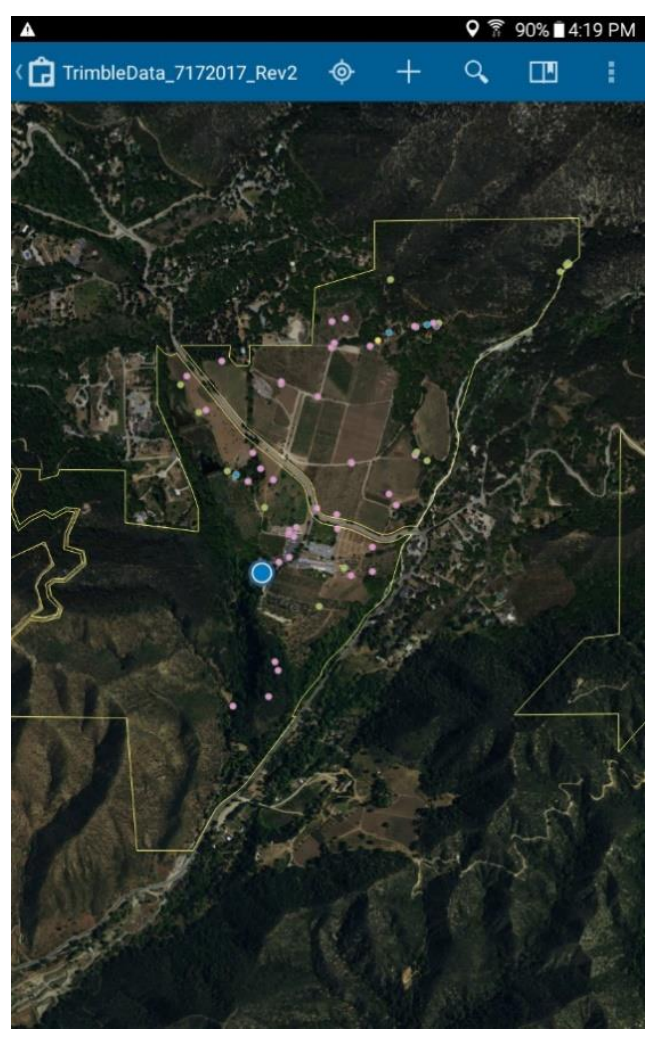

Figure 5-1: Collector User Interface

The Collector application was designed with two screens (Figure 5-2), so the staff members would only have to swipe one-time during each data point collection. To keep the Collector application on two screens, drop-down menus were used instead of radio buttons, which had a larger footprint. A note field gave the staff members the opportunity to include additional information in the original application. The photo attachment gave 
the end-user the ability to visualize each data point once the data was downloaded into ArcMap.

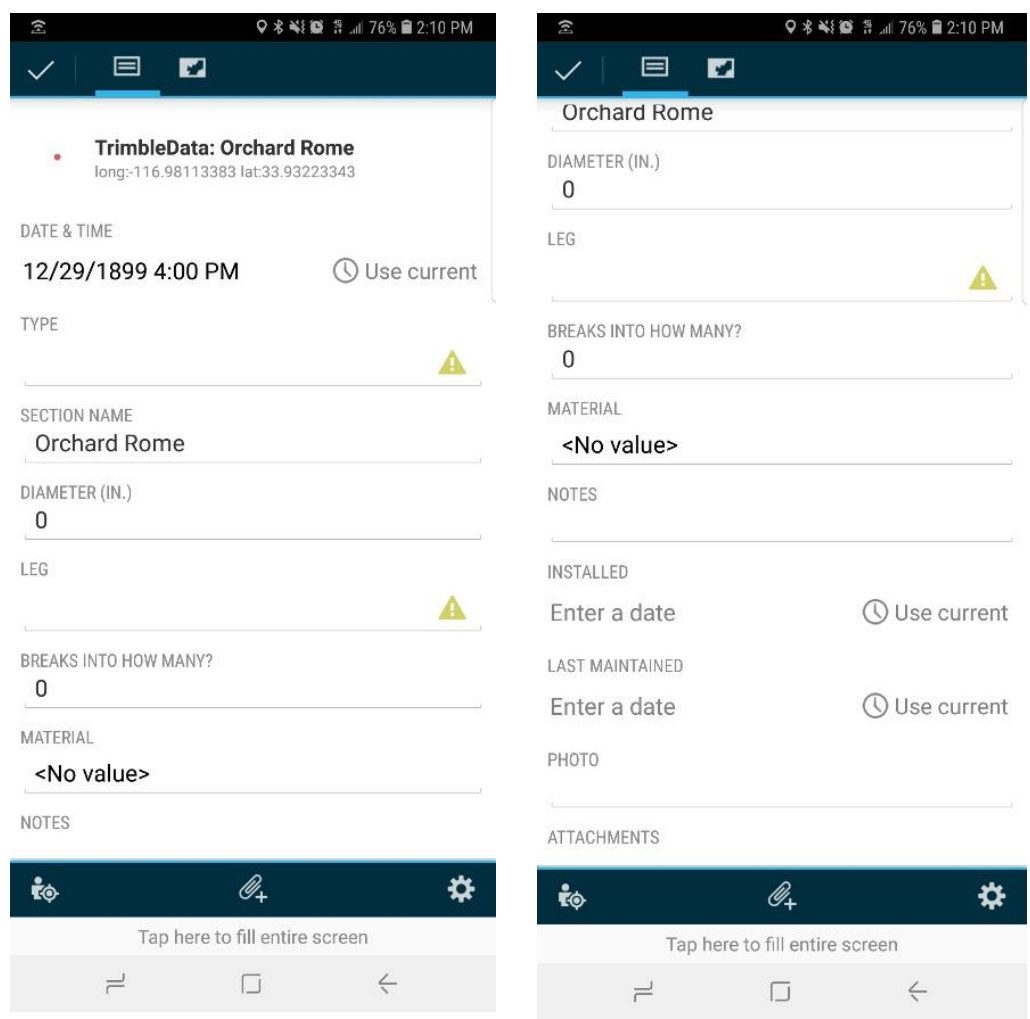

Figure 5-2: Two screen Collector Application

The two maps for this project are the Fixture map and the Geometric Network. The Fixture map feature classes can be moved into The Wildlands Conservancy's current map package, including the NAIP 2 NDVI analysis tool. The geometric network is a standalone geodatabase with standard tools to trace water flow direction. One matter that came up during the implementation stage was that the Geometric Network and the Fixture Map both needed the Trimble_Data feature class because TWC wanted the geometric network to be a stand-alone application and the same irrigation information needed to reside in the Fixture map. 
The Collector application for this project was designed using Survey123 Connect, and the Collector/Utility python script (Skinner, 2018). These tools made the design process easier than creating the project from scratch inside ArcMap. Figure 5-3 shows the Collector application and the data entry screen.
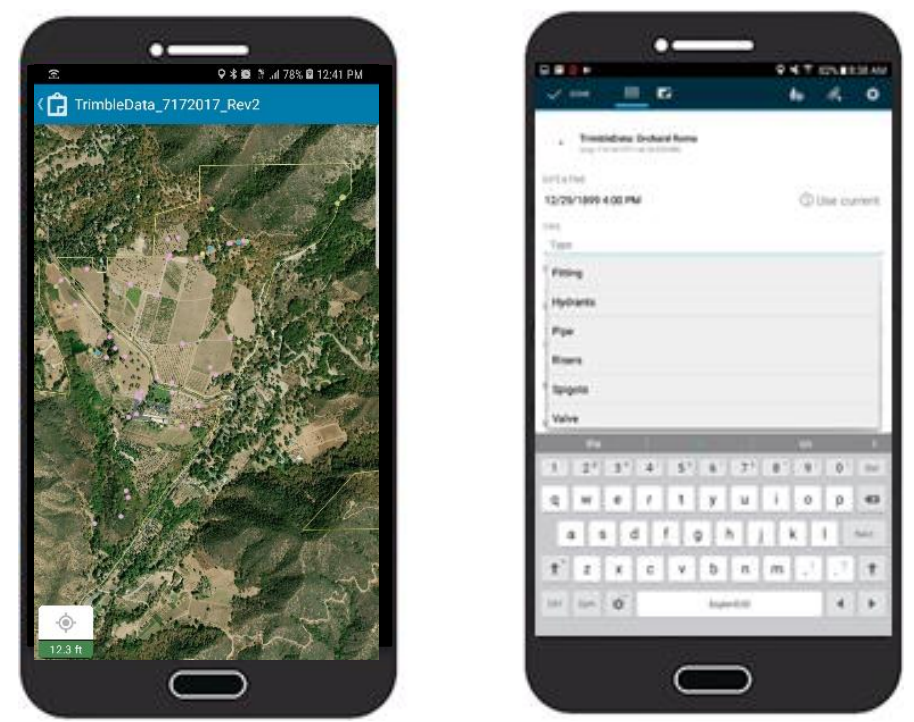

Figure 5-3: Collector Application Screens

\subsubsection{Survey123 Connect}

Survey 123 Connect is a spreadsheet-based application that makes creating the drop-down menus for Collector a straightforward process. Michelle has a strong background in Excel and building this survey with spreadsheets was the optimal choice for her. Survey 123 Connect automatically creates three spreadsheets that represent the final Survey 123 application. The three spreadsheets are: Survey, Choices, and Settings, and are used to design and manipulate a survey. Examples are shown on the following pages.

The "Survey" worksheet is where information is added for the Collector application. Table 5-1 shows how TWC Collection application was set up. Each row has specific characteristics; 
- TYPE column links to the worksheet also called TYPE which includes all the field types allowed in Collector.

- NAME is a one-word name for the field used by the program.

- LABEL is the title the end-user sees in Collector application.

- REQUIRED creates a rule that these fields cannot be NULL.

- APPEARANCE links to the worksheet types which tells Collector what type of keyboard to use for the field; numbers will display a number keyboard; signature presents a UI for a signature. For a complete list of types, refer to Appendix A at the end of this thesis document.

- DEFAULT is the text that auto-fills before the drop-down menu appears.

- ESRI:FIELDTYPE are hidden fields inside the Collector application. 
Table 5-1: Survey Worksheet Schema of Survey123 Connect

\begin{tabular}{|l|l|l|l|l|l|l|}
\hline \multicolumn{1}{|c|}{ type } & \multicolumn{1}{|c|}{ name } & \multicolumn{1}{c|}{ label } & required & appearance & default & esri:fieldType \\
\hline $\begin{array}{l}\text { begin } \\
\text { group }\end{array}$ & Irrigation_Collection & </H>Irrigation</H> & & & & \\
\hline category & Category & Type & yes & minimal & & \\
\hline text & Section_Name & Section Name & & & $\begin{array}{l}\text { Orchard } \\
\text { Rome }\end{array}$ & \\
\hline decimal & Diameter & Diameter & yes & numbers & & \\
\hline material & Material & Material & yes & & & \\
\hline date & Date_Installed & Date Installed & & & & esriFieldTypeDate \\
\hline date & Date_Maintained & Last Maintained & & & & esriFieldTypeDate \\
\hline note & Notes & Extra Information & & multiline & & \\
\hline image & Photo & Photo & & & & \\
\hline geopoint & Location & Location & & & & \\
\hline $\begin{array}{l}\text { end } \\
\text { group }\end{array}$ & Stop & Stop & & & & \\
\hline
\end{tabular}

The "Choices" worksheet (Figure 5-4) shows the drop-down menu. The

"list_name/Category" is linked to "name/Category" in the Survey worksheet (Table 5-1).

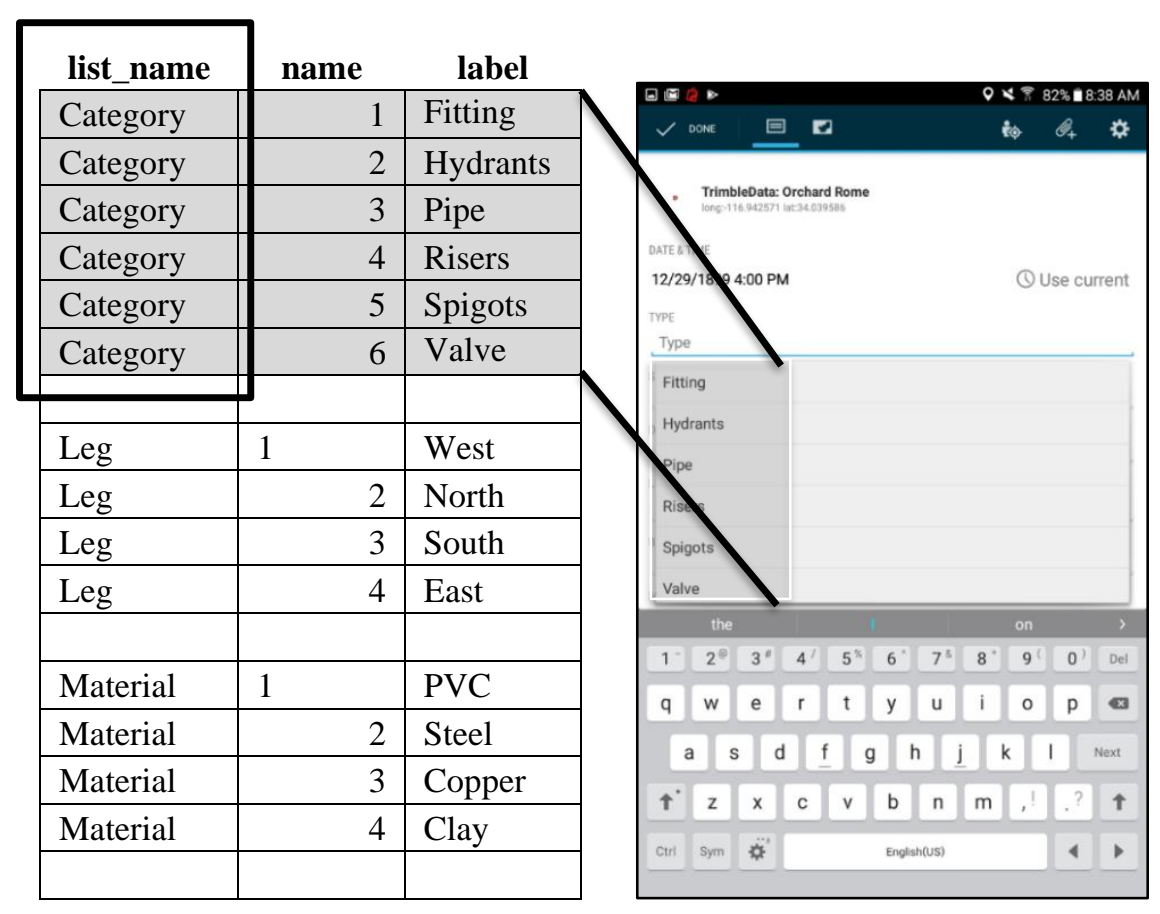

Figure 5-4: Choices Worksheet and the Collector Drop-down Menu 


\subsubsection{Collector/Utility}

Pairing a Trimble R1 unit to a mobile device requires that Global Navigation Satellite System (GNSS) specific fields are included in the TrimbleData feature class. GNSS is any satellite constellation that provides global positioning, navigation, and timing (National Coordination Office for Space-Based Positioning, Navigation, and Timing, 2018). The Collector/Utility application was downloaded from GitHub.com, which is a community of software developers who share programming code to help other programmers with similar issues. The Collector/Utility tool added the required GNSS specific fields to TWC TrimbleData feature class. Once the fields were added, the map package was shared to ArcGIS Online. Next, the online map package was opened in ArcGIS Online, and the Oak Glen Preserves boundary shapefile was added. Once the boundaries were included, a map service was created so the service could be shared with multiple users. The map resides in ArcGIS Online, so collected data points from several individuals can be uploaded to one location. Map services can also be accessed using several different platforms: desktop, web applications, and mobile devices. Before using Collector on our mobile devices, the GNSS software from the Android Play Store was installed on the mobile device, which allows the pairing of the phone with the Trimble R1 unit. Once the devices were paired, Collector was ready for fieldwork.

\subsection{Geometric Network}

The geometric network design began by downloading the collected TrimbleData from ArcGIS Online using the ArcGIS REST (Representational State Transfer) service. REST is the URL of the service where the collected field data can be downloaded into ArcMap. 
The Collector file was downloaded and then imported it into a feature class inside a feature dataset. The next step was to assign the roles for each category in the feature class. Several roles were needed: simple and complex edges, junctions, as well as the source of the water flow. Simple edges are lines that represent individual pieces of waterlines; for this project, they are called secondary waterlines. A complex edge is a line representing the main water line that branches out to secondary waterlines and is one continues piece. Junctions are the points connecting the edges represented by a spigot or valve in this project. Figure 5-5 shows how TWC project roles were assigned.

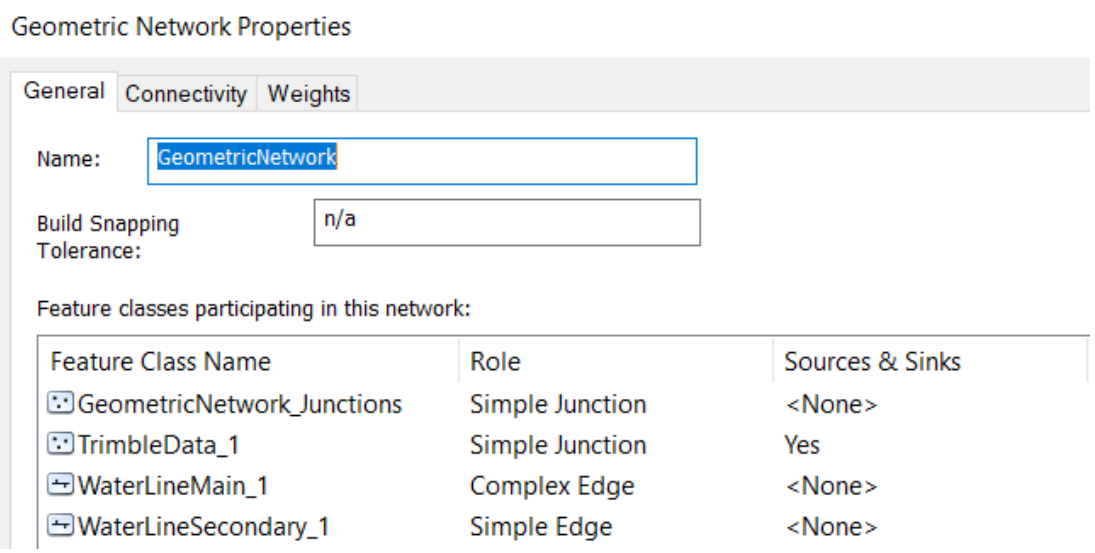

Figure 5-5: Geometric Network Properties 
Next, the subtypes were added inside the feature class properties. Subtypes are subsets of features which are used to constrain the input data into numeric values. Figure 5-6 shows the original domain values from TrimbleData; as well as the newly added domains which we discovered during the collection process. From this step forward, the TrimbleData values will be sourced to the Fixtures feature class in the geometric network dataset.

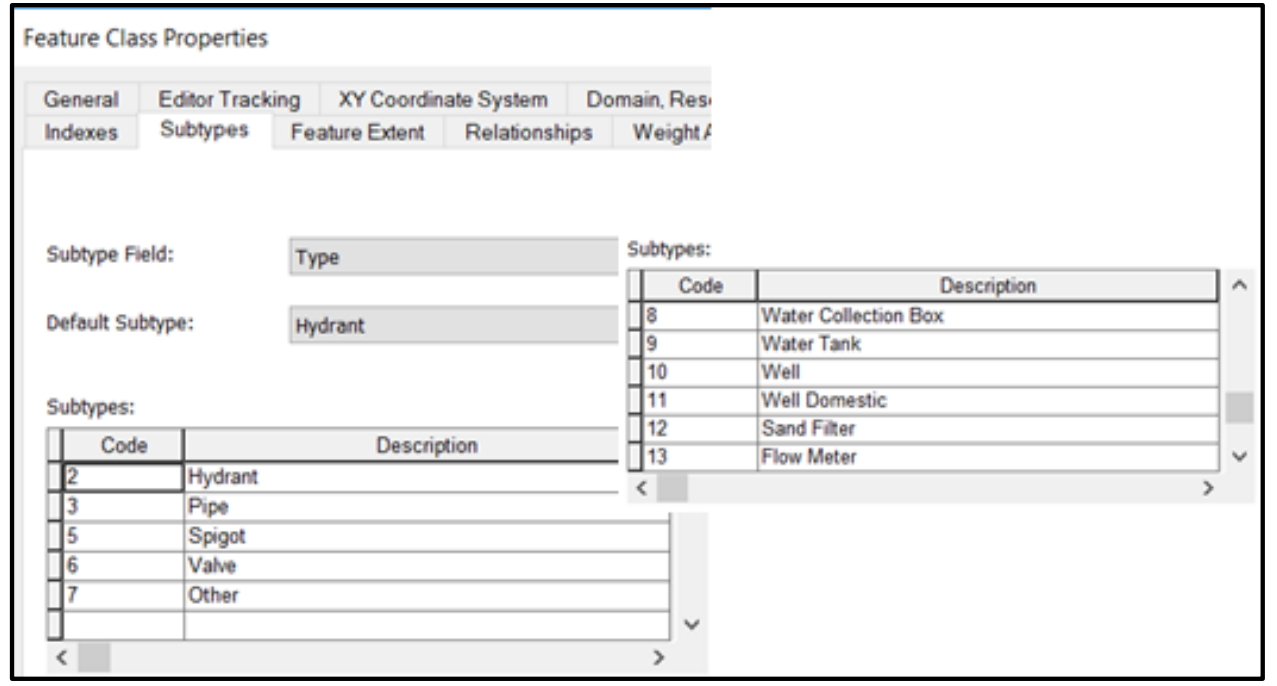

Figure 5-6: Adding Subtypes to Features in a Feature Class 
Geometric network rules are the foundation of the geometric network; the rules tell the software what to do. Table 5-2 was a reconstruction of a spreadsheet provided by the Esri "Working with Geometric Networks for Utilities" workshop. After designing the geometric network rules in Table 5-2, the rules could be transferred into the ArcMap geometric network, as shown in Figure 5-7.

Table 5-2: Geometric Network Rules (Esri, 2019)

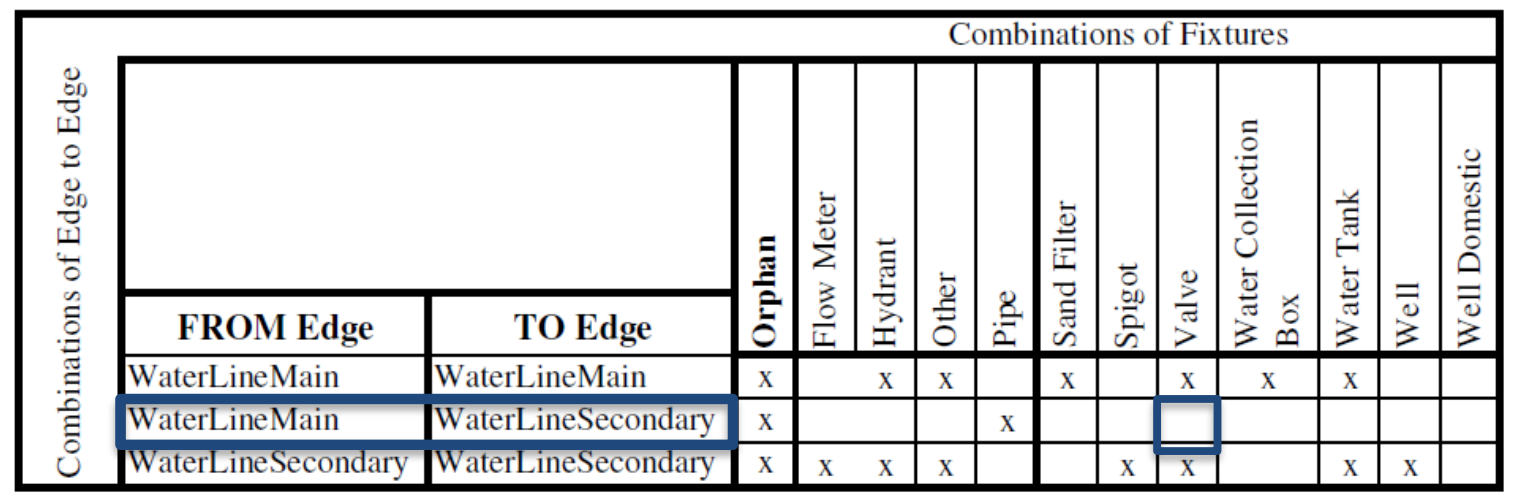


It should be noted that in Figure 5-7 that the valve subtype is the default value. The default valve (blue circle D) is what automatically appears when drawing the secondary water line; valves were the chosen default because 49 out of 66 junctions were valves.

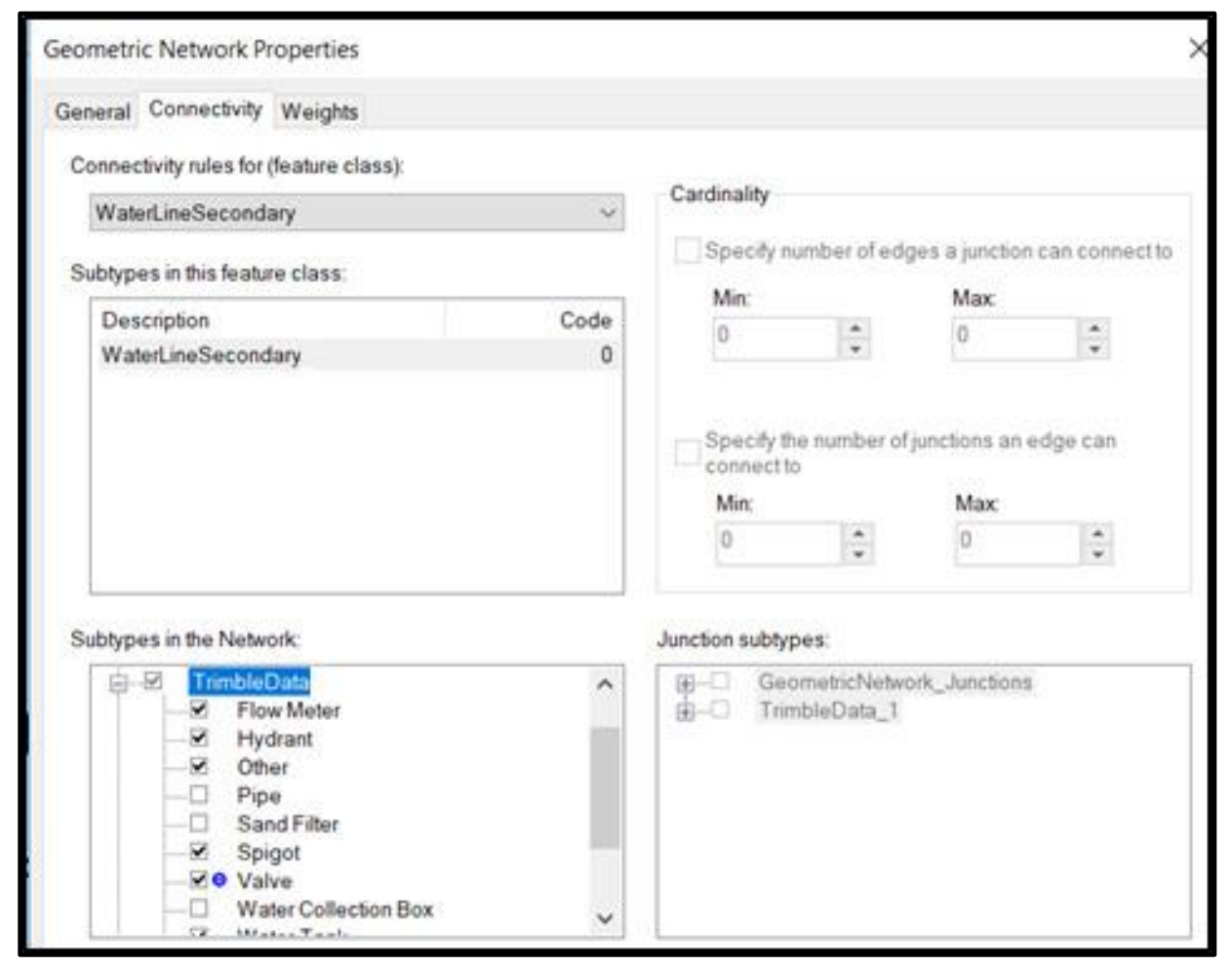

Figure 5-7: Geometric Network Connectivity Rules

After configuring the geometric network, the waterlines were drawn to connect each junction in the TrimbleData feature class. Figure 5-8 displays the hand drawing from the preserve ranger and the finished layout in GIS. 

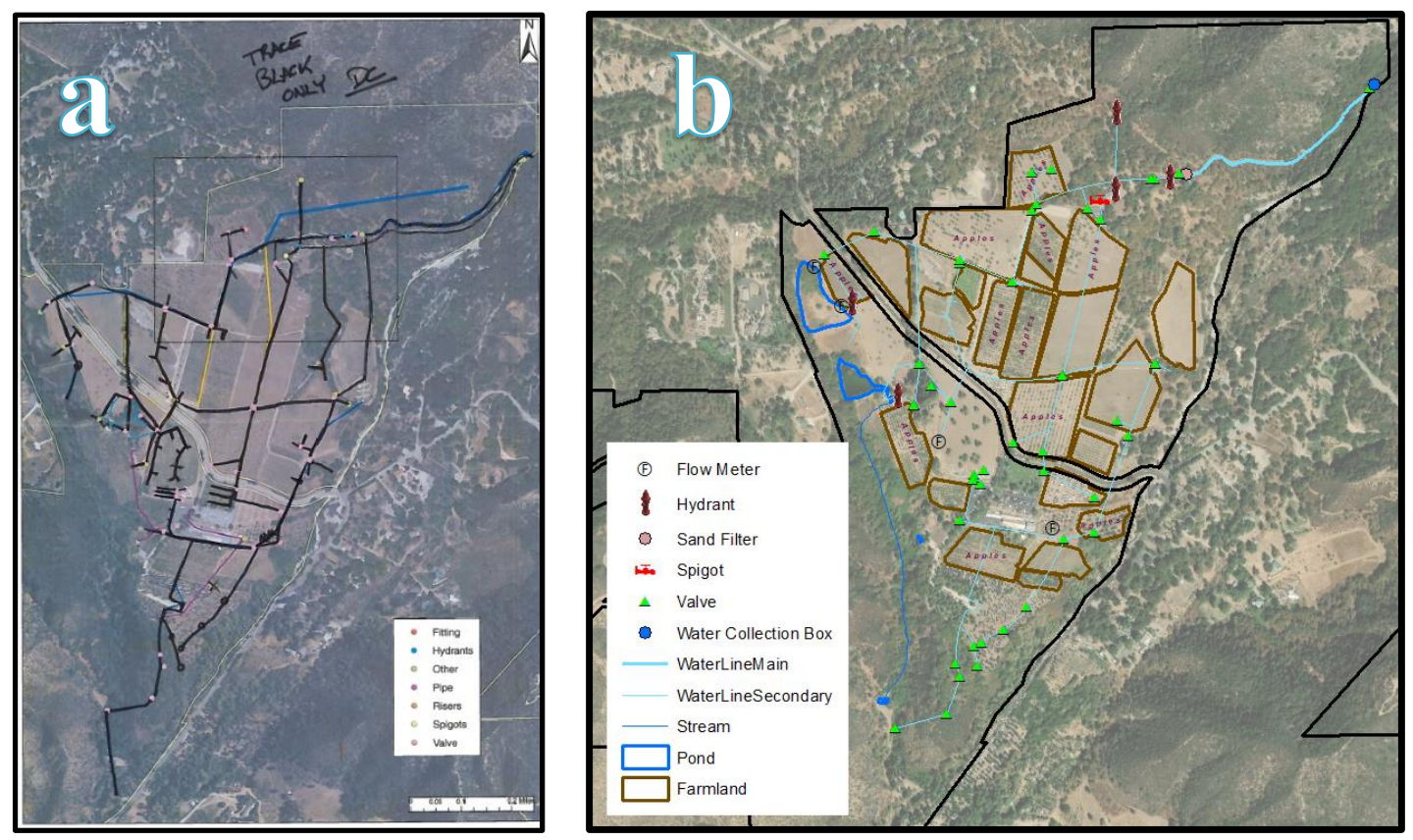

Figure 5-8: Handwritten (a) vs. ArcMap's Geometric Network (b)

The next step was to add the flow direction arrows to the map (Figure 5-9).

Directional flow arrows are automatically shown to match the source or sink value. There are two types of errors that showed up during the creation of geometric networks for directional flow; indeterminant and uninitialized. Indeterminant flow happens when waterlines (edges) form a loop, and uninitialized flows error occurs when it is missing an ending location (sink) or inlet (source) water supply. The uninitialized flow was an issue found during the creation of this geometric network, redrawing the water line in the direction of the flow repaired this error. After fixing the uninitialized flow errors, a network analysis was performed. In figure 5-9, the "Geometric Network" and the "About TWC" groups include lines, fixtures, farming plots, and the permanent structures at the 
preserve. There are six fixture types and two types of water lines that represent the irrigation system at the Oak Glen Preserve.

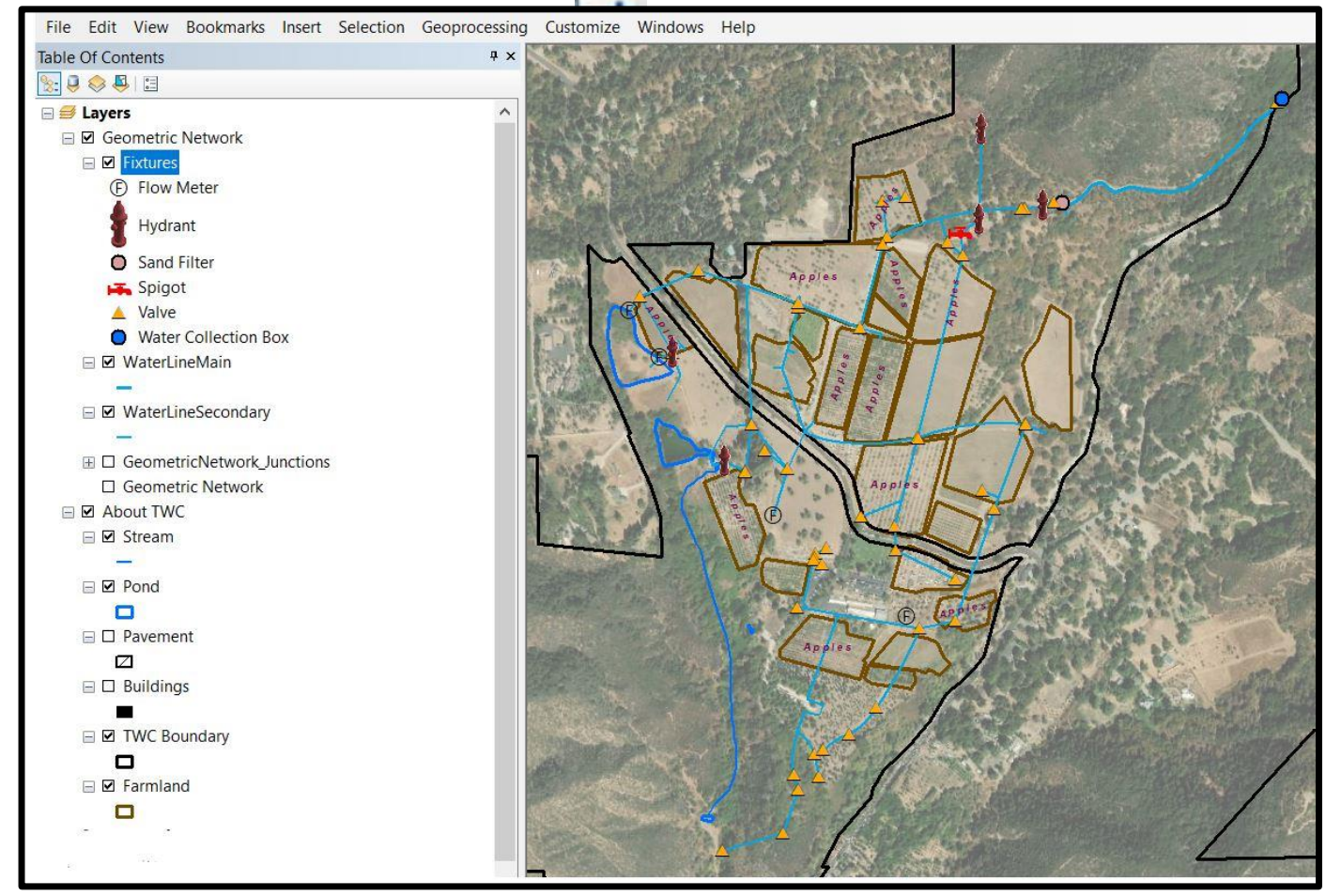

Figure 5-9: ArcMap Interface Showing the Geometric Network

The Geometric Network Editing toolbar shown in Figure 5-10 was used to interact with the network. Step 1 has three chooses in the drop-down menu; Display Arrows For..., Display Arrows, and Properties. First, choose what to display, for example, the main water line and or the secondary water line. Click on Display Arrows to show the designated flow direction. The arrow colors can be changed by using the properties field in the drop-down menu. Step 2 add flags to the geometric network to cause breakages in the waterline. Step 3 will Disable active layers, so it doesn't interfere with the analysis, this is where you can Clear Flags from the analysis and start over. The Options button is where weighted filters are added. Step 4 are the choices for analysis; then once flags are in place, the solve button will tell the program to execute the 
analysis. Figure 5-11 shows the flow direction with blue arrows with a white halo for distinction. The green square represents a flag (or breakage in the waterline). The cyan lines and dots show what is downstream from the breakage. Chapter 6 will go into detail about these results.

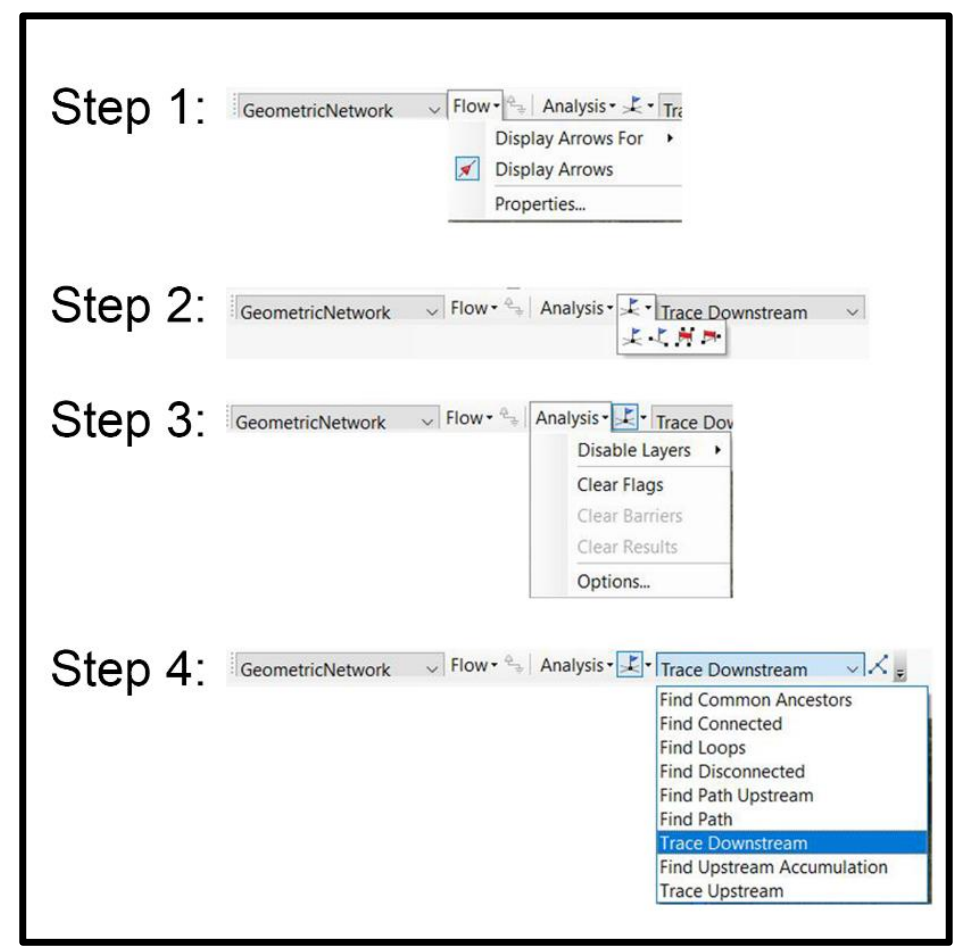

Figure 5-10: Geometric Network Edit Tools 


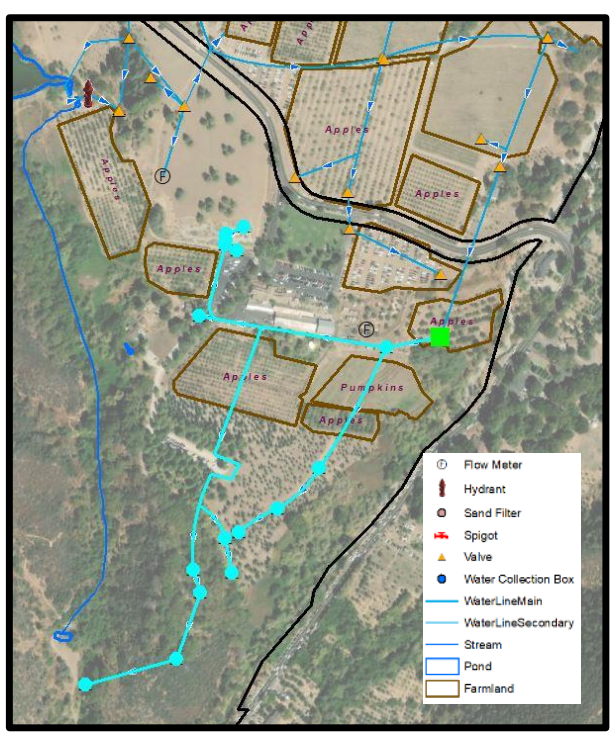

Figure 5-11: Output of Geometric Network, Bottom of Preserve

\subsection{Table Relationship}

One of the non-functional requirements was to reduce the time it took to find an irrigation line and the farmers who would be affected by a disconnected waterline. By creating a relationship between the farmer's table and the farmland shapefile (Figure 5-12), management would know who worked on which farmland. A relationship links multiple

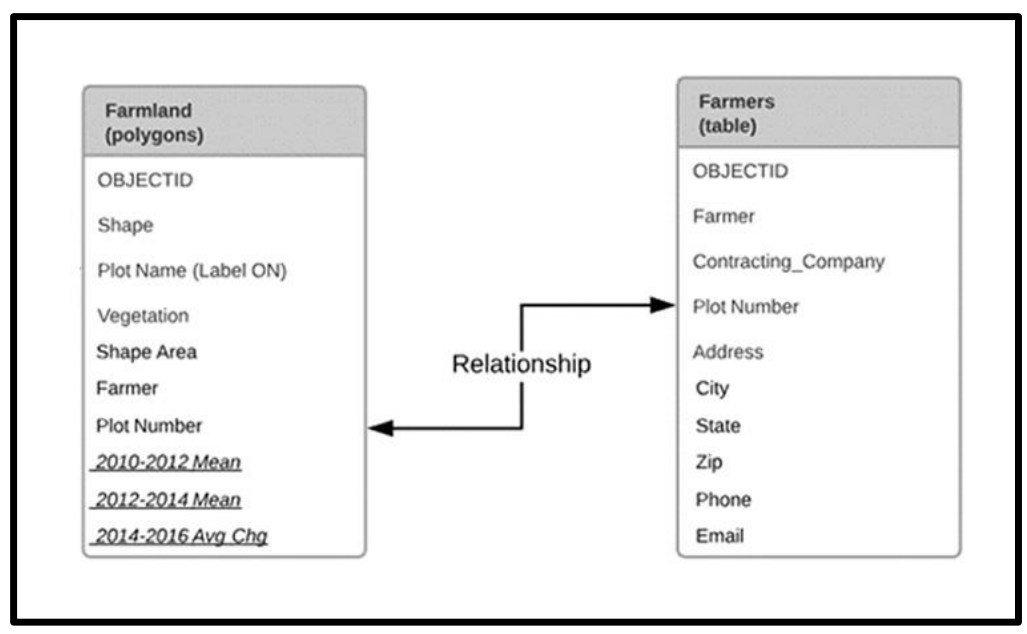

Figure 5-12: Relationship between Farmland and Farmers 
tables together, so when one table changes, the related tables can view the updated information immediately.

\subsection{Normalized Difference Vegetation Index (NDVI)}

To calculate the NDVI, Michelle found data on the USGS EarthExplorer site. Initially, using Landsat8 imagery but found the 10-meter resolution too massive to pinpoint tree health. After researching other imagery with the required red and NIR bands, the NAIP 1meter resolution imagery was chosen for its resolution size.

The next step was to run the custom-built tool called NAIP 2 NDVI (design details in section 5.5.5). This tool crops the NAIP image to the Oak Glen Preserve's boundary then calculates the NDVI and produced an NDVI raster layer. Figure 5-13 depicts the NAIP image with the NDVI calculation. A calculation was conducted for each NAIP

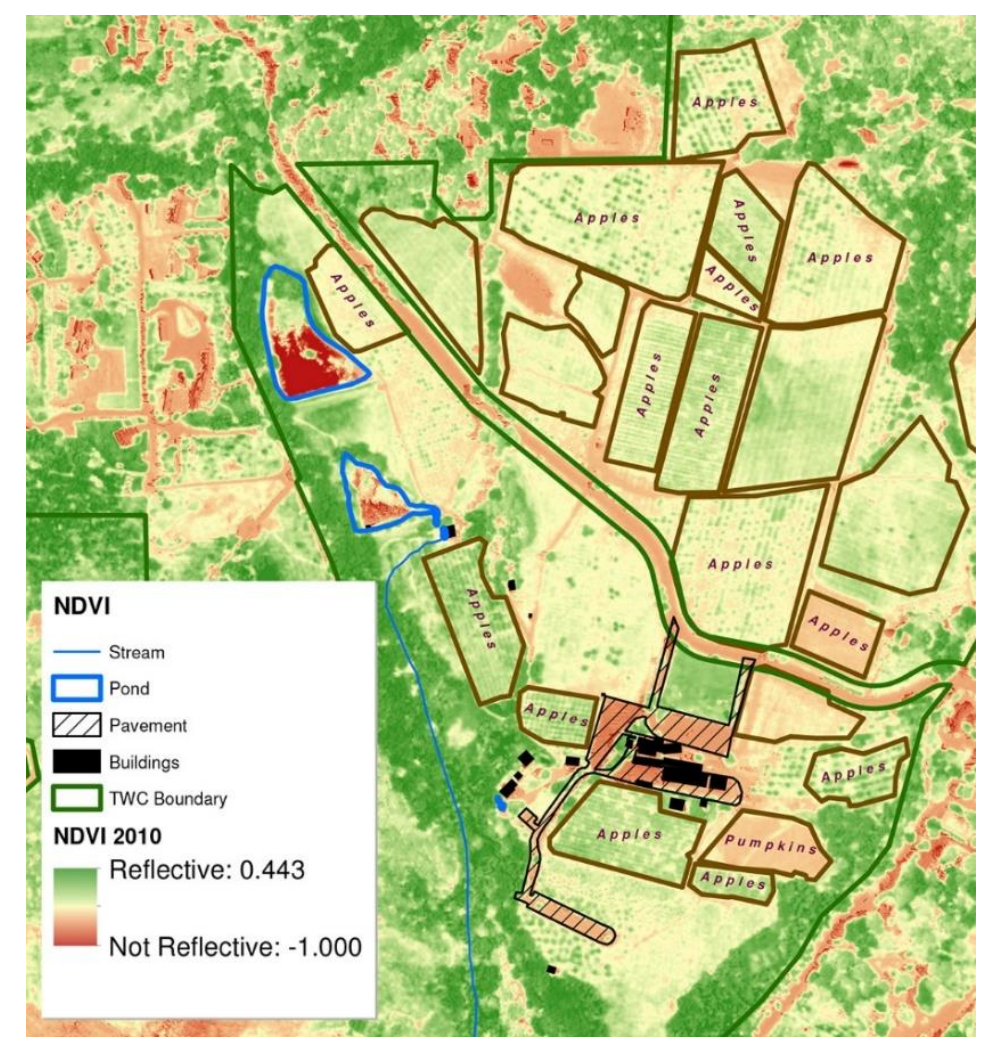

Figure 5-13: Calculated NDVI from NAIP Imagery in 2010 
image from 2010-2016 (even years). The deep red color shows a lack of reflectivity for the pond located on the left side of the image. The lighter red represents buildings, asphalt roads, dirt pathways, and freshly plowed fields. The lighter green areas could be new growth with exposed soil, and the dark green vegetation shows healthy vegetation. Notice the dark green path of healthy vegetation in the middle of the image, located around the stream, that vegetation resides in a canyon.

After completing the NDVI calculation, the next step was to find the difference between the two NDVI images (i.e., 2012-2010). The process for finding the differences between two images is included in Appendix B. Once the differences were calculated, a new raster layer was created, and then the symbology classification was changed to standard deviation of the mean. This classification was chosen so the outliers could be determined. For example, Figure 5-14 is a normal distribution where one standard deviation shows the highest concentration of data.

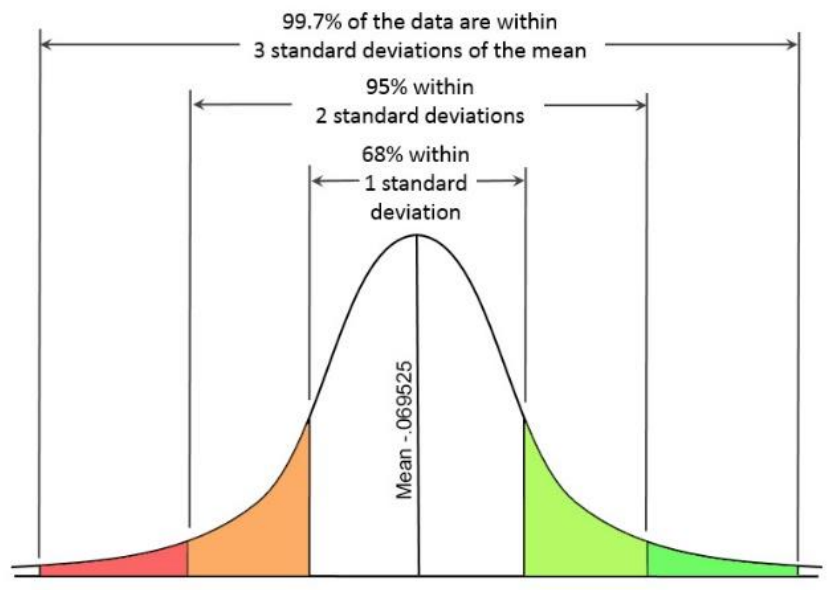

Figure 5-14: Bell Curve Image (Kernler, 2018) 
The legend in Figure 5-15 the two middle intervals have been removed to show only the outliers. The outliers residing in the tails are two and three standard deviations away from the mean which shows the greatest changes from 2010 thru 2012. The plots with consistent crops like apples and pumpkins are showing very little unhealthy changes for these years. The orange and red areas represent the ponds, asphalt, and freshly plowed fields.

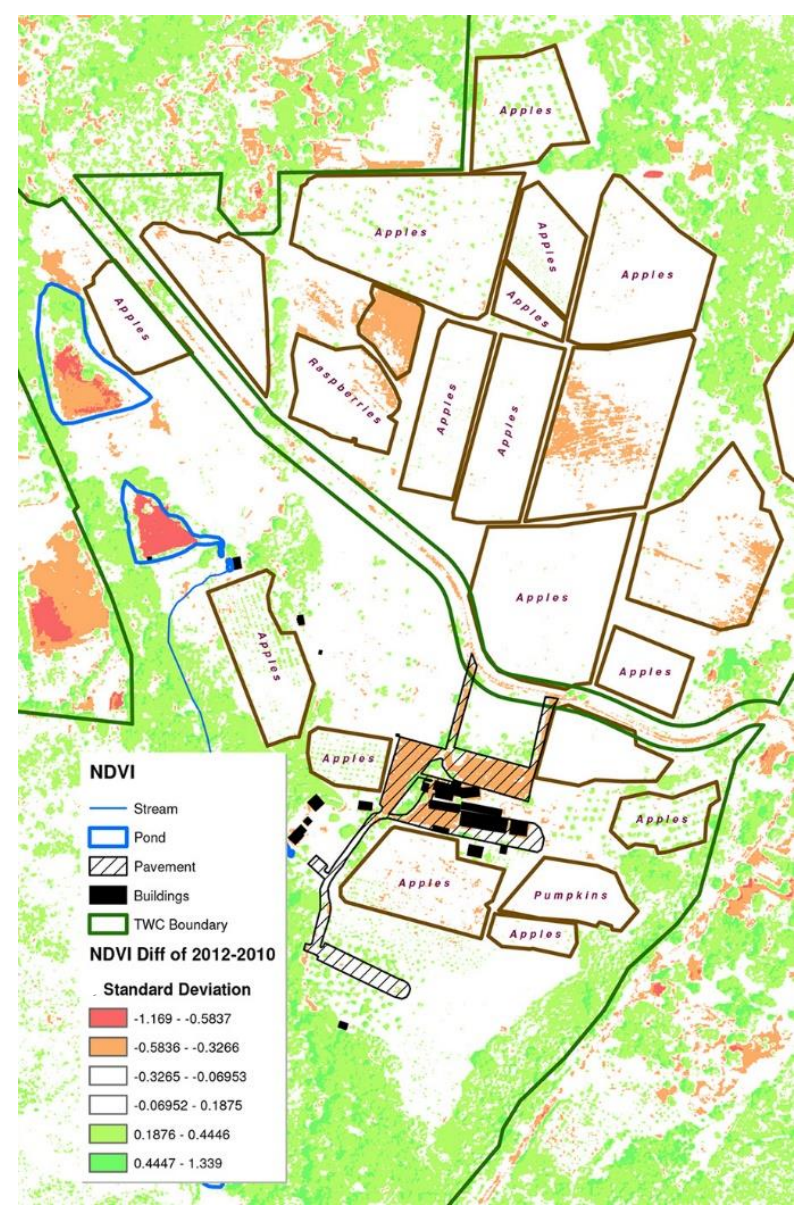

Figure 5-15: The Greatest Changes from 2010 \& 2012

\subsection{Project Workspace}

Workspace folders and geodatabases are the containers for all project files and data

(Figure 5-16). The map document (TWC.mxd) is where the project map pointers reside, 
which includes current display properties; the map document file does not contain the data files. The geodatabase (Project_Geodatabase.gdb) consists of the individual layers, datasets, and relationships needed to complete the map document. For example, deleting the TWCboundary shapefile inside the geodatabase and then opening the map document file which points to TWCboundary will cause an error with that shapefile.

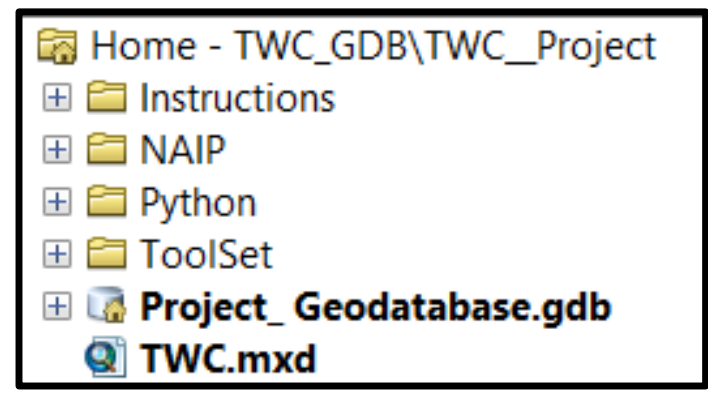

Figure 5-16: Workspace Layout

\subsubsection{Map Document (.mxd)}

Map Document files are proprietary data files for Esri products. The Wildland Conservancy has access to the Esri Suite of products and can open this type of file. A map document is a visual sandbox to view, manipulate, label, and symbolize the data that resides inside this file. Users can also run geoprocessing tools and custom tools inside a map document file.

\subsubsection{Python}

Python is the primary scripting language for Esri products. Python is a programming language that gives extra functionality to the Esri suite of software, as well as many other applications. Python scripts are used to customize tools when such tools aren't available in the standard software package. Beyond Python scripts, Esri products include an ArcPy tool which allows ArcMap geoprocessing tools to be used inside a Python script to 
enhance its capabilities to another level. The NDVI Python script was designed to perform a task once every two years. Thus a tool would simplify completing the same task with consistent standards every time.

The NDVI Python script uses the Geospatial Data Abstraction Library (GDAL) which is open-sourced software that reads and writes raster and vector geospatial files. The script uses GDAL to read the image raster file and its metadata; the metadata included the raster's projection, pixel characteristics, number of columns, and number of rows. Then an empty array is created for the red and near-infrared (NIR) bands using the previously accessed metadata to produce the correct number of rows and columns. Then the script retrieved data from the image raster pixel by pixel and add it to the appropriate band array. After filling in the red and NIR arrays, an additional array was created to calculate NDVI into memory utilizing the red and NIR numpy arrays in the previous steps. The NDVI formula inside the Python script is (NIR - Red)/ (NIR + Red). The last steps include setting the projection and the pixel characteristics before writing the data to a tiff file. Now, the Python script closes the input and output files. Figure 5-17 shows how the Python script works in pictorial form. 


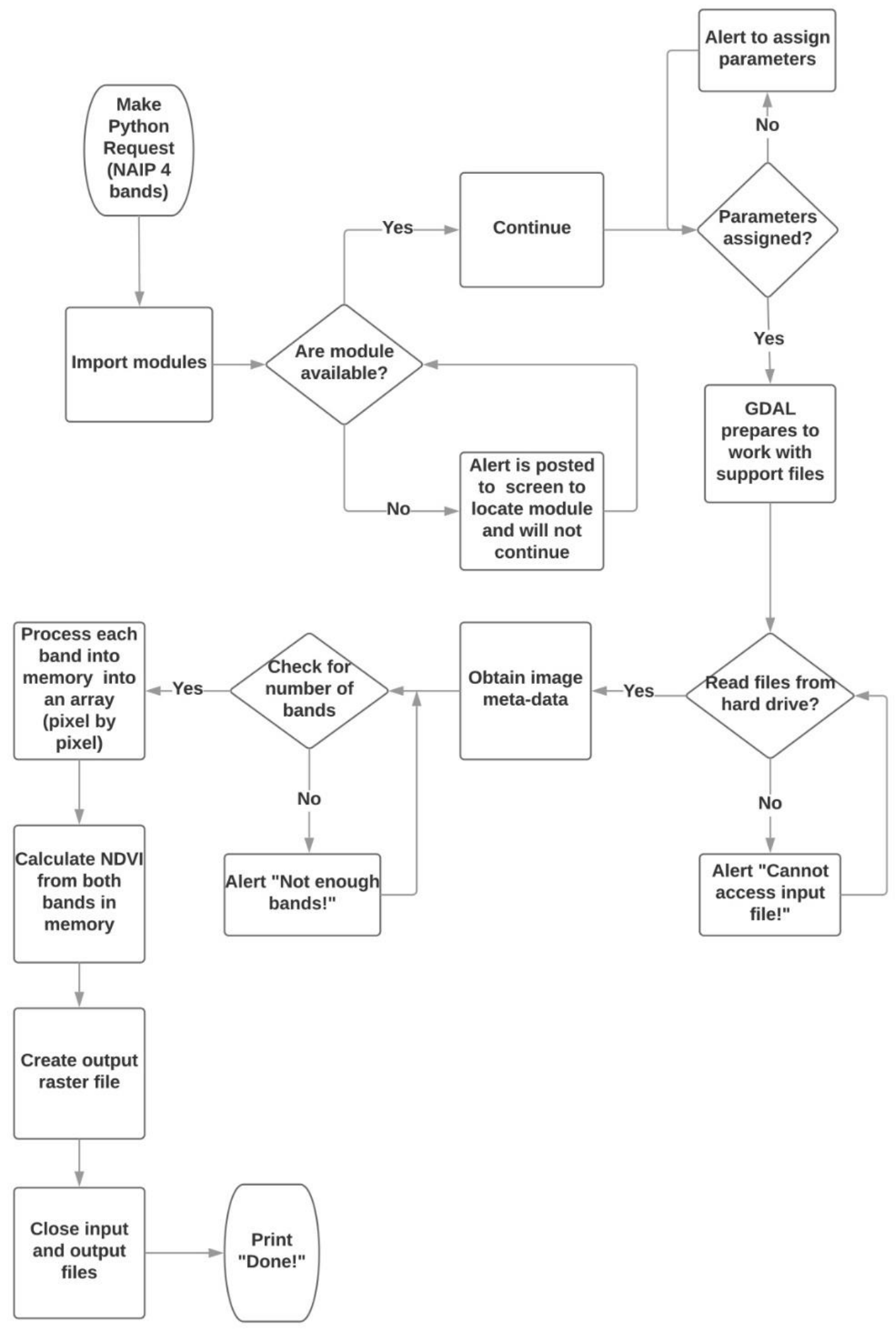

Figure 5-17: NDVI Python Flowchart 


\subsubsection{Toolbox Implementation}

Automation was used to condense many steps into a single tool. There are two types of tools inside Esri's suite of products; the system toolbox and the custom toolbox. The system toolboxes include standard toolsets to automate geoprocessing workflows. These toolboxes are broken down into categories to organize groups of tools by functions. Depending on an organization's ArcMap license, all functionalities may not be available. The Wildlands Conservancy has an advanced license which includes the toolsets needed to perform these tasks. Custom tools built on a machine with an advanced license may not run on a machine with a basic license because the tools might not exist on the basic machine. Custom tools are developed by a user to maximize the end user's needs. Custom tools can be set up in ModelBuilder to bring together the functionality of running many ArcMap system tools at one time. Python scripts can be brought into ModelBuilder and connected with system tools in the same manner.

For this project, the custom toolbox and its tools were placed inside the ToolSet folder inside the Home folder where the geodatabase resides, not inside the geodatabase (Figure 5-18). Creating folders in this manner makes the tool transferable. Custom toolboxes can reside inside the geodatabase when tools are not allowed to transfer to

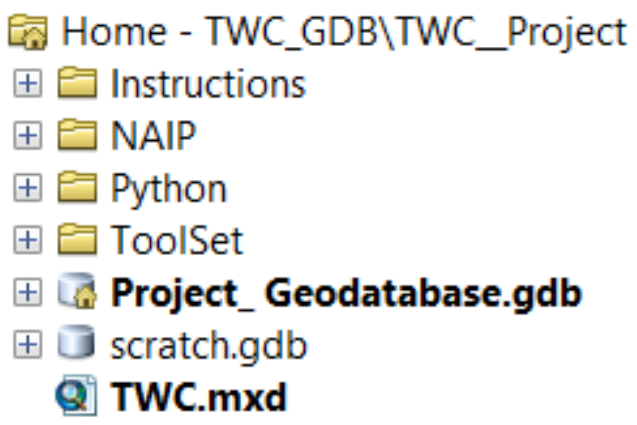

Figure 5-18: ToolSet Folder Layout 
other projects, meaning that the toolbox is accessible only inside one specific geodatabase.

\subsubsection{Modeling}

Models are workflows connecting geoprocessing tools and python scripts in a specific order to produce equivalent results using different inputs (parameters). ModelBuilder is the application inside ArcMap where models are built and edited. ModelBuilder is a visual programming language that can accommodate even an inexperienced programmer. Figure 5-19 shows the steps of TWC model workflow. Step one asks the end-user to fill in the empty parameters $(\mathrm{P})$. The software will then use the clip geoprocessing tool to clips the NAIP Yearly [raster] Image to the TWCboundary shapefile. Once the clipping is complete, the NAIP 2 NDVI Python script calculates the NDVI layer. The critical thing to know about this model is to use tiff files as the output files to retain the 4-band image.

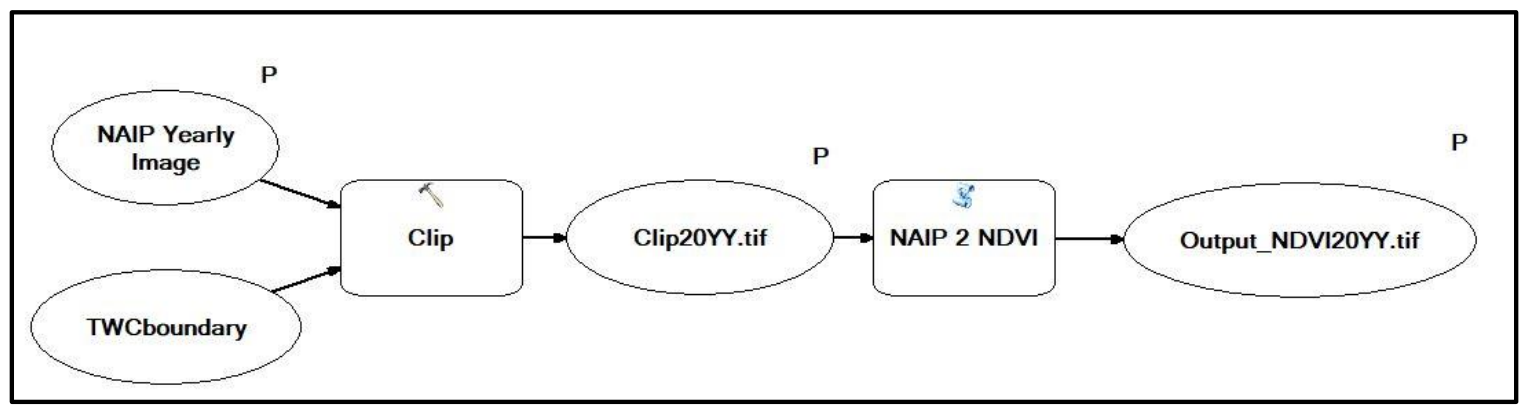

Figure 5-19: NDVI Model to Clip and Calculate the NDVI Layer

The user interface in Figure 5-20 is for future calculations. The dialog template guides the end-user to link the yearly NAIP image and to change the last two digits of the year for the output images. 
This tool makes sure the end-user knows what to do to perform this analysis.

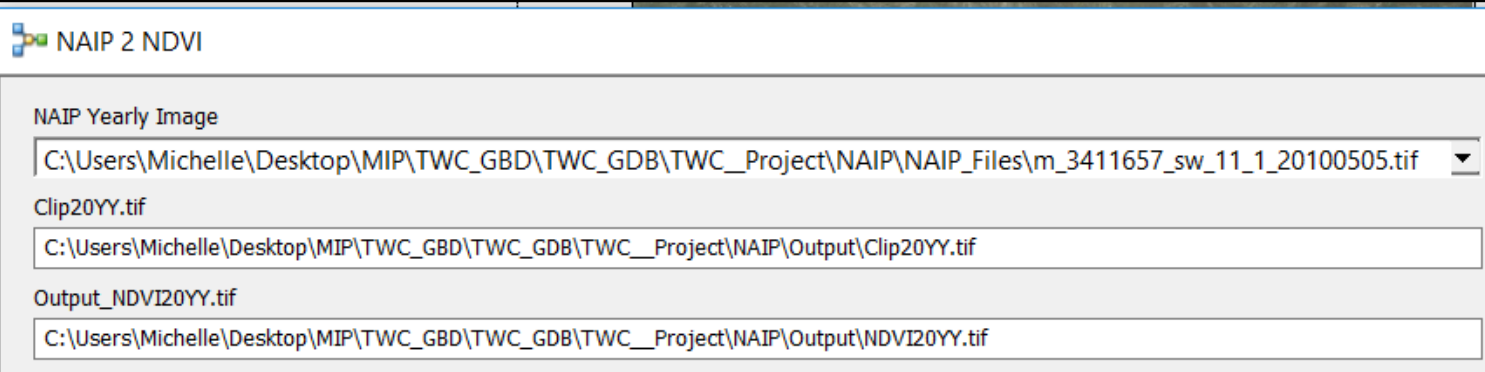

Figure 5-20: The NDVI Tool Input Interface for the End User

\subsection{Summary}

This chapter explained how to complete this project and why it was completed in a specific way. Section 5.1 was the Collector application and the processes taken, and the changes need for the next revision. In section 5.2 described how rules and subtype were created to define how the fixtures and waterlines react when drawn. Section 5.3 showed the relationship between tables. Section 5.4 talks about NAIP imagery, and how the NAIP 2 NDVI tool works, then finding the difference between two images. In section 5.5, we talk about file transferability, map documents, Python scripts, and tools. Chapter 6 is about the analysis and changes that would have made this project better. 


\section{Chapter 6 - Results and Analysis}

The main objective of this project was to locate and document the irrigation system of the

Oak Glen Preserve. The second objective was to find scientific proof for the health of the orchards. The final package of deliverables was sent to Wildlands Conservancy Oak Glen Preserve including a geodatabase of the original data collected, an ArcMap Toolbox containing the Python script for calculating the NAIP image into an NDVI image, and tutorials on conducting future work.

\subsection{Geometric Network}

Upon opening ArcMap TWC.mdx the GIS manager sees the interface shown in Figure 6.1, the Geometric Network and the About TWC groups are expanded to show the irrigation lines, it's fixtures, farming plots and the TWC boundary at the preserve. There are six fixture types and two types of water lines that represent the irrigation system at the Oak Glen Preserve.

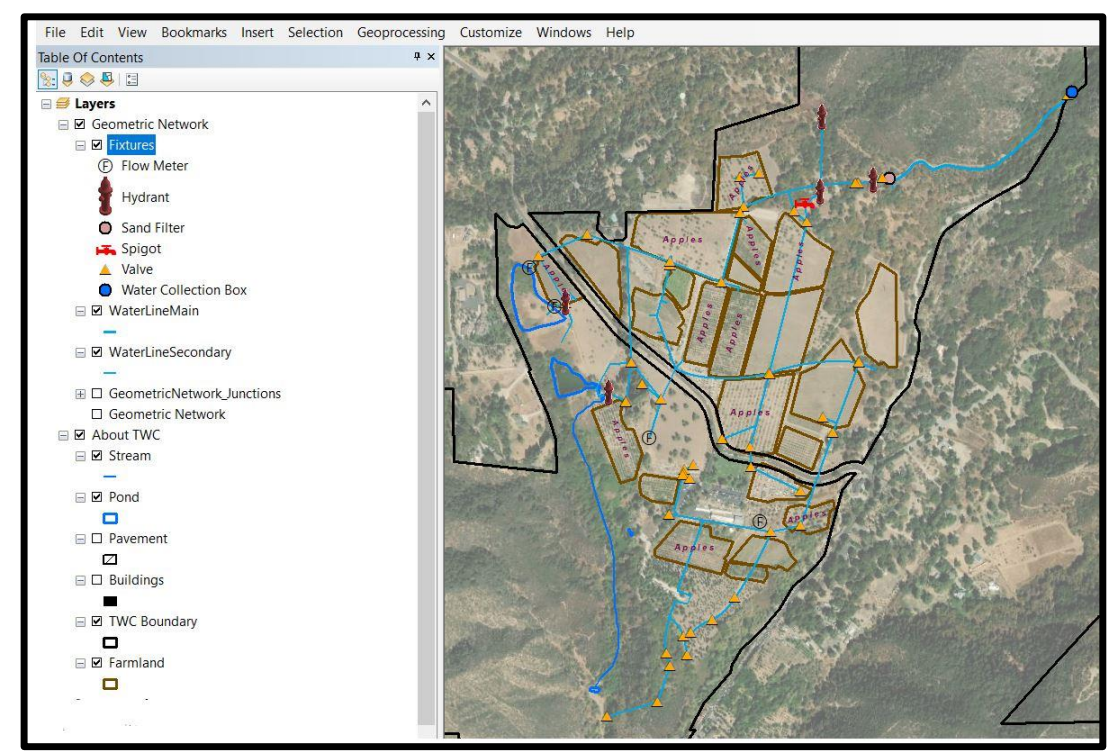

Figure 6-1: ArcMap Interface Showing the Geometric Network 
As stated in Chapter 5.2, by activating the geometric network, stakeholders can see what is downstream from a block valve, as seen in Figure 6-2. Tracing downstream also shows which plots of land are affected by the blocked valve. The GIS manager has access to each farmer's contact information for each affected plot. Contact information is found by opening the farmland attribute table and highlighting each plot number that is affected and then click the relationship button to show the affected farmers.

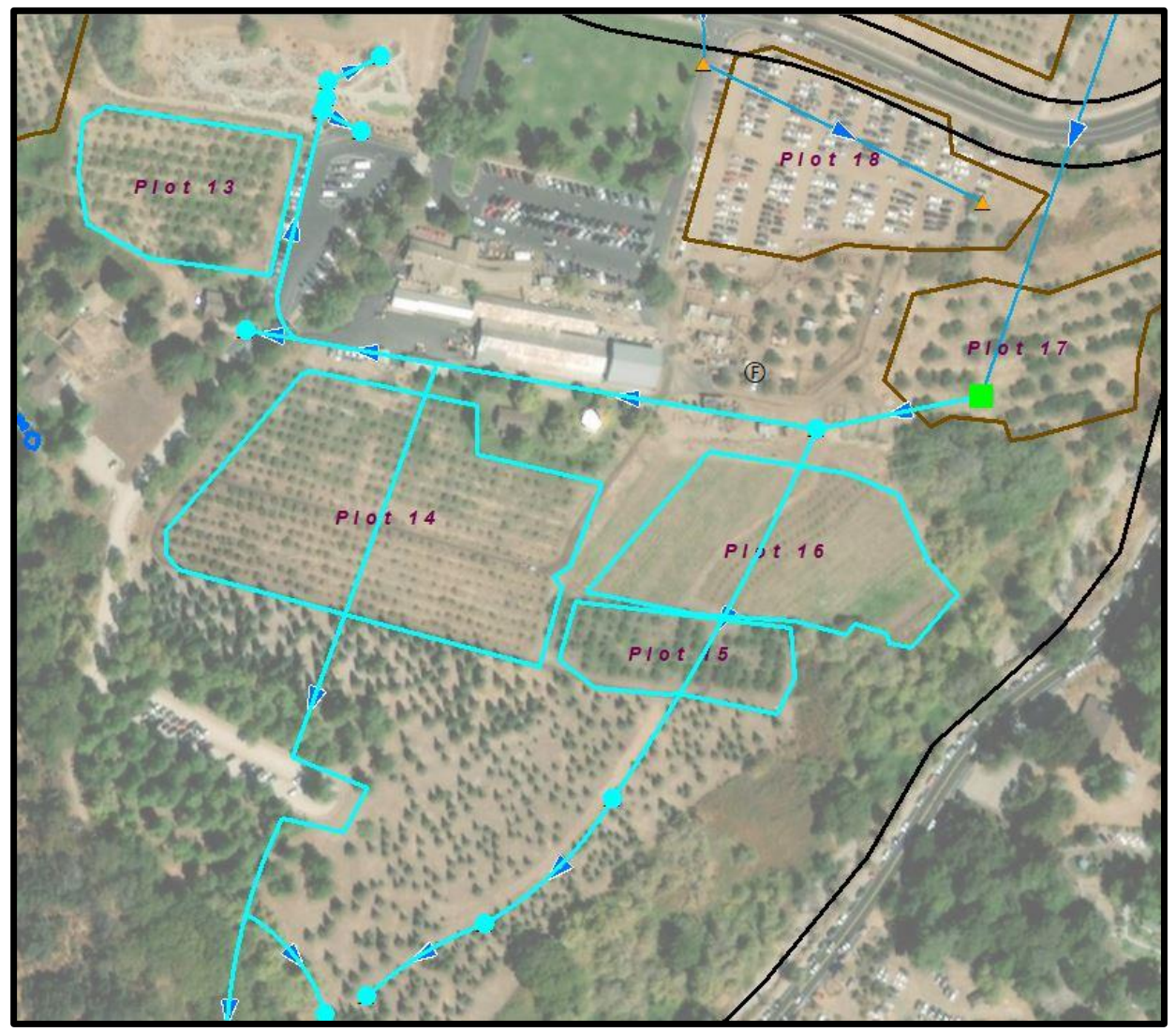

Figure 6-2: Flow Direction \& Traces Downstream 
Figure 6-3 shows the farmer's contact information for each affected plot numbers shown in Figure 6-2.

\begin{tabular}{|r|l|l|l|l|l|l|l|l|}
\hline Plot_Number & Farmer $^{*}$ & Contracting Company & Address & City & State & Zip & Phone & email \\
\hline 13 & Farmer 13 & Riley's Farm & 12273 Oak Glen Rd & Yucaipa & CA & 92399 & $(909) 797-7546$ & xxx13@Rileys.com \\
\hline 14 Farmer 14 & Riley's Farm & 12274 Oak Glen Rd & Yucaipa & CA & 92399 & $(909) 797-7547$ & $x x x 14 @$ Rileys.com \\
\hline 15 Farmer 15 & Riley's Farm & 12275 Oak Glen Rd & Yucaipa & CA & 92399 & $(909) 797-7548$ & xxx15@Rileys.com \\
\hline 16 Farmer 16 & Riley's Farm & 12276 Oak Glen Rd & Yucaipa & CA & 92399 & $(909) 797-7549$ & xxx16@Rileys.com \\
\hline
\end{tabular}

Figure 6-3: Farmer's Contact Information

\subsection{The Health of the Orchards}

Showing scientific proof for the health of the orchards is completed by calculating the difference between two different years. Inside the ArcMap (Figure 6-4), the groups that are expanded are the About TWC and the Health of the Orchards. The active layer under the Health of the Orchard, from bottom to top, is an NAIP file from earthexplorer.usgs.gov (m_3411657_sw_11_1_20100505.tif) which can be retrieved every two years. The NDVI_YYYY images are the converted files from using the NAIP 2 NDVI tool. Next is the NDVI Diff of Two Years raster files, which were calculated by using the difference tool. 


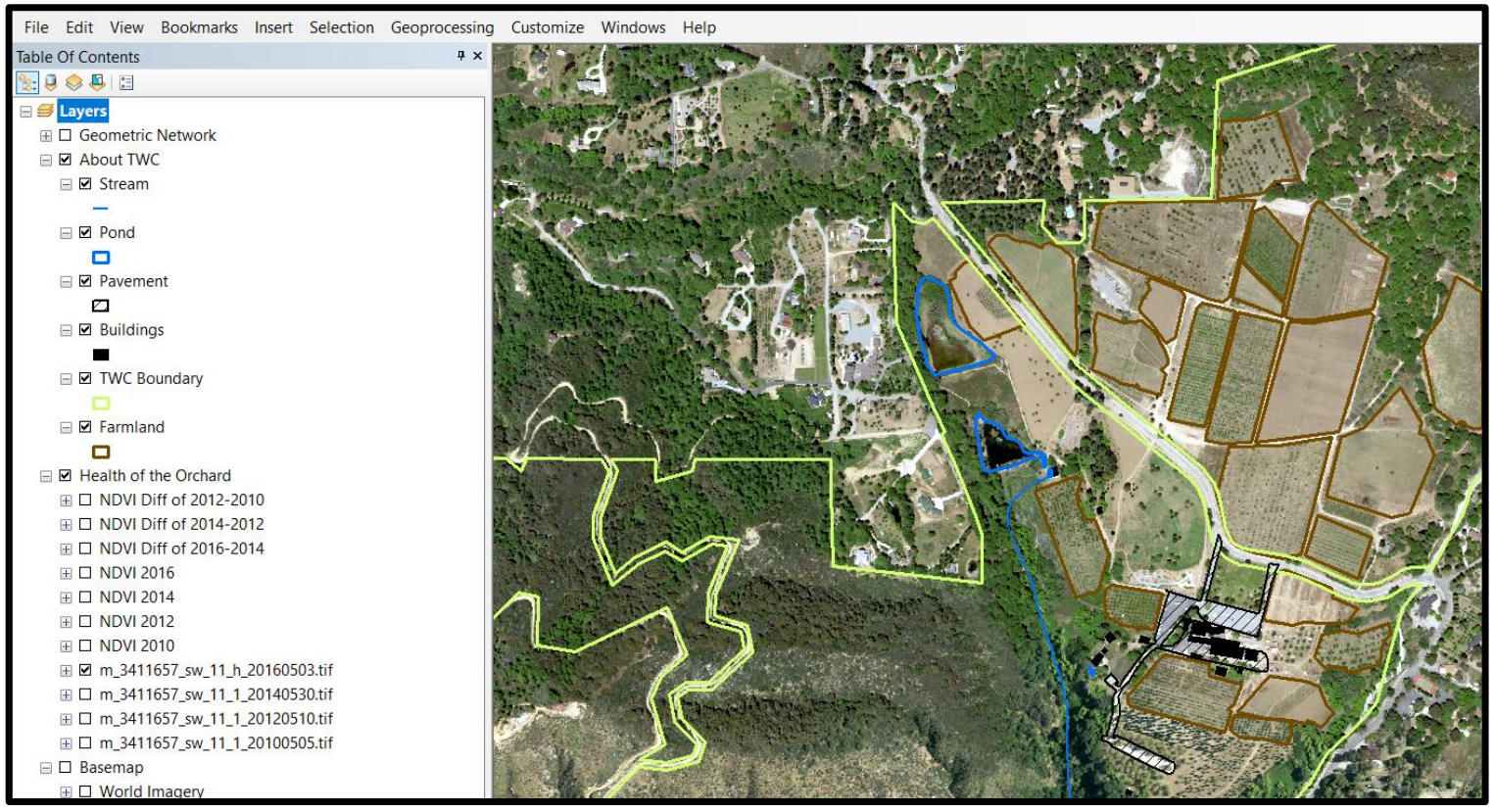

Figure 6-4: ArcMap Interface Showing the Health of the Orchard

Figure 6-5 shows the differences over a six-year period and how rainfall can affect irrigated orchards. 2012-2010 show consistent vegetation health with negative outliers showing in the ponds and the fields with varying crops. 2014-2012 shows positive health in the orchards and in the ponds, which tells us that the ponds are growing vegetation during these years, and the surrounding areas are showing scattered negative
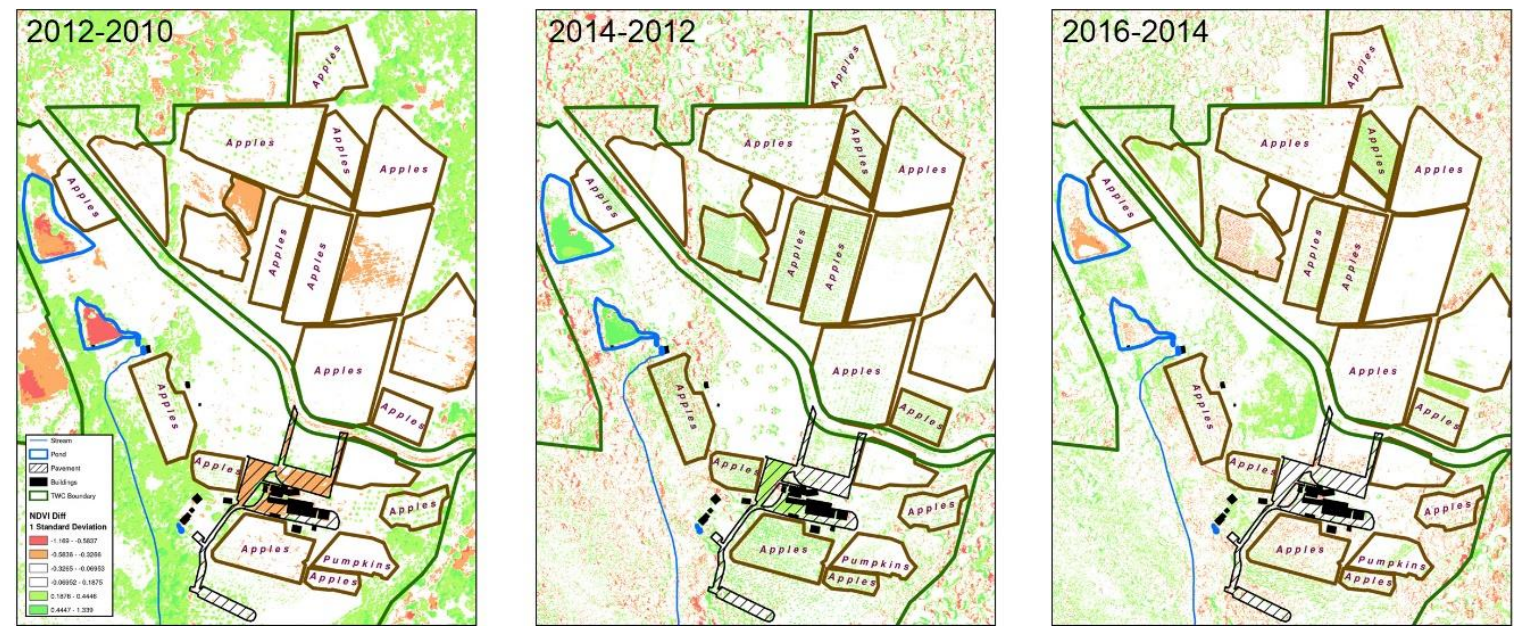

Figure 6-5: Showing the Differences Between Three Grouped Years 
health in the vegetation. 2016-2014 shows some scattered unhealthy vegetation in the apple orchards, which brought up the question about the weather during the years of the study.

Using the National Oceanic and Atmospheric Administration (NOAA) weather service, a discovery showed a significant change happened during this study period. In 2010 the Oak Glen area received approximately 27 inches of rain (Figure 6-6) (NOAA, 2018), which could be why in Figure 6-5 2012-2010 showed an unusually high amount of positive vegetation.

\section{Precipitation at the Redlands Station}

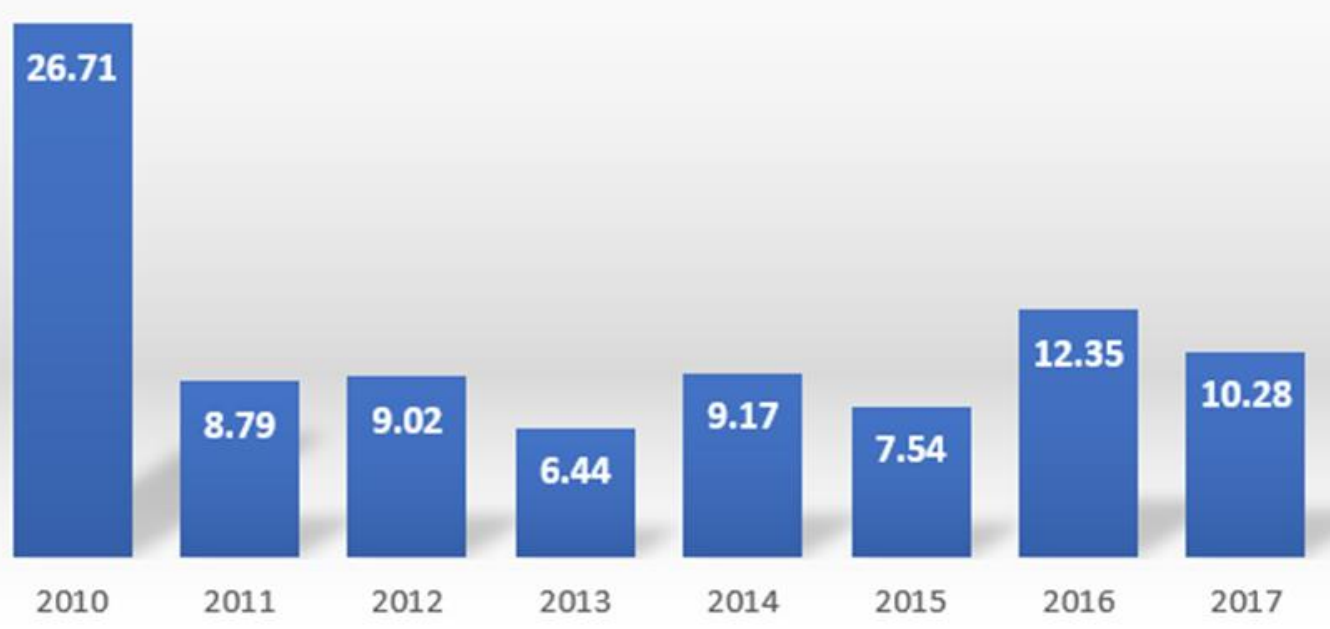

Figure 6-6: 2010-2017 Precipitation Bar Graph

The measuring station is located at March Air Force Base, approximately 30 miles from The Wildlands Conservancy in Oak Glen, while these measurements aren't an exact match for the precipitation in Oak Glen, they will work for this study. 


\subsection{Summary}

Section 6.1 shared the results of the geometric network and how to find the farmer's contact information for the affected plots. Analysis and results found in Section 6.2 brought to light that calculating vegetation health, with NAIP imagery, and then finding the difference between two images can provide scientific feedback. 


\section{Chapter 7 - Conclusions and Future Work}

Chapter 7 summarizes what we accomplished in this project as well as future work that could be accomplished by future students.

\subsection{Project Summary}

This project addressed the need to document the irrigation system and the health of the orchards into one GIS. This project explored many of Esri's products; Survey123 Connect, Collector, ArcGIS Online, and ArcMap. While incorporating tools to enhance aspects of the above software like Python scripts, GNSS software, and a Trimble R1 unit.

To address the needs of The Wildland Conservancy many deliverables were created a Collector application to collect data points in the field, an ArcMap geodatabase with the irrigation fixtures, water lines, plots of land, a table with the farmer's contact information, the geometric network, while also including an NDVI analysis over time using NAIP Imagery. The clients functional and non-functional requirements have been concluded.

The Collector application was uploaded to the clients ArcGIS Online account, so it could be used early in the process while the other files were delivered to the client's ArcGIS Online account after completion of the project.

\subsection{Future Work}

Plans could include the implementation of ArcGIS Workflow Manager, monthly drone flights over the orchards from May through October and measuring the diameters of each tree's canopy to maximize statistical measurements using LiDAR. 
Implementing ArcGIS Workflow Manager would help manage projects systematically and with higher accuracy. A simple workflow, for this project, could be downloading imagery, using tools to manipulate imagery, approval emails sent to management, redlines made, and approval emails resent until the completion of the project. ArcGIS Workflow Manager is an Enterprise tool used to follow GIS and nonGIS workflows through completion of a project. As The Wildland Conservancy continues to grow, GIS projects could be managed by one person with this application in place.

Future projects might include monthly drone flights over the orchards from May through October; the drone would have an RGB/NIR lens so NDVI calculations would be possible. Drone flights during these months would show the full growth cycle of the orchards. It would also bring the resolution into the centimeter range instead of the standard meter range of the NAIP imagery. Next, measuring the diameters of each tree canopy would maximize statistical measurements of each tree in the orchard. This task could be completed using LiDAR imagery and a Python script to strip out the trees from its surroundings; then the Zonal Statistics can be calculated for each tree. With these new processes in place, management can look at each tree and create a plan of action on an individual basis. 


\section{Works Cited}

Holland, D. A., Pook, C., \& Capstick, D. (2016). The Topographic Data Deluge Collecting and Maintaining Data in a 21st Century Mapping Agency. The International Archives of the Photogrammetry, Remote Sensing and Spatial Information Sciences, 727-731.

Abraham, Z. I., \& Schuster, J. A. (2002). Sanitary Sewer Flow Model and Storm Water Analysis for the Meadow Hills Subdivision in Rochester, MN.

Chivite, I. (2018, November 02). GeoNet. Retrieved from Survey123, Collector and GeoForm (a quick comparison): https://community.esri.com/groups/survey123/blog/2015/09/04/survey123collector-and-geoform-a-quick-comparison

Esri. (2018, September 14). What are geometric networks? Retrieved from ArcGIS for Desktop: http://desktop.arcgis.com/en/arcmap/10.5/manage-data/geometricnetworks/what-are-geometric-networks-.htm

Henry, D., \& Fellow, S. (2016). Comparing Apples and Oranges: Pittsburgh: Carnegie Mellon University.

Herning, J. (2013). A GIS Web Application for Oasis Ranch Management. Redlands: University of Redlands.

Jensen, J. R. (2007). Remote Sensing of the Environment: An Earth Resource Perspective. India: Pearson.

Kernler, D. (2018, September 17). Image of Empirical Rule. Retrieved from Wikimedia: https://upload.wikimedia.org/wikipedia/commons/a/a9/Empirical_Rule.PNG 
National Coordination Office for Space-Based Positioning, Navigation, and Timing. (2018, April 21). GPS Accuracy. Retrieved from GPS.GOV: https://www.gps.gov/systems/gps/performance/accuracy/

National Coordination Office for Space-Based Positioning, Navigation, and Timing. (2018, July 2). Other Global Navigation Satellite Systems (GNSS). Retrieved from GPS.gov: https://www.gps.gov/systems/gnss/

NOAA. (2018, May 4). Retrieved from Climate Data Online Search: https://www.ncdc.noaa.gov/cdoweb/search;jsessionid=5E49DA8670E0D0BD09CCC281989A176F

Schram, T. (2018, April 25th). Russian River NDVI (Normalized Difference Vegetation Index) Methodology and Use, California. Retrieved from USGS: https://www.fort.usgs.gov/sites/landsat-imagery-unique-resource/casestudies/russian-river-ndvi-normalized-difference

Skinner, J. (2018, January 15). GitHub. Retrieved from collector-tools/CollectorUtils: https://github.com/Esri/collector-tools/tree/master/CollectorUtils

Trammell, J. (2018, December 5). Administrative Assistant. (M. R. Williams, Interviewer)

USDA. (2018, August 7). United States Department of Agriculture. Retrieved from NAIP Imagery: https://www.fsa.usda.gov/programs-and-services/aerialphotography/imagery-programs/naip-imagery/

USDA. (2018, August 7). USDA Farm Service Agency. Retrieved from Agency History: https://www.fsa.usda.gov/about-fsa/history-and-mission/agency-history/index 
USDA-FSA-APFO Aerial Photography Field Office. (2016). Metadata From NAIP Image. Salt Lake City: USDA-FSA-APFO Aerial Photography Field Office. What is NDVI? (2018, January 27). Retrieved from GIS Geography: http://gisgeography.com/ndvi-normalized-difference-vegetation-index/ 



\section{Appendix A. Survey123 Connect Type Fields}

\begin{tabular}{|c|c|}
\hline Field Types & \\
\hline integer & Integer (i.e., whole number) input. \\
\hline decimal & Decimal input. \\
\hline text & Free text response. \\
\hline select_one [list_name] & $\begin{array}{l}\text { Multiple choice question; only one answer can be selected. Edit to reference } \\
\text { the correct list name. Ignore any warnings after changing values. }\end{array}$ \\
\hline $\begin{array}{l}\text { select_multiple } \\
\text { [list_name] }\end{array}$ & $\begin{array}{l}\text { Multiple choice question; multiple answers can be selected. Edit to reference } \\
\text { the correct list name. Ignore any warnings after changing values. }\end{array}$ \\
\hline note & Display a note on the screen, takes no input. \\
\hline geopoint & Collect a single GPS coordinate. \\
\hline date & Date input. \\
\hline time & Time input. \\
\hline dateTime & Date and time input. \\
\hline image & Takes a picture. \\
\hline begin group & Begin a group of questions. \\
\hline end group & End a group of questions. \\
\hline begin repeat & Begin a set of repeating questions. \\
\hline end repeat & End a set of repeating questions. \\
\hline calculate & $\begin{array}{l}\text { Performs a calculation on values in the form. The calculated field will contain } \\
\text { the outcome of the calculation. }\end{array}$ \\
\hline username & $\begin{array}{l}\text { When signed into ArcGIS Online, this field is automatically populated with the } \\
\text { account username. }\end{array}$ \\
\hline email & $\begin{array}{l}\text { When signed into ArcGIS Online, this field is automatically populated with the } \\
\text { account email address. }\end{array}$ \\
\hline hidden & $\begin{array}{l}\text { This will create a field in your feature service that will not be displayed on the } \\
\text { form. Use the bind::esri:fieldType and bind::esri:fieldLength columns to } \\
\text { specify the data schema for this field. }\end{array}$ \\
\hline barcode & Scan a barcode or a QR code. \\
\hline start & Start date and time of the survey. \\
\hline end & End date and time of the survey. \\
\hline \multicolumn{2}{|l|}{ Required } \\
\hline & Leave blank if field is not required. \\
\hline yes & Field is required to contain a value before form can be completed. \\
\hline \multicolumn{2}{|l|}{ Read Only } \\
\hline & Leave blank if field is not read-only \\
\hline yes & Field is read-only. Any values cannot be edited. \\
\hline \multicolumn{2}{|l|}{ Appearance } \\
\hline signature & $\begin{array}{l}\text { Applies to image fields presents a UI for signature capture. The signature will } \\
\text { be added to the feature as an attachment. }\end{array}$ \\
\hline minimal & $\begin{array}{l}\text { Applies to select_one, select_multiple, and barcode fields, as well as repeats. } \\
\text { Presents answers in a more space-efficient manner. }\end{array}$ \\
\hline
\end{tabular}




\begin{tabular}{|c|c|}
\hline multiline & Applies to text fields. Will make the text box multiple lines long. \\
\hline likert & Apples to select_one. Makes the answer choices appear as a Likert scale. \\
\hline month-year & Applies to date fields. Select a month and year only for the date. \\
\hline year & Applies to date fields. Select only a year for the date. \\
\hline week-number & Applies to date fields. Select a week number. \\
\hline distress & Applies to integer. A highly specific widget to measure distress. \\
\hline calculator & Applies to integer and decimal fields. Displays a custom calculator widget. \\
\hline numbers & Applies to integer and decimal fields. Displays a custom keyboard. \\
\hline spinner & $\begin{array}{l}\text { Applies to integer and decimal fields. Adds buttons to increase and decrease } \\
\text { value. }\end{array}$ \\
\hline horizontal & $\begin{array}{l}\text { Applies to select_one and select_multiple fields. Displays answer choices } \\
\text { horizontally, but in columns. }\end{array}$ \\
\hline horizontal-compact & $\begin{array}{l}\text { Applies to select_one and select_multiple fields. Displays answer choices } \\
\text { horizontally. }\end{array}$ \\
\hline autocomplete & $\begin{array}{l}\text { Applies to select_one fields. Answer choices appear in a pull-down menu, with } \\
\text { text input to narrow down options. }\end{array}$ \\
\hline compact & $\begin{array}{l}\text { Applies to groups and repeats. Group of questions will appear collapsed on } \\
\text { startup. }\end{array}$ \\
\hline minimal compact & Applies to repeats. Group of questions is displayed both collapsed and hidden. \\
\hline field-list & $\begin{array}{l}\text { Applies to groups and repeats, when style is set to pages. Displays group of } \\
\text { questions on a separate page. }\end{array}$ \\
\hline \multicolumn{2}{|l|}{ Default Values } \\
\hline today () & Set the default date to today's date, at midnight. Applies to date questions. \\
\hline now () & $\begin{array}{l}\text { Sets the default value to the current date and time. Applies to time and } \\
\text { dateTime questions. }\end{array}$ \\
\hline item1,item2,item3 & Use a comma separated list to set default values for select_multiple fields. \\
\hline \multirow[t]{2}{*}{ Cascading Selects } & Create additional attribute columns for your pick lists in the choices tab. \\
\hline & $\begin{array}{l}\text { Add an expression to the choices_filter column to restrict subsequent pick lists } \\
\text { using these attributes. }\end{array}$ \\
\hline Formula Operators & These operators can be used in constraint, relevant and calculation fields \\
\hline Operator & Description \\
\hline $\mid$ & Computes two node-sets \\
\hline+ & Addition \\
\hline- & Subtraction \\
\hline$*$ & Multiplication \\
\hline $\operatorname{div}$ & Division \\
\hline$=$ & Equal \\
\hline$!=$ & Not equal \\
\hline$<$ & Less than \\
\hline$<=$ & Less than or equal to \\
\hline$>$ & Greater than \\
\hline$>=$ & Greater than or equal to \\
\hline or & or \\
\hline and & and \\
\hline $\bmod$ & Modulus (division remainder) \\
\hline
\end{tabular}




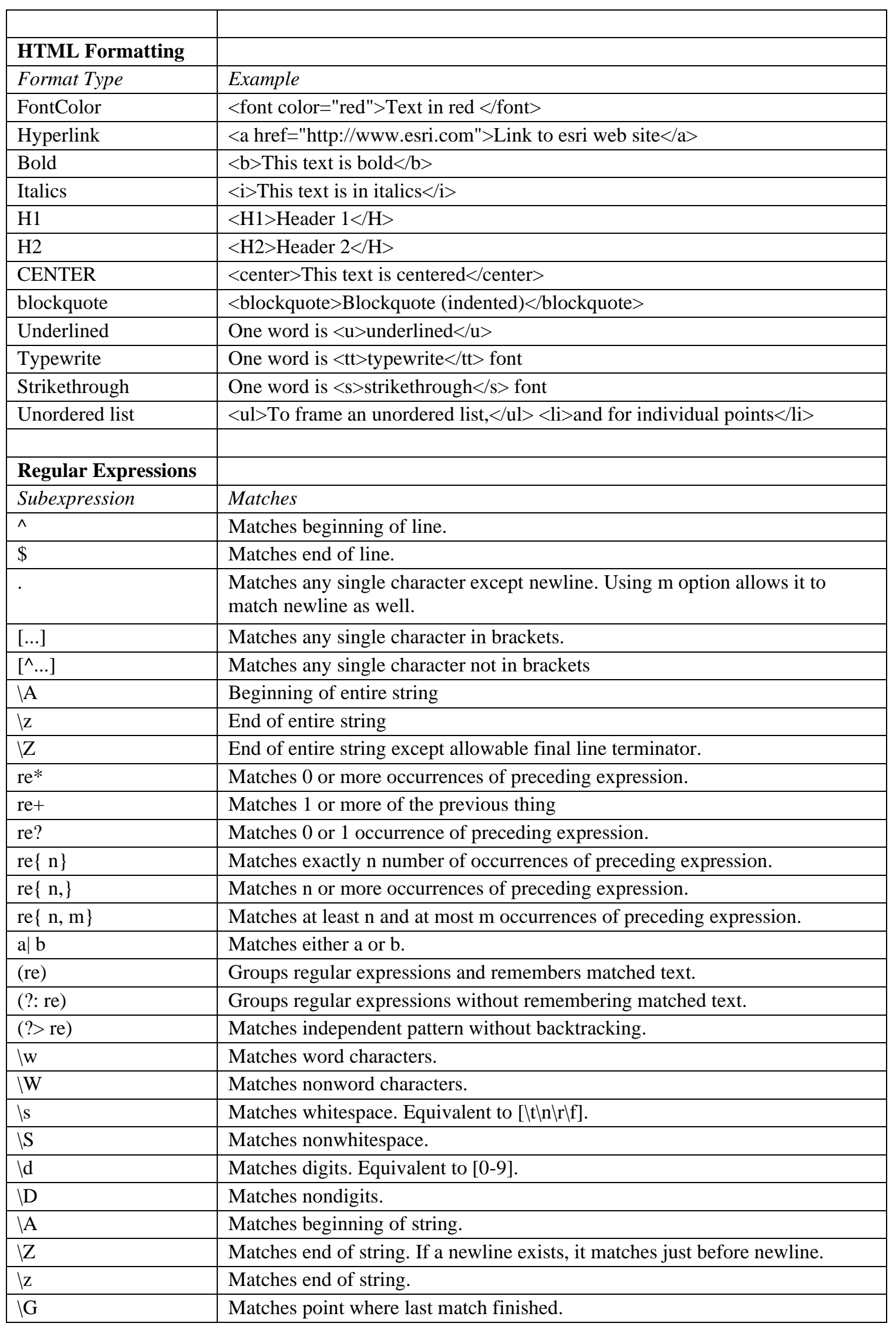




\begin{tabular}{|c|c|}
\hline $\ln$ & Back-reference to capture group number "n" \\
\hline $\mathrm{lb}$ & $\begin{array}{l}\text { Matches word boundaries when outside brackets. Matches backspace }(0 x 08) \\
\text { when inside brackets. }\end{array}$ \\
\hline IB & Matches nonword boundaries. \\
\hline$\backslash \mathrm{n}, \mathrm{It}$, etc. & Matches newlines, carriage returns, tabs, etc. \\
\hline IQ & Escape (quote) all characters up to $\backslash \mathrm{E}$ \\
\hline $\mathrm{VE}$ & Ends quoting begun with $\backslash \mathrm{Q}$ \\
\hline \multicolumn{2}{|l|}{ Esri Field Type } \\
\hline esriFieldTypeDate & Date \\
\hline esriFieldTypeDouble & Double-precision floating point numbers \\
\hline esriFieldTypeInteger & Whole numbers \\
\hline esriFieldTypeString & A series of alphanumeric symbols \\
\hline esriFieldTypePointZ & Adds $\mathrm{Z}$ axis support to geopoint question \\
\hline esriFieldTypeGUID & Globally Unique Identifier \\
\hline \multicolumn{2}{|c|}{ Mathematical Functions } \\
\hline Operator & Function \\
\hline pi() & Returns pi. \\
\hline acos(value) & Returns the arccosine of the value. \\
\hline $\operatorname{asin}($ value $)$ & Returns the arcsine of the value. \\
\hline atan(value) & Returns the arctangent of the value. \\
\hline $\cos ($ value $)$ & Returns the cosine of the value \\
\hline $\sin$ (value) & Returns the sine of the value. \\
\hline $\tan ($ value $)$ & Returns the tangent of the value as degrees in an angle. \\
\hline $\exp ($ value $)$ & Returns the natural exponent of the value. \\
\hline exp10(value) & Returns ten to the power of the value. \\
\hline $\log ($ value $)$ & Returns the natural logarithm of the value. \\
\hline $\log 10$ (value) & Returns the base-ten logarithm of the value. \\
\hline sqrt(value) & Returns the square root of the value. \\
\hline $\min ($ value1,value2) & Returns the minimum value in the given range. \\
\hline $\max ($ value1,value2) & Returns the maximum value in the given range. \\
\hline random & Returns a random value between 0 (inclusive) and 1 (exclusive). \\
\hline atan2(value1,value2) & Returns the arctangent of the quotient of the values. \\
\hline round(value1,value2) & Returns the rounded value. \\
\hline pow(value,power) & Returns the value to the power specified. \\
\hline
\end{tabular}




\section{Appendix B. Calculate the Difference Between 2 NDVI Features}

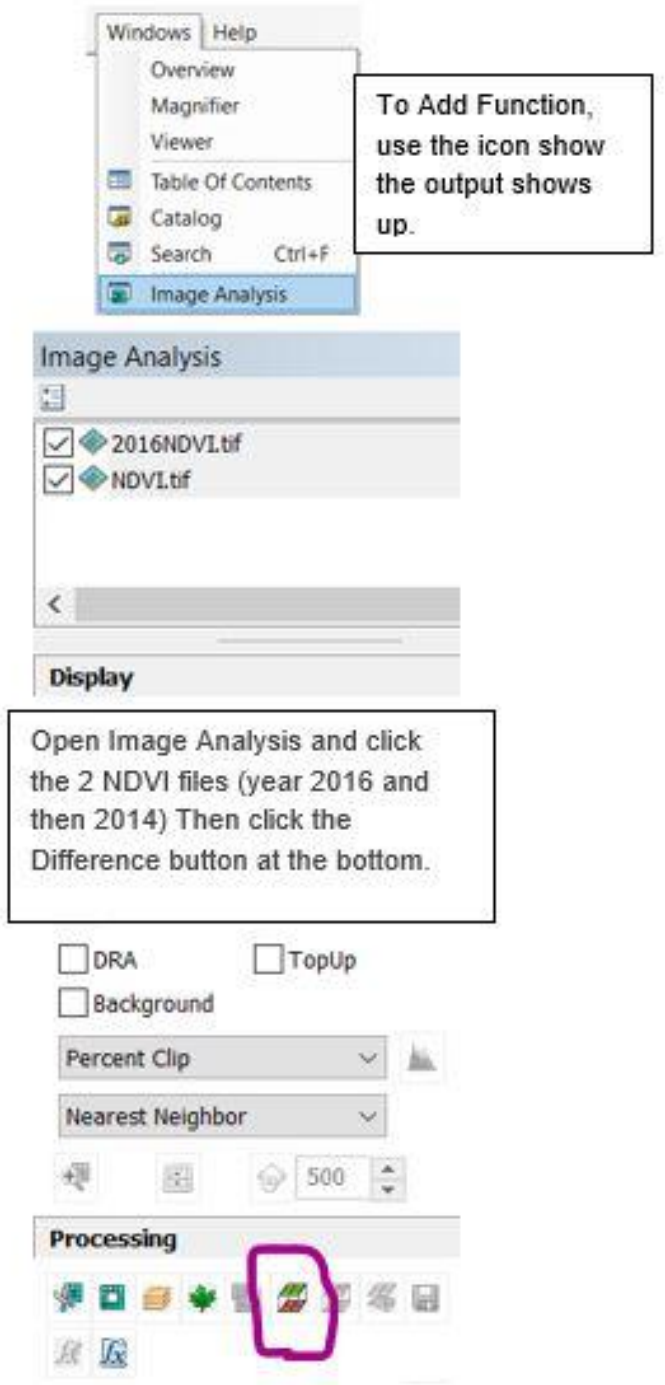

Now you have the outliers in the two tails outside $1 \mathrm{SD}$. Remove the color from $1 \mathrm{SD}$.
Diff_NDVI 2016-2010
1 Standard Deviation Outliers
$-0.819820985--0.427108945$
$-0.427108945--0.242527911$
$\square-0.242527911--0.057946878$
$-0.057946878-0.126634156$
$\square 0.126634156-0.311215189$
$0.311215189-1.293128222$ 


\section{Appendix C. Python Script to Calculate NDVI}

\#Source: Code was from Dr. Ma's coarse and manipulated to be included in MIP.

\#import related modules

import numpy

import sys

sys.path.append(r'C:IUsers\MichellelDesktoplGIS_MasterlMaRemotelbin\gdallpython') \#where GDAL resides- my link kept breaking so I hardcoded it.

from osgeo import gdal, gdalconst

import math

\#Get user input from command line [] is the placement of answer

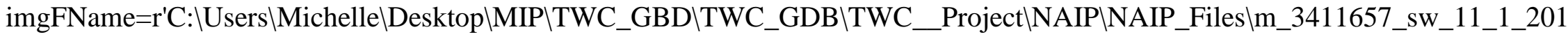
00505.tif'

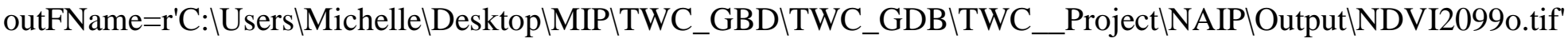

RedBand= int $(1)$ \#Red Band is 1

NIRBand= int(4) \#NIR Band is 4

"1"

\#Get user input from command line [] is the placement of answer imgFName=sys.argv[1] \#Input image file name

outFName=sys.argv[2] \#Output image file name

RedBand= int $(1)$ \#Red Band is 1

NIRBand= int(4) \#NIR Band is 4

""'"

\#Using GDAL

gdal.AllRegister() \#Note to self this is a redundant step. It is automatically called when GDAL is 
\#imported. It is used to prepare for working with all suported file format

rasterIn=gdal.Open(imgFName, gdalconst.GA_ReadOnly) \#read from hard drive if rasterIn is None:

print "Cannot access input file! $\mid n "$

sys.exit(0)

\#Obtain image metadata

projectionfrom $=$ rasterIn.GetProjection()

geotransform $=$ rasterIn.GetGeoTransform ()

colNums=rasterIn.RasterXSize \#Number of columns

rowNums=rasterIn.RasterYSize \#Number of rows+

\#--

bands=rasterIn.RasterCount \#Number of bands

if bands $<$ RedBand:

print 'Not enough bands! \r'

sys.exit $(0)$

if bands<NIRBand:

print 'Not enough bands! $\mid r$ '

sys.exit $(0)$

\#RED Process

Red0Grid=numpy.zeros $($ (rowNums,colNums,1),dtype=numpy.complex128)

band=rasterIn.GetRasterBand(RedBand)

Red0Grid[:,:,0]=band.ReadAsArray $(0,0$, colNums, rowNums $)$

R_Red0Grid=Red0Grid/Red0Grid.mean()

\#NIR Process

NIR0Grid=numpy.zeros $(($ rowNums,colNums, 1$)$,dtype=numpy.complex128)

\#float32 is bigger than a byte

band=rasterIn.GetRasterBand(NIRBand) 
NIR0Grid[:,:,0]=band.ReadAsArray $(0,0$, colNums,rowNums $)$

R_NIR0Grid=NIR0Grid/NIR0Grid.mean()

\#NDVI Process Retrieve data from input image and put it in a numpy matrix memory

NDVI=numpy.zeros((rowNums, colNums),dtype=numpy.complex128)

NDVI=(R_NIR0Grid-R_Red0Grid)/(R_NIR0Grid + R_Red0Grid +.00001)

\#Specify what type of file format to process. The list of suported formats can

\#be found at http://www.gdal.org/formats_list.html

\#Not every format can be created using the following approach. JPEG and PNG

\#cannot be created in this way. Instead, CreateCopy function can be used to create these type of files.

rasterOut=gdal.GetDriverByName('HFA').Create(outFName,colNums, rowNums, 1, gdalconst.GDT_Float64) \#1 = band \#driver=gdal.GetDriverByName('GTiff') \#Output Tiff/GeoTiff file.

\#driver.Register()

rasterOut.SetProjection(projectionfrom)

rasterOut.SetGeoTransform(geotransform)

rasterOut.GetRasterBand(1).WriteArray(NDVI) \#Also can use the image in memory imgData[:,:,band]

rasterIn=None \#Close the raster so that the file can be accessed by other software

rasterOut=None

print 'done! $! n '$ 


\section{Appendix D. Collector Errors from using a Second Mobile Device}

\begin{tabular}{|c|c|c|c|c|c|c|c|c|c|c|c|c|c|c|c|c|}
\hline $\begin{array}{l}\text { OBJECT } \\
\text { ID }\end{array}$ & Type & Section Name & $\begin{array}{l}\text { Dia } \\
\text { (in.) }\end{array}$ & Material & Notes & $\begin{array}{l}\text { Receiver } \\
\text { Name }\end{array}$ & $\begin{array}{l}\text { Hor Accy } \\
(\mathrm{m})\end{array}$ & $\begin{array}{l}\text { Vert Accy } \\
(\mathrm{m})\end{array}$ & Latitude & Longitude & Altitude & PDOP & HDOP & VDOP & Fix Type & $\begin{array}{c}\# \\
\text { Satellites }\end{array}$ \\
\hline 2 & Valve & Water Canyon & 6 & Steel & To sand filters & $<$ Null $>$ & $<$ Null $>$ & $<$ Null $>$ & $<$ Null $>$ & $<$ Null $>$ & $<$ Null $>$ & $<$ Null $>$ & $<$ Null $>$ & $<$ Null $>$ & $<$ Null $>$ & $<$ Null> \\
\hline 3 & Other & Water Canyon & 6 & Steel & water box outflow & $<$ Null $>$ & $<$ Null $>$ & $<$ Null $>$ & $<$ Null $>$ & $<$ Null $>$ & $<$ Null $>$ & $<$ Null $>$ & $<$ Null $>$ & $<$ Null $>$ & $<$ Null $>$ & $<$ Null $>$ \\
\hline 5 & $\begin{array}{l}\text { Water } \\
\text { Tank }\end{array}$ & Water Canyon & 4 & Steel & water tank & $<$ Null $>$ & $<$ Null $>$ & $<$ Null $>$ & $<$ Null $>$ & $<$ Null $>$ & $<$ Null $>$ & $<$ Null $>$ & $<$ Null $>$ & $<$ Null $>$ & $<$ Null $>$ & $<$ Null $>$ \\
\hline 7 & Valve & North Preserve & 3 & Steel & $\begin{array}{l}\text { valve from main } \\
\text { pipe after for the } \\
\text { lodge the oaks } \mathrm{h}\end{array}$ & $<$ Null $>$ & $<$ Null $>$ & $<$ Null $>$ & $<$ Null $>$ & $<$ Null $>$ & $<$ Null $>$ & $<$ Null $>$ & $<$ Null $>$ & $<$ Null $>$ & $<$ Null $>$ & $<$ Null $>$ \\
\hline 8 & Hydrant & North Preserve & 2 & Steel & $\begin{array}{l}\text { fire hydrant north } \\
\text { side of lodge }\end{array}$ & $<$ Null $>$ & $<$ Null $>$ & $<$ Null $>$ & $<$ Null $>$ & $<$ Null $>$ & $<$ Null $>$ & $<$ Null $>$ & $<$ Null $>$ & $<$ Null $>$ & $<$ Null> & $<$ Null > \\
\hline 9 & Valve & North Preserve & 2 & Steel & for irrigation & $<$ Null $>$ & $<$ Null $>$ & $<$ Null $>$ & $<$ Null $>$ & $<$ Null $>$ & $<$ Null $>$ & $<$ Null $>$ & $<$ Null $>$ & $<$ Null $>$ & $<$ Null $>$ & $<$ Null $>$ \\
\hline 10 & Valve & North Preserve & 2 & PVC & 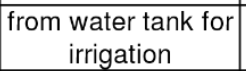 & $<$ Null $>$ & $<$ Null $>$ & $<$ Null $>$ & $<$ Null $>$ & $<$ Null $>$ & $<$ Null $>$ & $<$ Null $>$ & $<$ Null $>$ & $\mid<$ Null $>$ & $<$ Null $>$ & $<$ Null> \\
\hline 11 & Valve & North Preserve & 2 & PVC & $\begin{array}{c}\text { valve is the end } \\
\text { point from the } \\
\text { water tank }\end{array}$ & $<$ Null $>$ & $<$ Null $>$ & $<$ Null $>$ & $<$ Null $>$ & $<$ Null $>$ & $<$ Null $>$ & $<$ Null $>$ & $<$ Null $>$ & $<$ Null $>$ & $<$ Null $>$ & $<$ Null $>$ \\
\hline 12 & Valve & North Preserve & 1.5 & Steel & $\begin{array}{c}\text { from water tank for } \\
\text { irrigation END OF } \\
\text { line }\end{array}$ & $<$ Null $>$ & $<$ Null $>$ & $<$ Null $>$ & $<$ Null $>$ & $<$ Null $>$ & $<$ Null $>$ & $<$ Null $>$ & $<$ Null $>$ & $<$ Null $>$ & $<$ Null $>$ & $<$ Null $>$ \\
\hline 13 & Valve & North Preserve & 3 & PVC & \begin{tabular}{|c|}
$\begin{array}{c}\text { for irrigation of the } \\
\text { two sections north } \\
\text { of road }\end{array}$ \\
\end{tabular} & $<$ Null $>$ & $<$ Null $>$ & $<$ Null $>$ & $<$ Null $>$ & $<$ Null $>$ & $<$ Null $>$ & $<$ Null $>$ & $<$ Null $>$ & $<$ Null $>$ & $<$ Null $>$ & $<$ Null $>$ \\
\hline 14 & $\begin{array}{l}\text { Water } \\
\text { Tank }\end{array}$ & North Preserve & 2 & Steel & \begin{tabular}{c|} 
Cedar house \\
reserve water tank
\end{tabular} & $<$ Null $>$ & $<$ Null $>$ & $<$ Null $>$ & $<$ Null $>$ & $<$ Null $>$ & $<$ Null $>$ & $<$ Null $>$ & $<$ Null $>$ & $<$ Null $>$ & $<$ Null $>$ & $<$ Null $>$ \\
\hline 15 & Well & North Preserve & 4 & PVC & \begin{tabular}{|c|}
$\begin{array}{c}\text { well - with flow to } \\
\text { stream lines }\end{array}$ \\
\end{tabular} & $<$ Null $>$ & $<$ Null $>$ & $<$ Null $>$ & $<$ Null $>$ & $<$ Null $>$ & $<$ Null $>$ & $<$ Null $>$ & $<$ Null $>$ & $<$ Null $>$ & $<$ Null $>$ & $<$ Null $>$ \\
\hline 16 & Valve & North Preserve & 2 & & from the north well & $<$ Null $>$ & $<$ Null $>$ & $<$ Null $>$ & $<$ Null $>$ & $<$ Null $>$ & $<$ Null $>$ & $<$ Null $>$ & $<$ Null $>$ & $<$ Null $>$ & $<$ Null $>$ & $<$ Null $>$ \\
\hline 17 & Valve & North Preserve & 3 & Steel & $\begin{array}{l}\text { for irrigation of } \\
\text { blue sky park - } \\
\text { crosses road }\end{array}$ & $<$ Null $>$ & $<$ Null $>$ & $<$ Null $>$ & $<$ Null $>$ & $<$ Null $>$ & $<$ Null $>$ & $<$ Null $>$ & $\mid<$ Null $>$ & $\mid<$ Null $>$ & $<$ Null $>$ & $<$ Null $>$ \\
\hline 18 & \begin{tabular}{|c|} 
Water \\
Collectio \\
n Box \\
\end{tabular} & Water Canyon & 0 & PVC & $\begin{array}{c}\text { Water Box (starting } \\
\text { point) }\end{array}$ & \begin{tabular}{|c|} 
Trimble \\
$\# 56144690$ \\
82 \\
\end{tabular} & 1.650 & 2.950 & 34.048 & -116.931 & 1565.740 & 3.214 & 1.438 & 2.875 & $\begin{array}{c}\text { Differential } \\
\text { GPS }\end{array}$ & 9 \\
\hline 19 & $\begin{array}{l}\text { Sand } \\
\text { Filter }\end{array}$ & Water Canyon & 6 & Steel & $\begin{array}{c}\text { rock, sand to filter } \\
\text { water. silt gets } \\
\text { back flushed }\end{array}$ & \begin{tabular}{|c|} 
Trimble \\
$\# 56144690$ \\
82 \\
\end{tabular} & 1.241 & 1.426 & 34.047 & -116.936 & 1528.836 & 2.240 & 1.125 & 1.938 & $\begin{array}{c}\text { Differential } \\
\text { GPS }\end{array}$ & 12 \\
\hline
\end{tabular}




\begin{tabular}{|c|c|c|c|c|c|c|c|c|c|c|c|c|c|c|c|c|}
\hline $\begin{array}{l}\text { OBJECT } \\
\text { ID }\end{array}$ & Type & Section Name & $\begin{array}{l}\text { Dia } \\
\text { (in.) }\end{array}$ & Material & Notes & $\begin{array}{l}\text { Receiver } \\
\text { Name }\end{array}$ & $\begin{array}{l}\text { Hor Accy } \\
(\mathrm{m})\end{array}$ & $\begin{array}{c}\text { Vert Accy } \\
(\mathrm{m})\end{array}$ & Latitude & Longitude & Altitude & PDOP & HDOP & VDOP & Fix Type & $\begin{array}{c}\# \\
\text { Satellites }\end{array}$ \\
\hline 20 & Valve & Water Canyon & 3 & Steel & to Hidden Hollow & \begin{tabular}{|c|} 
Trimble \\
$\# 56144690$ \\
82 \\
\end{tabular} & 0.986 & 1.040 & 34.047 & -116.936 & 1529.032 & 2.070 & 1.000 & 1.812 & $\begin{array}{c}\text { Differential } \\
\text { GPS }\end{array}$ & 13 \\
\hline 21 & Hydrant & North Preserve & 6 & Steel & & \begin{tabular}{|c|} 
Trimble \\
$\# 56144690$ \\
82 \\
\end{tabular} & 0.727 & 1.208 & 34.047 & -116.936 & 1527.359 & 1.630 & 0.875 & 1.375 & $\begin{array}{c}\text { Differential } \\
\text { GPS }\end{array}$ & 14 \\
\hline 22 & Valve & North Preserve & 2 & Steel & $\begin{array}{l}\text { to deconstructed } \\
\text { house, hay bails }\end{array}$ & \begin{tabular}{|c|} 
Trimble \\
$\# 56144690$ \\
82
\end{tabular} & 0.758 & 0.887 & 34.047 & -116.937 & 1527.302 & 1.664 & 0.938 & 1.375 & \begin{tabular}{|c|} 
Differential \\
GPS
\end{tabular} & 13 \\
\hline 23 & Spigot & North Preserve & 2 & Steel & to orchard & \begin{tabular}{|c|} 
Trimble \\
$\# 56144690$ \\
82 \\
\end{tabular} & 1.102 & 1.192 & 34.046 & -116.938 & 1518.791 & 1.544 & 0.812 & 1.312 & $\begin{array}{c}\text { Differential } \\
\text { GPS }\end{array}$ & 14 \\
\hline 24 & Valve & North Preserve & 2 & Steel & & \begin{tabular}{|c|} 
Trimble \\
$\# 56144690$ \\
82 \\
\end{tabular} & 1.002 & 1.110 & 34.046 & -116.938 & 1516.010 & 1.613 & 0.938 & 1.312 & $\begin{array}{c}\text { Differential } \\
\text { GPS }\end{array}$ & 13 \\
\hline 25 & Hydrant & North Preserve & 4 & PVC & $\begin{array}{l}\text { to the hydrant, fire } \\
\text { suppression tank }\end{array}$ & \begin{tabular}{|c|} 
Trimble \\
$\# 56144690$ \\
82 \\
\end{tabular} & 0.804 & 1.422 & 34.048 & -116.938 & 1557.389 & 1.613 & 0.938 & 1.312 & $\begin{array}{c}\text { Differential } \\
\text { GPS }\end{array}$ & 13 \\
\hline 26 & Valve & North Preserve & 3 & Steel & & \begin{tabular}{|c|} 
Trimble \\
$\# 56144690$ \\
82 \\
\end{tabular} & 1.127 & 1.313 & 34.046 & -116.940 & 1507.946 & 1.388 & 0.812 & 1.125 & $\begin{array}{c}\text { Differential } \\
\text { GPS }\end{array}$ & 17 \\
\hline 27 & Valve & North Preserve & 2 & PVC & $\begin{array}{l}\text { center pipe input, } 2 \\
\text { outputs to orchard }\end{array}$ & \begin{tabular}{|c|} 
Trimble \\
$\# 56144690$ \\
82 \\
\end{tabular} & 3.037 & 4.953 & 34.045 & -116.940 & 1485.926 & 1.301 & 0.750 & 1.063 & GPS & 17 \\
\hline 28 & Valve & North Preserve & 2 & PVC & to cedar tree & \begin{tabular}{|c|} 
Trimble \\
$\# 56144690$ \\
82 \\
\end{tabular} & 2.906 & 4.772 & 34.045 & -116.942 & 1481.341 & 1.352 & 0.750 & 1.125 & GPS & 16 \\
\hline 29 & Valve & North Preserve & 4 & Steel & $\begin{array}{c}\text { to upper and lower } \\
\text { pond west on N. } \\
\text { position? }\end{array}$ & & & & & & & & & & & \\
\hline 30 & Valve & North Preserve & 4 & Steel & from sand filters & \begin{tabular}{|c|} 
Trimble \\
$\# 56144690$ \\
82 \\
\end{tabular} & 2.959 & 5.625 & 34.043 & -116.937 & 1471.352 & 1.388 & 0.813 & 1.125 & GPS & 16 \\
\hline 31 & Valve & North Preserve & 4 & Steel & 2nd try same point & \begin{tabular}{|c|} 
Trimble \\
$\# 56144690$ \\
82 \\
\end{tabular} & 0.971 & 1.199 & 34.043 & -116.937 & 1469.971 & 1.352 & 0.750 & 1.125 & $\begin{array}{c}\text { Differential } \\
\text { GPS }\end{array}$ & 17 \\
\hline
\end{tabular}




\begin{tabular}{|c|c|c|c|c|c|c|c|c|c|c|c|c|c|c|c|c|}
\hline $\begin{array}{l}\text { OBJECT } \\
\text { ID }\end{array}$ & Type & Section Name & $\begin{array}{l}\text { Dia } \\
\text { (in.) }\end{array}$ & Material & Notes & $\begin{array}{l}\text { Receiver } \\
\text { Name }\end{array}$ & $\begin{array}{l}\text { Hor Accy } \\
\text { (m) }\end{array}$ & $\begin{array}{l}\text { Vert Accy } \\
(\mathrm{m})\end{array}$ & Latitude & Longitude & Altitude & PDOP & HDOP & VDOP & Fix Type & $\begin{array}{c}\# \\
\text { Satellites }\end{array}$ \\
\hline 32 & Valve & North Preserve & 4 & PVC & to cedar house & \begin{tabular}{|c|} 
Trimble \\
$\# 56144690$ \\
82 \\
\end{tabular} & 0.578 & 0.880 & 34.042 & -116.938 & 1453.132 & 1.512 & 0.750 & 1.313 & $\begin{array}{c}\text { Differential } \\
\text { GPS }\end{array}$ & 15 \\
\hline 33 & Valve & North Preserve & 1 & Steel & & \begin{tabular}{|c|} 
Trimble \\
$\# 56144690$ \\
82 \\
\end{tabular} & 0.934 & 2.130 & 34.041 & -116.937 & 1449.308 & 1.491 & 0.812 & 1.250 & \begin{tabular}{|c|}
$\begin{array}{c}\text { Differential } \\
\text { GPS }\end{array}$ \\
\end{tabular} & 12 \\
\hline 34 & Valve & North Preserve & 3 & Steel & $\begin{array}{c}\text { from stream, North } \\
\text { most valve }\end{array}$ & \begin{tabular}{|c|} 
Trimble \\
$\# 56144690$ \\
82 \\
\end{tabular} & 0.577 & 0.835 & 34.043 & -116.939 & 1465.784 & 1.405 & 0.750 & 1.188 & $\begin{array}{c}\text { Differential } \\
\text { GPS }\end{array}$ & 16 \\
\hline 35 & Valve & North Preserve & 2 & PVC & Flume Cleanout & \begin{tabular}{|c|} 
Trimble \\
$\# 56144690$ \\
82 \\
\end{tabular} & 0.759 & 1.123 & 34.041 & -116.940 & 1445.720 & 1.526 & 0.875 & 1.250 & \begin{tabular}{|c|} 
Differential \\
GPS
\end{tabular} & 16 \\
\hline 37 & Valve & Ford & 4 & PVC & 4" upper pond & \begin{tabular}{|c|} 
Trimble \\
$\# 56144690$ \\
82 \\
\end{tabular} & 1.143 & 1.447 & 34.045 & -116.945 & 1452.341 & 1.577 & 0.875 & 1.312 & \begin{tabular}{|c} 
Differential \\
GPS
\end{tabular} & 16 \\
\hline 38 & $\begin{array}{l}\text { Flow } \\
\text { Meter }\end{array}$ & Ford & 4 & PVC & flow metered & \begin{tabular}{|c|} 
Trimble \\
$\# 56144690$ \\
82 \\
\end{tabular} & 1.896 & 3.551 & 34.045 & -116.945 & 1451.430 & 2.096 & 0.938 & 1.875 & $\begin{array}{c}\text { Differential } \\
\text { GPS }\end{array}$ & 11 \\
\hline 39 & $\begin{array}{l}\text { Flow } \\
\text { Meter }\end{array}$ & Ford & 2 & PVC & $\begin{array}{c}\text { flow meter, 2" } \\
\text { upper }\end{array}$ & \begin{tabular}{|c|} 
Trimble \\
$\# 56144690$ \\
82 \\
\end{tabular} & 0.482 & 0.732 & 34.044 & -116.945 & 1446.236 & 1.233 & 0.625 & 1.062 & \begin{tabular}{|c|} 
Differential \\
GPS
\end{tabular} & 18 \\
\hline 40 & Valve & Ford & 2 & PVC & $\begin{array}{l}2 \text { inch fill to lower } \\
\text { pond }\end{array}$ & \begin{tabular}{|c|} 
Trimble \\
$\# 56144690$ \\
82 \\
\end{tabular} & 0.674 & 0.956 & 34.044 & -116.944 & 1450.098 & 1.405 & 0.750 & 1.188 & $\begin{array}{c}\text { Differential } \\
\text { GPS }\end{array}$ & 13 \\
\hline 42 & Other & Ford & 1.5 & PVC & to lower pond & \begin{tabular}{|c|} 
Trimble \\
$\# 56144690$ \\
82 \\
\end{tabular} & 0.777 & 1.174 & 34.042 & -116.944 & 1440.023 & 1.491 & 0.812 & 1.250 & \begin{tabular}{|c} 
Differential \\
GPS
\end{tabular} & 14 \\
\hline 43 & Hydrant & Ford & 1.5 & PVC & & \begin{tabular}{|c|} 
Trimble \\
$\# 56144690$ \\
82 \\
\end{tabular} & 0.910 & 1.398 & 34.042 & -116.943 & 1441.135 & 1.318 & 0.688 & 1.125 & \begin{tabular}{|c} 
Differential \\
GPS
\end{tabular} & 18 \\
\hline 44 & Valve & Tree Trail & 2 & PVC & to lower pond & \begin{tabular}{|c|} 
Trimble \\
$\# 56144690$ \\
82 \\
\end{tabular} & 0.870 & 1.953 & 34.042 & -116.943 & 1446.332 & 1.544 & 0.812 & 1.312 & $\begin{array}{c}\text { Differential } \\
\text { GPS }\end{array}$ & 15 \\
\hline 45 & $\begin{array}{l}\text { Flow } \\
\text { Meter }\end{array}$ & Tree Trail & 2 & PVC & $\begin{array}{c}\text { metered water } \\
\text { source Tree Trail } \\
\text { Well }\end{array}$ & \begin{tabular}{|c|} 
Trimble \\
$\# 56144690$ \\
82 \\
\end{tabular} & 0.518 & 0.738 & 34.041 & -116.942 & 1441.846 & 1.179 & 0.625 & 1.000 & \begin{tabular}{|c|}
$\begin{array}{c}\text { Differential } \\
\text { GPS }\end{array}$ \\
\end{tabular} & 21 \\
\hline
\end{tabular}




\begin{tabular}{|c|c|c|c|c|c|c|c|c|c|c|c|c|c|c|c|c|}
\hline $\begin{array}{l}\text { OBJECT } \\
\text { ID }\end{array}$ & Type & Section Name & $\begin{array}{l}\text { Dia } \\
\text { (in.) }\end{array}$ & Material & Notes & $\begin{array}{l}\text { Receiver } \\
\text { Name }\end{array}$ & $\begin{array}{l}\text { Hor Accy } \\
\text { (m) }\end{array}$ & $\begin{array}{l}\text { Vert Accy } \\
(\mathrm{m})\end{array}$ & Latitude & Longitude & Altitude & PDOP & HDOP & VDOP & Fix Type & $\begin{array}{c}\# \\
\text { Satellites }\end{array}$ \\
\hline 46 & Valve & Tree Trail & 2 & Steel & $\begin{array}{l}\text { cedar tree } \\
\text { sprinklers }\end{array}$ & \begin{tabular}{|c|} 
Trimble \\
$\# 56144690$ \\
82 \\
\end{tabular} & 2.186 & 1.717 & 34.042 & -116.942 & 1449.598 & 1.526 & 0.875 & 1.250 & $\begin{array}{c}\text { Differential } \\
\text { GPS }\end{array}$ & 14 \\
\hline 47 & Valve & Conifer loop & 0.75 & PVC & feeds drip lines & \begin{tabular}{|c|} 
Trimble \\
$\# 56144690$ \\
82 \\
\end{tabular} & 1.073 & 1.586 & 34.043 & -116.943 & 1450.892 & 1.737 & 0.875 & 1.500 & \begin{tabular}{|c} 
Differential \\
GPS
\end{tabular} & 17 \\
\hline 48 & Valve & Artist Palette & 2 & Steel & & \begin{tabular}{|c|} 
Trimble \\
$\# 56144690$ \\
82 \\
\end{tabular} & 0.637 & 0.991 & 34.042 & -116.942 & 1450.470 & 1.127 & 0.625 & 0.938 & $\begin{array}{c}\text { Differential } \\
\text { GPS }\end{array}$ & 21 \\
\hline 49 & Valve & Blue Sky & 2 & Steel & $\begin{array}{c}\text { flows into sprinkler } \\
\text { system }\end{array}$ & \begin{tabular}{|c|} 
Trimble \\
$\# 56144690$ \\
82 \\
\end{tabular} & 0.846 & 1.005 & 34.041 & -116.940 & 1442.302 & 1.388 & 0.812 & 1.125 & \begin{tabular}{|c|} 
Differential \\
GPS
\end{tabular} & 16 \\
\hline 50 & Valve & $\begin{array}{l}\text { Overflow } \\
\text { Parking }\end{array}$ & 3 & PVC & feeds Blu Sky & \begin{tabular}{|c|} 
Trimble \\
$\# 56144690$ \\
82 \\
\end{tabular} & 0.552 & 0.859 & 34.040 & -116.938 & 1435.704 & 1.214 & 0.688 & 1.000 & \begin{tabular}{|c|}
$\begin{array}{c}\text { Differential } \\
\text { GPS }\end{array}$ \\
\end{tabular} & 18 \\
\hline 51 & Valve & $\begin{array}{c}\text { East Demestic } \\
\text { Well }\end{array}$ & 3 & Steel & $\begin{array}{c}\text { East of domestic } \\
\text { well }\end{array}$ & \begin{tabular}{|c|} 
Trimble \\
$\# 56144690$ \\
82 \\
\end{tabular} & 0.602 & 0.930 & 34.039 & -116.938 & 1423.988 & 1.352 & 0.750 & 1.125 & \begin{tabular}{|c} 
Differential \\
GPS
\end{tabular} & 15 \\
\hline 52 & Valve & Horse Corral & 3 & Steel & & \begin{tabular}{|c|} 
Trimble \\
$\# 56144690$ \\
82
\end{tabular} & 0.520 & 0.659 & 34.039 & -116.939 & 1425.613 & 1.127 & 0.625 & 0.938 & \begin{tabular}{|c|} 
Differential \\
GPS
\end{tabular} & 19 \\
\hline 53 & $\begin{array}{c}\text { Well } \\
\text { Domestic }\end{array}$ & \begin{tabular}{|c|} 
East of Apple \\
Shed
\end{tabular} & 2 & Steel & Domestic Well & \begin{tabular}{|c|} 
Trimble \\
$\# 56144690$ \\
82 \\
\end{tabular} & 0.939 & 1.104 & 34.039 & -116.939 & 1428.638 & 1.214 & 0.688 & 1.000 & \begin{tabular}{|c} 
Differential \\
GPS
\end{tabular} & 17 \\
\hline 54 & $\begin{array}{l}\text { Flow } \\
\text { Meter }\end{array}$ & $\begin{array}{c}\text { east of apple } \\
\text { shed }\end{array}$ & 0 & Steel & $\begin{array}{c}\text { flow meter breaks } \\
\text { into many }\end{array}$ & \begin{tabular}{|c|} 
Trimble \\
$\# 56144690$ \\
82 \\
\end{tabular} & 0.769 & 0.860 & 34.039 & -116.939 & 1429.473 & 1.214 & 0.688 & 1.000 & \begin{tabular}{|c} 
Differential \\
GPS
\end{tabular} & 16 \\
\hline 55 & Valve & $\begin{array}{l}\text { Hiddon } \\
\text { Meadow }\end{array}$ & 2 & PVC & $\begin{array}{l}\text { PVC to bendable } \\
\text { pipe. }\end{array}$ & \begin{tabular}{|c|} 
Trimble \\
$\# 56144690$ \\
82 \\
\end{tabular} & 1.034 & 1.207 & 34.036 & -116.942 & 1400.890 & 1.908 & 1.000 & 1.625 & \begin{tabular}{|c} 
Differential \\
GPS
\end{tabular} & 14 \\
\hline 56 & Valve & $\begin{array}{l}\text { Hidden } \\
\text { Meadow }\end{array}$ & 2 & Steel & & \begin{tabular}{|c|} 
Trimble \\
$\# 56144690$ \\
82 \\
\end{tabular} & 1.002 & 1.629 & 34.036 & -116.942 & 1408.740 & 1.985 & 0.938 & 1.750 & $\begin{array}{c}\text { Differential } \\
\text { GPS }\end{array}$ & 14 \\
\hline 57 & Valve & $\begin{array}{l}\text { Hidden } \\
\text { Meadow }\end{array}$ & 2 & Steel & & \begin{tabular}{|c|} 
Trimble \\
$\# 56144690$ \\
82 \\
\end{tabular} & 1.106 & 1.876 & 34.037 & -116.942 & 1412.692 & 2.101 & 1.062 & 1.812 & \begin{tabular}{|c|}
$\begin{array}{c}\text { Differential } \\
\text { GPS }\end{array}$ \\
\end{tabular} & 15 \\
\hline
\end{tabular}




\begin{tabular}{|c|c|c|c|c|c|c|c|c|c|c|c|c|c|c|c|c|}
\hline $\begin{array}{l}\text { OBJECT } \\
\text { ID }\end{array}$ & Type & Section Name & $\begin{array}{l}\text { Dia } \\
\text { (in.) }\end{array}$ & Material & Notes & $\begin{array}{l}\text { Receiver } \\
\text { Name }\end{array}$ & $\begin{array}{l}\text { Hor Accy } \\
\text { (m) }\end{array}$ & $\begin{array}{c}\text { Vert Accy } \\
(\mathrm{m})\end{array}$ & Latitude & Longitude & Altitude & PDOP & HDOP & VDOP & Fix Type & $\begin{array}{c}\# \\
\text { Satellites }\end{array}$ \\
\hline 58 & Valve & Parking Lot & 3 & Steel & $\begin{array}{c}\text { to Hummingbird } \\
\text { Hill. Irrigation } \\
\text { water } \\
\end{array}$ & \begin{tabular}{|c|} 
Trimble \\
$\# 56144690$ \\
82 \\
\end{tabular} & 0.915 & 1.210 & 34.040 & -116.941 & 1428.874 & 1.427 & 0.688 & 1.250 & $\begin{array}{c}\text { Differential } \\
\text { GPS }\end{array}$ & 16 \\
\hline 59 & Valve & building10 & 1 & PVC & $\begin{array}{c}\text { domestic water on } \\
\text { and off. supplying } \\
4 \text { buildings }\end{array}$ & \begin{tabular}{|c|} 
Trimble \\
$\# 56144690$ \\
82
\end{tabular} & 0.830 & 1.458 & 34.040 & -116.942 & 1427.292 & 1.761 & 0.812 & 1.562 & $\begin{array}{c}\text { Differential } \\
\text { GPS }\end{array}$ & 14 \\
\hline 60 & Valve & Orchard Rome & 2 & PVC & 3 hydrants, 2 res. & \begin{tabular}{|c|} 
Trimble \\
$\# 56144690$ \\
82
\end{tabular} & 1.342 & 1.607 & 34.035 & -116.943 & 1353.329 & 1.716 & 0.938 & 1.438 & $\begin{array}{c}\text { Differential } \\
\text { GPS }\end{array}$ & 12 \\
\hline 61 & Valve & Orchard Rome & 1 & PVC & $\begin{array}{l}\text { overhead } \\
\text { sprinklers }\end{array}$ & \begin{tabular}{|c|} 
Trimble \\
$\# 56144690$ \\
82
\end{tabular} & 0.707 & 0.995 & 34.041 & -116.941 & 1439.599 & 1.266 & 0.688 & 1.062 & $\begin{array}{c}\text { Differential } \\
\text { GPS }\end{array}$ & 16 \\
\hline 62 & Valve & Orchard Rome & 1 & PVC & $\begin{array}{l}\text { overhead } \\
\text { sprinklers }\end{array}$ & \begin{tabular}{|c|} 
Trimble \\
$\# 56144690$ \\
82 \\
\end{tabular} & 0.473 & 0.694 & 34.040 & -116.941 & 1437.223 & 1.388 & 0.812 & 1.125 & $\begin{array}{c}\text { Differential } \\
\text { GPS }\end{array}$ & 15 \\
\hline 63 & Valve & $\underset{\text { Hill }}{\text { Hummingbird }}$ & 2 & PVC & $\begin{array}{l}\text { two next to each } \\
\text { other. left is }\end{array}$ & \begin{tabular}{|c|} 
Trimble \\
$\# 56144690$ \\
82
\end{tabular} & 0.557 & 0.934 & 34.040 & -116.941 & 1436.228 & 1.318 & 0.688 & 1.125 & $\begin{array}{c}\text { Differential } \\
\text { GPS }\end{array}$ & 16 \\
\hline 64 & Valve & Orchard Rome & 1 & PVC & drip system & \begin{tabular}{|c|} 
Trimble \\
$\# 56144690$ \\
82
\end{tabular} & 0.559 & 0.826 & 34.040 & -116.941 & 1434.609 & 1.163 & 0.688 & 0.938 & $\begin{array}{c}\text { Differential } \\
\text { GPS }\end{array}$ & 17 \\
\hline 65 & Valve & $\underset{\text { Hill }}{\text { Hummingbird }}$ & 1 & PVC & drip system & \begin{tabular}{|c|} 
Trimble \\
$\# 56144690$ \\
82
\end{tabular} & 0.595 & 0.998 & 34.041 & -116.941 & 1441.711 & 1.127 & 0.625 & 0.938 & $\begin{array}{c}\text { Differential } \\
\text { GPS }\end{array}$ & 17 \\
\hline 66 & Spigot & & 0 & & & $<$ Null $>$ & $<$ Null $>$ & $<$ Null $>$ & $\mid<$ Null $>$ & $<$ Null $>$ & $<$ Null $>$ & <Null $>$ & $<$ Null $>$ & $<$ Null $>$ & $<$ Null $>$ & $<$ Null $>$ \\
\hline 67 & Spigot & & 0 & & & $<$ Null $>$ & $<$ Null $>$ & $<$ Null $>$ & $<$ Null $>$ & $<$ Null $>$ & $<$ Null $>$ & $\mid<$ Null $>$ & $<$ Null $>$ & $<$ Null $>$ & $<$ Null $>$ & $<$ Null $>$ \\
\hline 68 & Spigot & & 0 & & & $<$ Null $>$ & $<$ Null $>$ & $<$ Null $>$ & $<$ Null $>$ & $<$ Null> & $<$ Null $>$ & $<$ Null $>$ & $<$ Null $>$ & $<$ Null $>$ & $<$ Null $>$ & <Null> \\
\hline 69 & Spigot & & 0 & & & $<$ Null $>$ & $<$ Null $>$ & $<$ Null $>$ & $<$ Null $>$ & $<$ Null $>$ & $<$ Null $>$ & $<$ Null $>$ & $<$ Null $>$ & $<$ Null $>$ & $<$ Null $>$ & $<$ Null $>$ \\
\hline 70 & Spigot & & 0 & & & $<$ Null $>$ & $<$ Null $>$ & $<$ Null $>$ & $<$ Null $>$ & $<$ Null $>$ & $<$ Null $>$ & $\mid<$ Null $>$ & $\langle$ Null $>$ & $<$ Null $>$ & $<$ Null $>$ & $<$ Null $>$ \\
\hline 72 & Spigot & & 0 & & & $<$ Null $>$ & $<$ Null $>$ & $<$ Null> & $<$ Null $>$ & $<$ Null $>$ & $<$ Null> & $<$ Null $>$ & $<$ Null $>$ & $<$ Null> & $<$ Null> & $<$ Null $>$ \\
\hline 73 & Valve & & 0 & & & $<$ Null $>$ & $<$ Null $>$ & $<$ Null $>$ & $<$ Null $>$ & $<$ Null $>$ & $<$ Null $>$ & $<$ Null $>$ & $<$ Null $>$ & $<$ Null $>$ & $<$ Null $>$ & $<$ Null $>$ \\
\hline
\end{tabular}

